\title{
Results of a Technical Review of the U.S. Climate Change Technology Program's R\&D Portfolio
}

\author{
Marilyn A. Brown ${ }^{1}$ \\ Matt Antes ${ }^{2}$ \\ Charlotte Franchuk ${ }^{3}$ \\ Burton H. Koske ${ }^{4}$ \\ Gordon Michaels \\ Joan Pellegrino ${ }^{2}$ \\ Sponsored by:

\section{U.S. CLIMATE CHANGE TECHNOLOGY PROGRAM www.climatetechnology.gov}

May 2006

Prepared by:

Oak Ridge National Laboratory

P.O. Box 2008

Oak Ridge, Tennessee 37831

Managed by:

UT-Battelle, LLC

for the

U.S. Department of Energy

under contract DE-AC05-00OR22725

\footnotetext{
${ }^{1}$ Oak Ridge National Laboratory

2 Energetics, Inc.

${ }^{3}$ Data Support Services

${ }^{4}$ Idaho National Laboratory
} 



\section{Table of Contents}

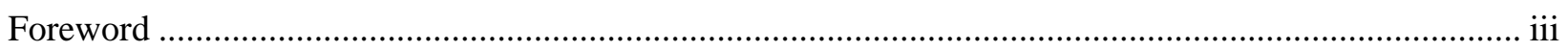

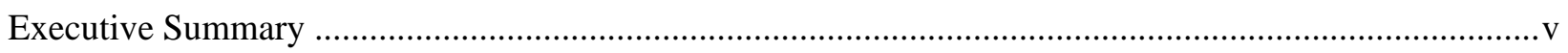

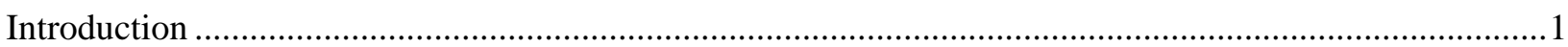

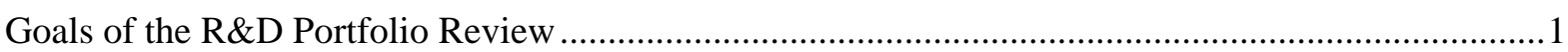

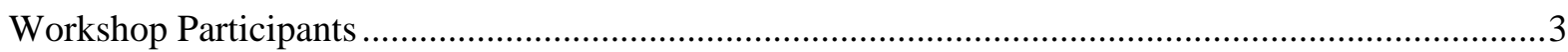

Structured Methodology and Workshop Format .................................................................................

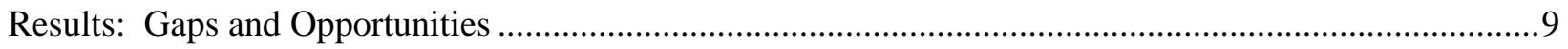

Goal 1 - Reduce Emissions from Energy End-Use and Infrastructure.............................................9

Goal 2 - Reduce Emissions from Energy Supply ............................................................................15

Goal 3 - Capture and Sequester Carbon Dioxide …...........................................................................20

Goal 4 - Reduce Emissions of Non- $\mathrm{CO}_{2}$ Greenhouse Gases ...........................................................25

Goal 5 - Improve Capabilities to Measure and Monitor GHG Emissions .........................................31

Goal 6 - Bolster Basic Science Contributions to Technology Development .......................................36

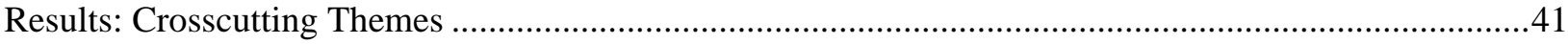

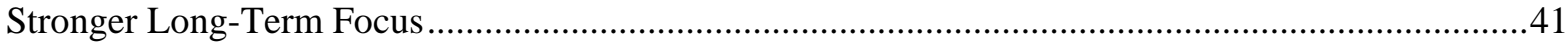

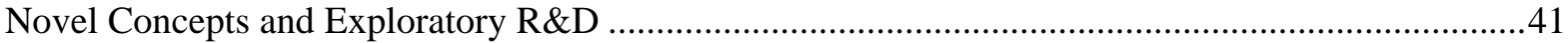

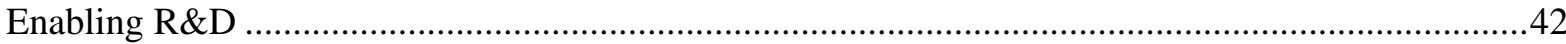

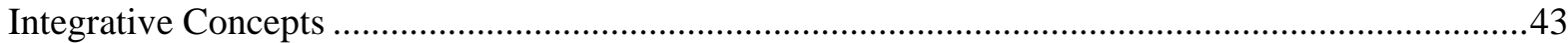

Science to Technology Workshops..................................................................................................44

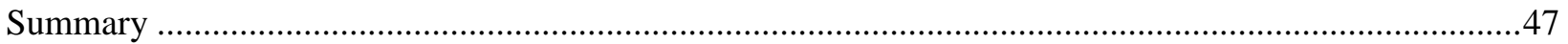

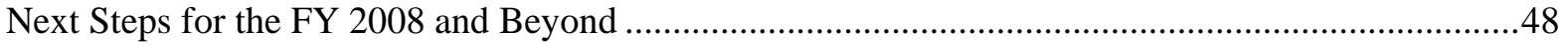

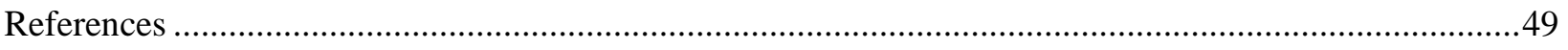

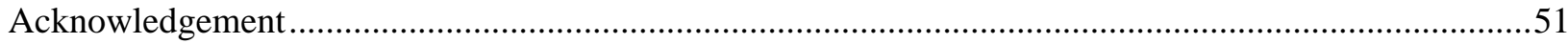

Appendix A - Participant List

Appendix B - Sample Agenda and Homework Assignments

Appendix C - One-Page Summaries of Gaps and Opportunities 


\section{Foreword}

The U.S. Climate Change Technology Program (CCTP) is a multi-agency planning and coordinating entity led by the U.S. Department of Energy. Its purpose is to accelerate the development and facilitate the adoption of new and advanced technologies to address climate change. To ensure that Federal investments in climate change technology research and development (R\&D) are made effectively, the CCTP periodically reviews the adequacy of the multi-agency R\&D portfolio.

In late 2005, as part of its planning and coordination functions, the CCTP sponsored a review of its R\&D portfolio, employing technical experts in various fields in a series of six workshops. The workshops were organized by Oak Ridge National Laboratory, supported by others, including Idaho National Laboratory, and facilitated by Energetics, Incorporated. A group of 75 broadly experienced professionals with expertise in fields relevant to the CCTP goals participated in the review. Sixty of the participants represented non-Federal organizations, outside of DOE and its national laboratory system, giving CCTP the benefit of independent and diverse technical insights.

The purpose of the review was to assess the CCTP's R\&D portfolio in terms of its adequacy to attain, or to make meaningful technical progress toward each of CCTP's six strategic goals. The review identified portfolio strengths, gaps and opportunities, and prioritized recommendations for CCTP's consideration in various technology areas supporting each CCTP strategic goal. Each of five workshops focused exclusively on one of CCTP's five technology-related goals. A sixth workshop integrated and synthesized the results from the first five workshops and explored key roles for basic research in supporting the applied technology R\&D programs.

This report, Results of a Technical Review of the U.S. Climate Change Technology Program's $R \& D$ Portfolio, presents an overview of the workshop process and the findings related to current portfolio strengths, gaps, and opportunities. The findings are expected to be used to further refine the CCTP Strategic Plan, especially in the sections on possible future research directions. The report will be provided to CCTP participating agencies as a means of sharing the developed insights for R\&D portfolio planning and of strengthening the overall CCTP R\&D portfolio in the future.

This work was commissioned by the U.S. Climate Change Technology Program and supervised by Dr. Robert Marlay, Director of DOE's Office of Science and Technology Policy and Deputy Director of CCTP, and Dr. Michael Curtis, DOE Project Technical Director.

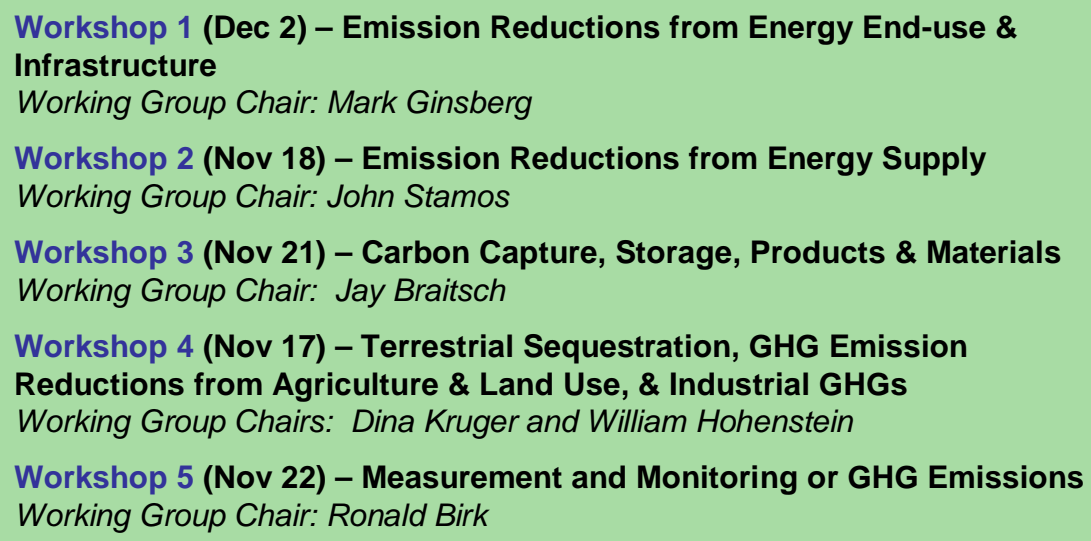




\section{Executive Summary}

Climate change is a complex, long-term challenge. As a party to the United Nations Framework Convention on Climate Change (UNFCCC), the United States shares with many other countries the UNFCCC's ultimate goal of stabilizing greenhouse gases (GHGs) in the atmosphere at a level that avoids dangerous human interference with the climate system. There is broad international recognition that climate change concerns cannot be addressed in isolation from other pressing needs, such as economic development, pollution reduction and energy supply. Successfully addressing these complementary concerns requires the development and commercialization of advanced technologies, particularly those that have the potential to fundamentally alter the way we produce and use energy.

It is within this context that the United States is pursuing a comprehensive strategy on climate change. The U.S. Climate Change Technology Program (CCTP) represents the technology component of this overall strategy. It is charged with coordinating and prioritizing the Federal government's climaterelated technology programs. CCTP functions as a multi-agency planning and coordinating entity whose activities are guided and carried out by representatives of participating R\&D agencies. CCTP provides strategic direction for and coordinates a significant portfolio of investments in climatechange related technology research, development, demonstration and deployment (R\&D).

CCTP takes a century-long look at the nature of the climate change challenge and the potential for technological solutions across a range of uncertainties. The sources of GHG emissions are varied and complex, as are the potential strategies for their mitigation, as afforded by advanced climate change technologies. The challenge is to accelerate the scientific advances needed to facilitate the reduction, avoidance, capture and storage of man-made emissions of GHGs. Advances in technology through a far-reaching R\&D portfolio can play a powerful role in affordably reducing GHG emissions.

The fact that climate science is evolving and new climate technologies are being advanced gives rise to the need to periodically review and adjust climate change R\&D investments and execution strategies. Indeed, CCTP's Vision and Framework for Strategy and Planning (CCTP, 2005a) calls for the need to "periodically assess the adequacy of the multi-agency portfolio with respect to its ability to achieve, or make technical progress toward, CCTP strategic goal attainment; identify gaps, opportunities, and make recommendations.”

\section{A Systematic Review of the R\&D Portfolio}

In late 2005, CCTP asked Oak Ridge National Laboratory with support from Idaho National Laboratory, Energetics Incorporated, and others to conduct a review of the CCTP R\&D portfolio using structured workshops. Each workshop focused on one of CCTP's six strategic goals.

The objectives of the workshops were to: assess the adequacy of the $\mathrm{R} \& \mathrm{D}$ portfolio in each respective goal area; identify the portfolio's strengths and weakness with respect to the goal; identify potential gaps in the portfolio; suggest opportunities that would add important balance or represent

\section{SIX STRATEGIC GOALS FOR THE CCTP}

1. Reduce emissions from energy end-use and infrastructure

2. Reduce emissions from energy supply

3. Capture and sequester carbon dioxide

4. Reduce emissions of non-CO2 greenhouse gases

5. Improve capabilities to measure and monitor GHG emissions

6. Bolster basic science contributions to technology development

potentially high impact options for goal attainment; and prioritize the gaps and opportunities. 


\section{A Diversified R\&D Portfolio}

One conclusion emerging from the portfolio review is that success will require the pursuit of multiple technology pathways to address CCTP goals; no single technology is sufficient to address the impacts of climate change. The R\&D timeline below represents the diversity and breadth of technologies that could arise over the near-, mid-, and long-term from ongoing and future CCTP research investments. It is based on CCTP's current R\&D portfolio, and also incorporates future research directions that were proposed in the portfolio review workshops.

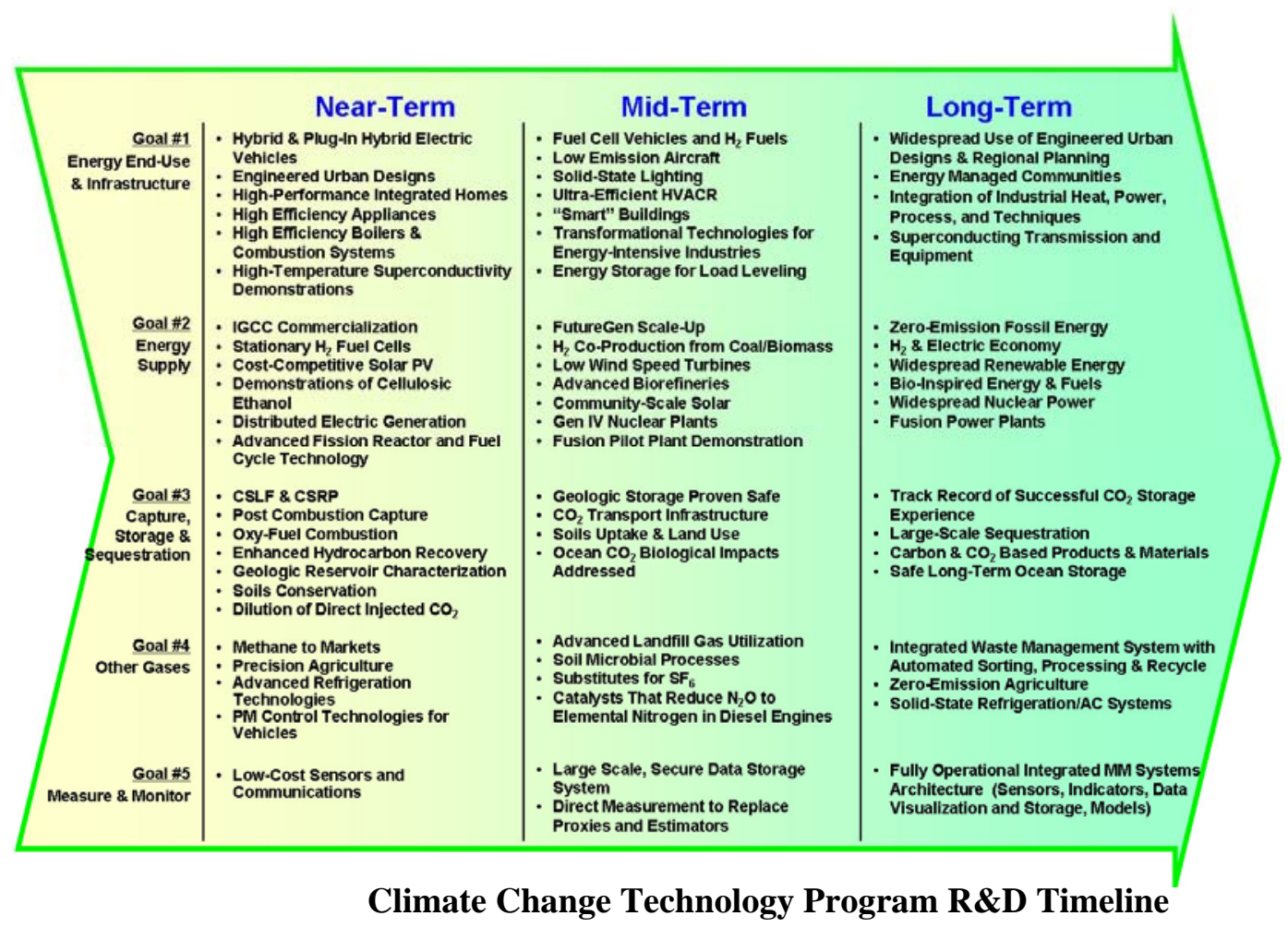

Note: With some overlap, "near-term" envision reductions are expected to result from technology adoption occurring within 10 to 20 years from present; "mid-term" represents technology adoption in a period of 20 to 40 years; and "long-term" impacts occur in a period of 40 to 60 years.

\section{CCTP RESEARCH TAXONOMY}

- Strategic research - basic research that is inspired by technical challenges in the applied R $\omega D$ programs

- Fundamental research - basic research that provides the underlying foundation of scientific knowledge that can lead to fundamental new discoveries

- Exploratory research - basic research, or exploratory study of applied concepts, undertaken in the pursuit of bighrisk, novel, emergent, integrative or enabling approaches, not covered elsewhere
To incorporate the contributions of different research and technology strategies, the portfolio review considered a balance of strategic, fundamental and exploratory research as defined at left. Incremental technology improvements, fundamental enabling breakthroughs, advances in the basic sciences, and the pursuit of innovative ideas will all be needed. In addition, synergies among technologies need to be exploited to optimize the success of new concepts in mitigating climate change. This balance helps to create a diversified $\mathrm{R} \& \mathrm{D}$ portfolio with high potential to produce real impacts on climate change in the future. 


\section{Current Portfolio Strengths}

The portfolio review generally concluded that the CCTP R\&D portfolio is strong and relatively wellbalanced particularly with respect to near-term technology development. Some of the specific strengths of the current R\&D portfolio are listed in the table below.

\begin{tabular}{|c|c|}
\hline \multicolumn{2}{|c|}{ Goal 1: Reduce Emissions from Energy End-use and Infrastructure } \\
\hline $\begin{array}{l}\text { Transportation: Light Vehicles/Hybrids; Heavy Vehicles; } \\
\text { Alternative Fuel Vehicles; Intelligent Transport Systems; } \\
\text { Aviation Fuel Efficiency }\end{array}$ & $\begin{array}{l}\text { Buildings: Building Envelope; Building Equipment; Integrated } \\
\text { Design/Operation; Albedo/Urban Heat Island }\end{array}$ \\
\hline $\begin{array}{l}\text { Industry: Energy Conversion \& Utilization; Resource Recovery } \\
\text { \& Utilization; Industrial Process Efficiency; Enabling } \\
\text { Technologies }\end{array}$ & $\begin{array}{l}\text { Infrastructure: High Temperature Superconductivity; } \\
\text { Transmission \& Distribution; Distributed Generation; } \\
\text { Energy Storage; Sensors/Controls; Power Electronics }\end{array}$ \\
\hline \multicolumn{2}{|c|}{ Goal 2: Reduce Emissions from Energy Supply } \\
\hline $\begin{array}{l}\text { Low-Emissions Fossil-Based Power \& Fuels: Advanced } \\
\text { Power Systems; Distributed Generation - Fuel Cells; Co- } \\
\text { Production Hydrogen }\end{array}$ & $\begin{array}{l}\text { Hydrogen: Hydrogen From Fission/Fusion; Hydrogen From } \\
\text { Fossil/Alternative Energy; Hydrogen Storage \& Use; } \\
\text { Systems Technology Validation; Infrastructure Safety }\end{array}$ \\
\hline $\begin{array}{l}\text { Renewable Energy \& Fuels: Wind Energy; Photovoltaics, } \\
\text { Photoconversion; Solar, Concentrating; Bio-Fuels/ } \\
\text { Biomass }\end{array}$ & $\begin{array}{l}\text { Nuclear Fission: Nuclear: Near-Term Deployment; } \\
\text { Generation IV; Advanced Fuel Cycle Initiative (GNEP) }\end{array}$ \\
\hline
\end{tabular}

Fusion Energy: Fusion Sciences; ITER

Goal 3: Capture and Sequester Carbon Dioxide

\begin{tabular}{|c|c|}
\hline Carbon Capture: Carbon Capture; $\mathrm{CO}_{2}$ Separation & $\begin{array}{l}\text { Geologic Storage: Knowledge Base for } \mathrm{CO}_{2} \text { Storage; Novel } \\
\text { Sequestration Systems; Health, Safety \& Environment; } \\
\text { Regional Partnerships; International Partnerships }\end{array}$ \\
\hline $\begin{array}{l}\text { Terrestrial Sequestration: Land Management; Biotechnology } \\
\text { (Soil Carbon); Improved Measuring \& Monitoring (M\&M) }\end{array}$ & Ocean Sequestration: Direct Injection of $\mathrm{CO}_{2}$ in Hydrates \\
\hline \multicolumn{2}{|c|}{ Goal 4: Reduce Emissions of Non- $\mathrm{CO}_{2}$ GHGs } \\
\hline $\begin{array}{l}\text { Methane Emissions from Energy \& Waste: Landfill Gas } \\
\text { Programs; Coal Mine/Bed Methane; Methane to Markets }\end{array}$ & $\begin{array}{l}\text { Methane and } \mathrm{N}_{2} \mathrm{O} \text { Emissions from Agriculture: Advanced } \\
\mathrm{AG}-\mathrm{N}_{2} \mathrm{O} \text { Reduction; Manure Management; Enteric } \\
\text { Emissions Reductions }\end{array}$ \\
\hline $\begin{array}{l}\text { Emissions of High GWP Gases: Substitutes for High GWP } \\
\text { Gases; Substitutes for SF6; Refrigeration - HFC Reduction }\end{array}$ & $\begin{array}{l}\mathrm{N}_{2} \mathrm{O} \text { Emissions from Combustion \& Industry: } \mathrm{N}_{2} \mathrm{O} \\
\text { Abatement - Nitric Acid; } \mathrm{N}_{2} \mathrm{O} \text { Abatement - } \\
\text { Transportation }\end{array}$ \\
\hline \multicolumn{2}{|l|}{$\begin{array}{l}\text { Tropospheric Ozone Precursors \& Black Carbon: } \\
\text { Abatement - TOPs \& BC }\end{array}$} \\
\hline \multicolumn{2}{|c|}{ Goal 5: Measuring and Monitoring of GHGs } \\
\hline $\begin{array}{l}\text { Energy Production/Efficiency: M\&M for Energy Production \& } \\
\text { Efficiency }\end{array}$ & $\mathrm{CO}_{2}$ Capture \& Sequestration: $\mathrm{M} \& M$ for Geologic Storage \\
\hline Terrestrial Sequestration: M\&M for Terrestrial Sequestration & Oceanic Sequestration: M\&M for Ocean Sequestration \\
\hline Other Gases: M\&M for Other Gases & $\begin{array}{l}\text { Integrated M\&M System Architecture: M\&M Observation } \\
\text { System }\end{array}$ \\
\hline
\end{tabular}

The portfolio review also commended the series of science and technology workshops sponsored by the DOE Office of Science to identify basic science needs to support DOE's energy goals. These workshops have resulted in comprehensive reports outlining future research needs in energy technology areas important to CCTP. Several new workshop topics were recommended, including topics for which workshops are already planned. Most of these topics are crosscutting and could have broad impact over many sectors including sensors, controls and communications; energy storage; thermoelectrics; solid state lighting; and measuring and monitoring of climate change mitigation). 


\section{A Need to Balance Impact and Risk}

Participants in the portfolio review itemized more than 90 preliminary R\&D gaps and opportunities. The top ideas were identified by examining the potential impact on climate change versus the probability of success for each idea. 'Impact' was defined as progress toward the particular CCTP strategic goal; 'Probability of Success' reflects the level of certainty that the technology would be successfully developed and achieve the impact. The figure represents a selection of top ideas from the first five

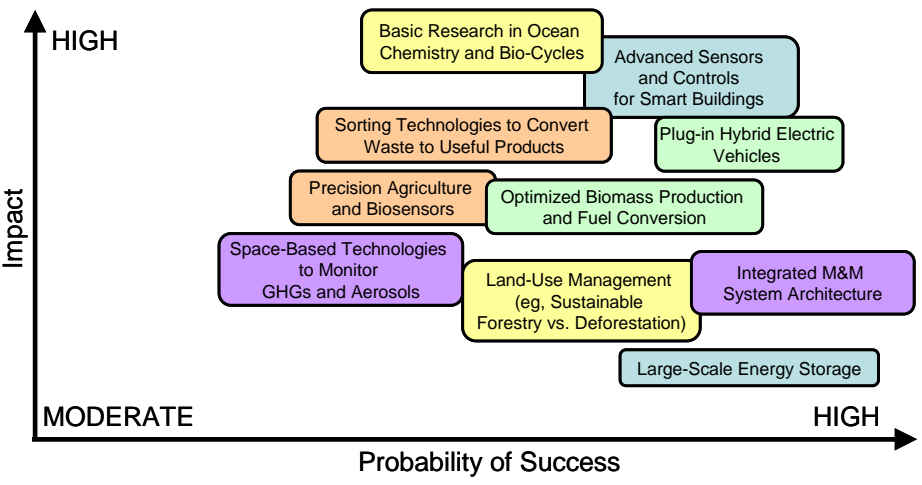
goals. The positioning of gaps and opportunities does not represent an absolute prioritization of ideas, but rather indicates relative impact and risk.

\section{Enhancing the R\&D Portfolio Priority Gaps and Opportunities}

\section{Goal 1: Reduce Emissions from Energy End-use and Infrastructure} Enabling Technologies for Low-GHG Plug-in Hybrid Electric Vehicles Advanced Applications of Biotechnology

Advanced Sensors, Communications and Controls for Smart Buildings Advanced Thermoelectric Concepts to Convert Temperature Differentials Large-Scale Energy Storage Goal 2: Reduce Emissions from Energy Supply Integration with Carbon Capture and Storage

Integration of Electricity and $\mathrm{H}_{2}$ Production with the Transportation Sector Biomass Genomics and Alternative Fuels, Materials, and Chemicals Systems Approach to Waste Management, including Waste-to-Energy Advanced Fuel Resources and Fuel Cycles for Fission Radiation-Resistant Materials for Fusion Energy Systems Goal 3: Capture and Sequester Carbon Dioxide

\begin{tabular}{c} 
Goal 3: Capture and Sequester Carbon Dioxide \\
\hline Advanced Materials (including membranes) for $\mathrm{CO}_{2}$ Separations, Transport, and Storage \\
Integrated Modeling Framework to Evaluate CCS Technologies \\
Understanding $\mathrm{CO}_{2}$ Movement in Hydrocarbon-Bearing Formations \\
Systems Approach across Sectors and Gases (Energy Crops, Sequestration, Nitrogen) \\
Potential from Land-Use Management (e.g., Sustainable Forestry vs. Deforestation) \\
Basic Research in Ocean Chemistry and Biological Cycles \\
Goal 4: Reduce Emissions of Non-CO $\mathrm{CO}_{2}$ GHGs \\
\hline Automated Mining Systems that Eliminate Methane Emissions \\
Tagging and Sorting Technologies to Convert Waste to Useful Products \\
Precision Agriculture and Biosensors \\
Improved Understanding of Rumen Microbial Processes and Nutrient Needs \\
Alternatives to SF6 in HV Electric Transformers, Circuit Breakers \& Other Equipment \\
Eliminate GHG-Emitting Working Fluids in Refrigeration and Air-Conditioning \\
Understanding of Formation and Life of Nitrous Oxides from Combustion \\
Analysis of Role of Black \& Organic Carbon and Tropospheric Ozone Precursors \\
Goal 5: Measuring and Monitoring of GHGs \\
\hline Protocols for Multiple Assessments of Performance of Energy End-Uses \\
Improvements in Temporal and Spatial Resolution Measurements \\
Remote Subsurface/Near Surface CO ${ }_{2}$ Monitoring \\
Measurement and Tracking of Injected CO 2 \\
Space-Based Technologies for Long-Term Monitoring of GHGs and Aerosols \\
Integrated Measuring \& Monitoring System Architecture \\
Wide Area Networks that Provide Robust (Sensor to Sensor) Communications \\
Platforms for Spatial Scales and Measurement Layers
\end{tabular}

A selection of top priority gaps and opportunities from each goal-specific workshop is presented at left. The portfolio review identified a number of strengths, particularly in near-term technology development. However, given the potential impacts on climate over a 100-year time horizon, reviewers suggested a need to accelerate $R \& D$ on technologies that could provide more mid- and long-term technology solutions to climate change.

The first three goal areas have historically been relatively well-supported, albeit with a more nearterm focus. The gaps and opportunities shown for these goals reflect technologies that should receive greater emphasis in the mid- and long-term. The large number of gaps and opportunities for goals 4 and 5 reflect current and historically low levels of $R \& D$ effort in these areas. 


\section{A Need for Crosscutting Fundamental Research}

To address the century-scale problem of climate change will require advances in scientific knowledge to broaden the range of technology options possible today. Research in the basic sciences will provide the underlying knowledge foundation on which new technologies can be built. The findings of the portfolio review reiterate the importance of strengthening the basic sciences to better understand and reduce sources of GHG emissions.

An important conclusion of the portfolio review was that integration of basic scientific research with applied technology development will be critical to achieving CCTP goals. The table below, developed during the portfolio review, illustrates twenty crosscutting strategic research areas and the fundamental sciences needed to support technological innovations in these areas. The table also shows how basic science R\&D contributes to CCTP goals.

Scientific advances can often be applied across a diversity of technologies. For example, as shown below, plant and microbial genomics are central to advancing biofuels and biobased chemicals, reducing methane emissions from landfills and livestock, and expanding the terrestrial sequestration of carbon. Similarly, materials that perform well in high temperature environments are essential to improving the efficiency of industrial processes and are needed to enable the next generation of fossil and nuclear power plants.

\section{Crosscutting Fundamental Research Areas}

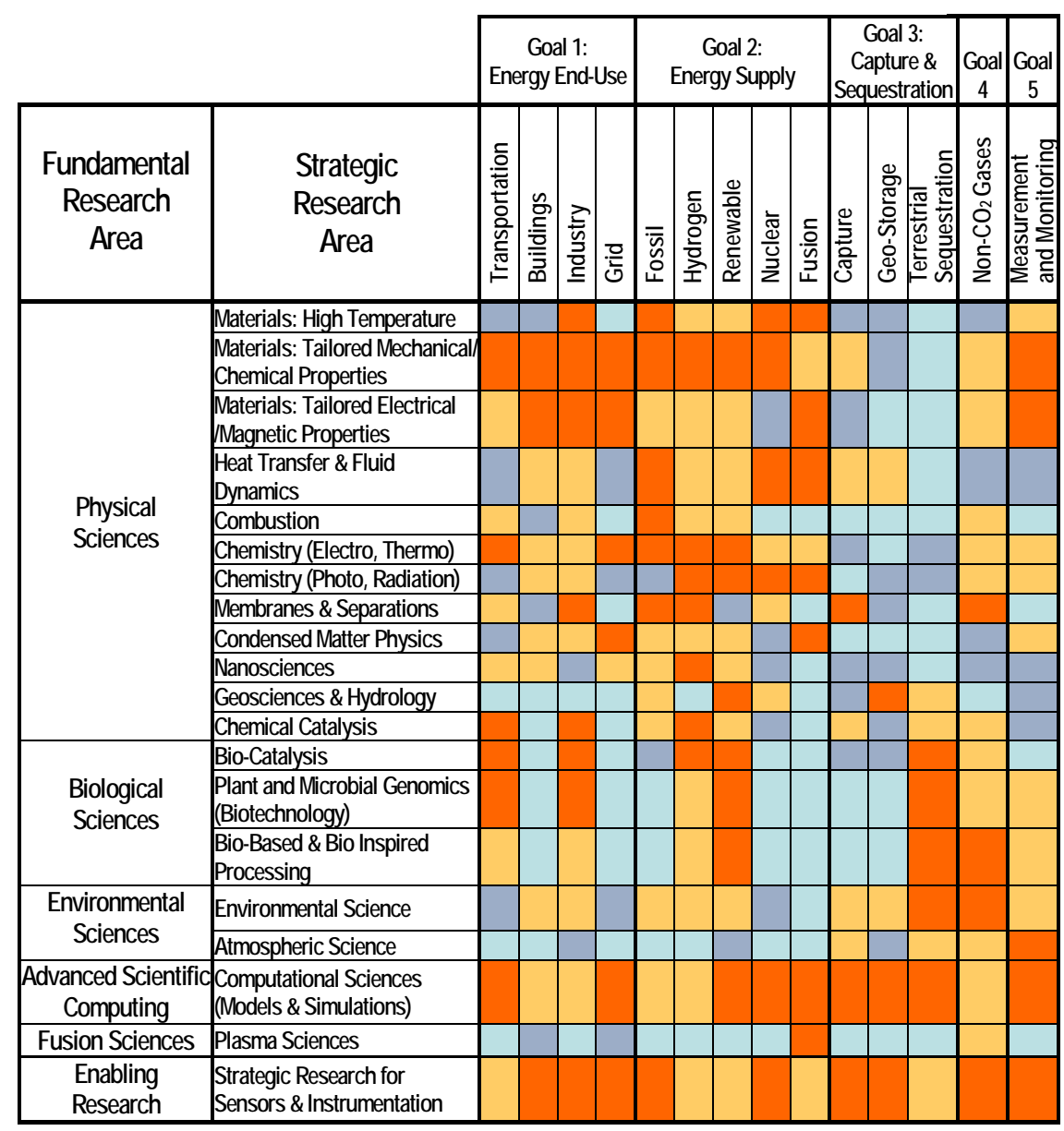

A strategic research area that is central to advancing the technology approach A strategic research area that is expected to contribute significantly to the technology approach A strategic research area that has the potential to contribute significantly to the technology approach A strategic research area that is not expected to contribute significantly to the technology approach 


\section{A Need for Enabling Technology}

Enabling R\&D facilitates the development, deployment, and use of complementary or ancillary technologies, and is necessary to the success of mainstream climate change technologies. Enabling technologies often represent the scientific and engineering breakthroughs needed to move nextgeneration concepts forward along the development cycle. In addition, by cutting across multiple disciplines, enabling technologies can lead to the diffusion of new concepts in multiple areas. Such technological progress will facilitate the means for change and a smooth transition to a near-zero emission future. Many of the areas identified were crosscutting and could have broad impact across many sectors.

\section{Selected Enabling Technologies}

- Energy storage (both small- and large-scale) to reduce cost associated with intermittency and seasonal swings in power production, and to enable plug-in hybrid electric and fuel cell vehicles

- Sensors, communications, and controls to enable smart buildings, detect high GWP gas-emitters, measure soil carbon, optimize industrial processes, and provide wide area electric grid controls

- New materials discovery, design, and fabrication for energy use reduction through light-weighting, performance under extreme conditions, and improved thermal management

- Innovative designer catalysts, membranes and separations for gas purification, carbon capture from flue gases, high-efficiency chemical processing, fuel cell membranes, and low-energy desalination

- Low-loss power transmission and distribution via nanotubes or other materials (without cryogenics) to enable space-based solar farms or wireless power on earth

- Bio-materials and bio-chemical interfaces, especially at the nanoscale for more productive biomass feedstocks, more efficient conversion to biofuels, and bio-inspired systems that mimic photosynthesis at higher rates

- Revolutionary analytical instruments that enable atmospheric GHG imaging, theoretical modeling and visualization, nanoscale materials characterization, and other enabling applications

\section{Exploratory Research: Integrative Concepts}

Integrative concepts combine systems and cut across technologies, disciplines, and sometimes sectors of the economy. Developing integrative concepts is an inter-disciplinary, complex undertaking that may require new partnerships and alliances. The combination of concepts into integrated, more efficiently functioning systems could have potentially large implications for climate change and should be encouraged. Selected integrative concepts emerging from the portfolio review are shown below.

\section{Selected Integrative Concepts}

- Integration of plug-in hybrid electric vehicles with zero energy buildings and utility peak-shaving to reduce GHGs from vehicles using low-carbon power.

- Systems engineered urban planning designed to reduce vehicle travel and allow co-location of activities with common energy, water, and other resource requirements.

- Integration of energy used to support water distribution and treatment, and more efficient use of water to support energy supply.

- Biomass gasification to produce electricity merged with carbon sequestration and production of clean diesel (dimethyl ether) as an alternative transportation fuel.

- Integrated system architecture for measuring and monitoring GHGs that fuses instrumentation platforms, data, models and decision-support tools.

- Underground energy extraction from hydrocarbons (oil and coal) integrated with the production of heat and power that is brought to the surface. 


\section{Exploratory Research: Novel and Advanced Concepts}

Participants recommended greater emphasis on exploratory research addressing novel and advanced concepts to uncover "breakthrough technology" to strengthen research and broaden the R\&D portfolio. Such research could lead to revolutionary advances in technology and thereby dramatically change the way energy is produced, transformed, and used in the global economy. "Atypical" or "outof-the-box" novel concepts often do not fit within the boundaries of traditional R\&D. These ideas may require scientific disciplines outside the usual fields, involve application of previously unexplored methods, and offer approaches that compete with more traditional practices.

\begin{tabular}{l} 
Selected Novel and Advanced Concepts \\
- Innovative ways to capture and sequester carbon: \\
$>$ Direct atmospheric $\mathrm{CO}_{2}$ capture \\
$>$ Ionize $\mathrm{CO}_{2}$ to enable separation via electric fields \\
$>$ Microbial fixation of carbon in geologic formations \\
\hline - Biosciences combined with nanotechnology, computer sciences, and other fields to create new \\
materials (bio-X) \\
$>$ Use of "enzyme machines" \\
$>$ New organic-inorganic hybrids materials \\
- Innovative and renewable ways to produce or convert energy: \\
$>$ High-altitude wind kites/turbines \\
$>$ Harnessing fugitive energy in buildings \\
$>$ Tidal dams generating power at ebb tides \\
\hline - Low-loss energy transport: \\
$>$ Power beaming or wireless power transmission \\
$>$ "Thermal wires" that move heat in one direction \\
- Novel modes for mitigation of GHG concentrations: \\
$>$ Geo-engineering the rate of solar insolation with nano-particles \\
$>$ Increasing the earth's surface albedo to reduce temperatures and $N_{x}$ production \\
\hline
\end{tabular}

\section{The Path Forward}

This assessment revealed both strengths and weaknesses in the current R\&D portfolio. The need to place more emphasis on long-term, revolutionary technologies as well as programs that foster truly innovative, unconventional approaches emerged as essential for meeting the century-long challenges of climate change. This might require a greater percentage of funding to go to potential breakthrough technology versus research that provides only incremental improvements. There is a need for more high-risk but high pay-off research.

The portfolio review reiterated the value of pursuing exploratory, out-of-the-box concepts that may be outside the realm of traditional thinking but that could potentially have large impacts for climate change. To support exploratory concepts as well as mainstream technologies, more research in the basic sciences and enabling disciplines of materials, biology, physical sciences, computational sciences, nanotechnology and others will be required. This will produce the scientific knowledge and discovery needed for a revolutionary change in the way we produce and use energy. Integrative concepts - those that combine technologies and ideas across sectors and disciplines - will also be essential to addressing climate change over the long term.

Going forward, the Federal agencies of the CCTP should evaluate the high priority gaps and opportunities identified in this portfolio review. Tractable means should be established for addressing both crosscutting and integrative needs. Finally, mechanisms should be strengthened and formalized for stimulating novel concepts and enabling exploratory R\&D. 


\section{Introduction}

The U.S. Climate Change Technology Program (CCTP) is a multi-agency planning and coordinating entity led by the U.S. Department of Energy. Its purpose is to accelerate the development and facilitate the adoption of new and advanced technologies to address climate change. The CCTP works with other Federal agencies to provide strategic direction for the CCTP-related elements of the Federal research and development $(\mathrm{R} \& \mathrm{D})$ portfolio, and to facilitate the coordinated planning, programming, budgeting and implementation of the technology development and deployment aspects of U.S. climate change strategy. The agencies participate in CCTP R\&D planning and coordination as members of Working Groups, which are primarily responsible for carrying out the missions and staff functions of the CCTP in a coordinated manner.

CCTP's Vision and Framework for Strategy and Planning (CCTP, 2005a, p. 35) calls out the need to "Periodically assess the adequacy of the multi-agency portfolio with respect to its ability to achieve, or make technical progress toward, CCTP strategic goal attainment; identify gaps, opportunities, and make recommendations." The fact that climate science is continually evolving and new climate technologies are being advanced, gives rise to the need to periodically review and adjust climate change $R \& D$ investments and execution strategies.

In late 2005, CCTP asked Oak Ridge National Laboratory and Energetics Incorporated to organize and coordinate a review of the CCTP R\&D portfolio using structured workshops. Each workshop focused on one of CCTP's six strategic goals, described in the CCTP's Draft Strategic Plan (CCTP, 2005b), and available at www.climatetechnology.gov. The Strategic Plan also provides information about current R\&D activities related to the goals along with suggested future research directions. The CCTP strategic goals are to:

1. Reduce emissions from energy end-use and infrastructure

2. Reduce emissions from energy supply

3. Capture and sequester carbon dioxide

4. Reduce emissions of non- $\mathrm{CO}_{2}$ greenhouse gases

5. Improve capabilities to measure and monitor GHG emissions

6. Bolster basic science contributions to technology development

To promote meaningful dialogue while ensuring broad coverage, a group of broadly experienced professionals with expertise in fields relevant to each CCTP goal were asked to participate in the portfolio reviews and

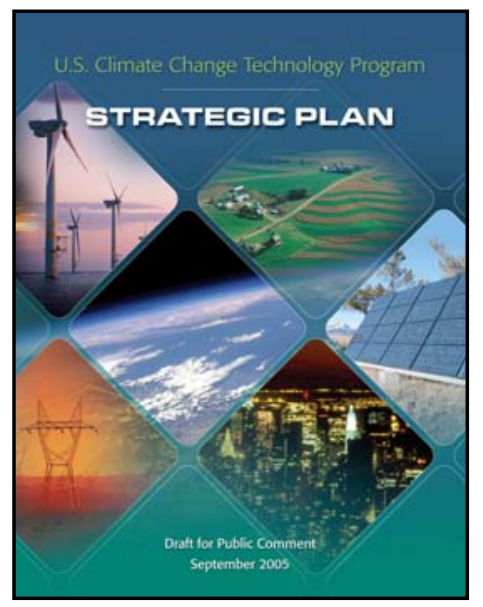
associated workshops. In coordination with the Working Group chairs, a total of 75 experts participated in the workshops. Sixty of the participants represented non-Federal organizations, outside of DOE and its national laboratory system, giving CCTP the benefit of independent and diverse technical insights. This report summarizes the findings of the workshops and the results of the Delphi assessment of the CCTP R\&D portfolio.

\section{Goals of the R\&D Portfolio Review}

The goal of the workshops were to assess the adequacy of the R\&D portfolio in each respective goal area, to identify the portfolio's strengths and weakness with respect to the goal, to identify potential gaps in the portfolio, to suggest opportunities that would add important balance or represent potentially high impact options for goal attainment, and to prioritize the gaps and opportunities. 
Five one-day workshops focusing on each of the five technology goals took place in November and early December 2005. The CCTP Working Group Chairs (or co-chairs) attended the workshop covering their area of goal responsibility, and designated an "integrator" who was responsible for subsequently participating in Workshop 6 to assure continuity of input. The sixth workshop took place over two days in mid-December. It covered the basic science goal and also integrated the results across the five previous goal-oriented workshops.

\section{Workshop 1 (Dec 2) - Emission Reductions from Energy End-Use \& Infrastructure \\ Workshop 2 (Nov 18) - Emission Reductions from Energy Supply \\ Workshop 3 (Nov 21) - Carbon Capture, Storage, Products \& Materials \\ Workshop 4 (Nov 17) - Terrestrial Sequestration, GHG Emission Reductions from Agriculture \& Land Use, \& Industrial GHGs}

Workshop 5 (Nov 22) - Measurement and Monitoring of GHG Emissions

In considering the roles for applied and basic research in advancing the development of climate change technology, the portfolio review used the following taxonomy of R\&D opportunities:

- Strategic Research: Strategic research is basic research that is inspired by technical challenges in the applied R\&D programs. It is problem-driven research that may lead to fundamental discoveries (e.g., new properties, phenomena, or materials) or scientific understanding, but is intended primarily to solve specific problems or technical barriers impeding progress in technology development in energy supply and end-use, carbon capture, storage and sequestration, non- $\mathrm{CO}_{2} \mathrm{GHGs,}$, and monitoring and measurement. This "strategic" research applies knowledge gained from more fundamental science research to the more practical problems associated with technology R\&D.

- Fundamental Research: Basic research provides the underlying foundation of scientific knowledge and can lead to fundamental new discoveries. It is not problem-driven research. It is the systematic study of system properties and natural behavior that can lead to greater knowledge and understanding of the fundamental aspects of phenomena, processes, and observable facts, but without prior specification toward applications to design or develop specific processes or products. It includes scientific study and experimentation in the physical, biological, and environmental sciences, and many interdisciplinary areas, such as computational sciences to advance understanding. Although not directly related to CCTP, it is a source of underlying knowledge that will enable future progress in CCTP. 
- Exploratory Research: Exploratory research is undertaken in the pursuit of novel or emergent concepts, not elsewhere covered. Many novel approaches are pursued within existing R\&D programs, but sometimes new concepts do not fit neatly within the constructs of existing mission- or discipline-specific programs. In addition, experimental research may be too risky or multidisciplinary for a particular R\&D program to sustain. Therefore, not all of the research on innovative concepts for climate-related technology is, or should be, aligned directly with an existing Federal R\&D mission-related program. This Plan calls for exploratory research that could lead to new breakthroughs in technology development, and thereby dramatically change the way energy is produced, transformed, and used in the global economy. Exploratory research of innovative and novel concepts, not elsewhere covered, is one way to uncover such "breakthrough technology," strengthen the research community, and broaden the R\&D portfolio.

The workshops considered the potential research contributions to climate-related technology development of each of the above categories. The primary focus was on R\&D and not on demonstration and deployment of existing technologies.

\section{Workshop Participants}

Seventy-five experts from varied backgrounds participated in the six workshops (see Appendix A for a list of participants):

- $\quad$ Research Universities (Stanford, Harvard, MIT, McGill, Texas A\&M, U. of Wisconsin, Washington State University, UC-Davis, U. of Tennessee, ...)

- Industry (Exxon-Mobil, Chevron-Texaco, EPRI, Edison Electric Institute, AFPA, TVA, Solar Turbines, Marlow Industries, Energy Industries of Ohio, ...)

- Government (DOE, EPA, NSF, NIST, NASA, USDA, OSTP, USAID, NYSERDA, ...)

- National Labs (NREL, ORNL, PNNL, LBL, ANL, INL, PPPL, NASA Glenn Research Center, NASA Langley Research Center, ...)

- Research Organizations (National Academy of Sciences, Research Triangle International, World Resources Institute, ICF Consulting,

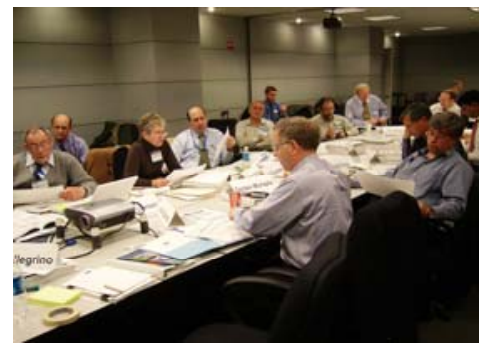
Energetics, ...)

\section{Structured Methodology and Workshop Format}

Each of the technology goal-oriented workshops brought together technical experts to discuss the topic in a one-day, facilitated format. The facilitated format was designed to focus discussions and optimize the use of time, while being sufficiently flexible to permit a lively exchange of ideas.

The following guidance was prepared for the workshop:

Prior to the Workshop - Participants were asked to complete a homework assignment that was provided to them prior to the workshop. Hard copies of responses to the assignment as well as supporting materials were provided by some participants. 
During the Workshop - Participants actively shared ideas through facilitated sessions. Structured brainstorming and critical analysis were used to gain input on key gaps and opportunities, as well as on under-funded areas of the current R\&D portfolio.

After the Workshop - A draft of the findings was prepared and portions were circulated to participants for review and comment. Some additional material was sought to clarify points and provide technical insight. The results of these workshops were also used as the foundation for the sixth workshop to integrate ideas and discuss basic science needs.

The agenda for each of the five technology goal workshops followed the topics of the homework assignments, as shown in Appendix B. A series of brainstorming and consensus-building activities were used to identify and prioritize high priority R\&D opportunities and technology gaps and to assess portfolio balance. The following general guidelines were developed and shared with participants:

- Big picture concepts are encouraged - think out of the box

- Technology development is considered over a near-, mid-, and long-term (100-year) time horizon

- Research and development is the primary focus, rather than deployment and demonstration of existing technology

- Systems approaches should be considered (i.e., combinations of new and/or existing technologies, potentially bridging multiple goal areas)

- Think along the lines of gigaton (i.e., billion ton) reductions of carbon emissions

To illustrate, a gigaton/year of carbon mitigation could be achieved by building 1,000 "zero-emission" 500-MW coal-fired power plants in lieu of coal-fired plants without carbon capture and storage. Alternatively, a gigaton/year could be obtained by deploying one billion new cars at 40 miles per gallon (mpg) instead of $20 \mathrm{mpg}$. Or a gigaton/year could be achieved by converting a barren area about 30 times the size of Iowa's farmland to new forest (Placet, Humphreys, and Mahasenan, 2004, p. 202).

In addition to being provided relevant chapters from the Draft CCTP Strategic Plan and a selection of the individual technology descriptions from the document Technology Options for the Near and Long Term (CCTP, 2005c), participants were provided with spreadsheets of information about the CCTP budget. The data provided basic information about the concentration of expenditures within goal areas (e.g., transportation, buildings) and by stage of development ( $R \& D$ versus deployment). This information is summarized in the following charts for fiscal years 2005 through 2007. Summing across the six CCTP goals, the Federal government spends about \$3 billion/year on climate change technology development.

The Federal government through tax incentives and other subsidies spends as much if not more on new energy sources and technologies. With the passage of the Energy Policy Act of 2005, Federal tax breaks of $\$ 14.5$ billion are provided for the time period 2005 to 2015. Detailed data were not available to examine the full range of Federal incentives relative to the CCTP portfolio.

Participants were also briefed on the climate change technology scenarios completed by the Pacific Northwest National Laboratory (Placet, Humphreys, and Mahasenan, 2004) that are also summarized in the Draft CCTP Strategic Plan. Three scenarios are used to illustrate the range of technology possibilities in somewhat orthogonal directions:

- Closing the loop on carbon: Advanced coal gasification with carbon capture and sequestration augmented by hydrogen technologies allow coal to continue to dominate power production.

- New energy backbone: Technological advances in renewable energy and nuclear power give rise to new competitive realities, reducing the dominant role of fossil fuels. 


\section{CCTP Budget Summary: Reduce Emissions from Energy End-Use and Infrastructure}
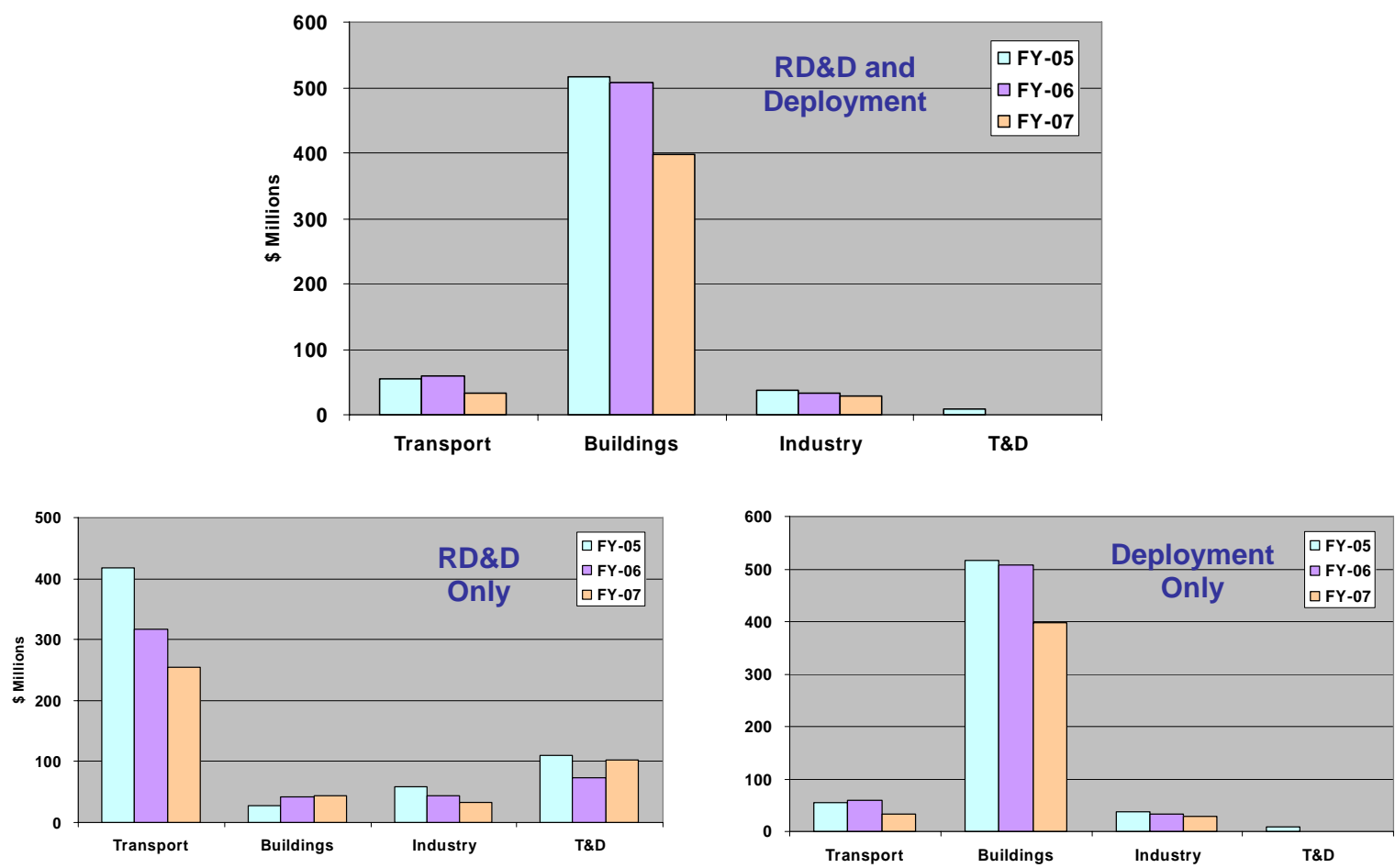

CCTP Budget Summary: Reduce Emissions from Energy Supply
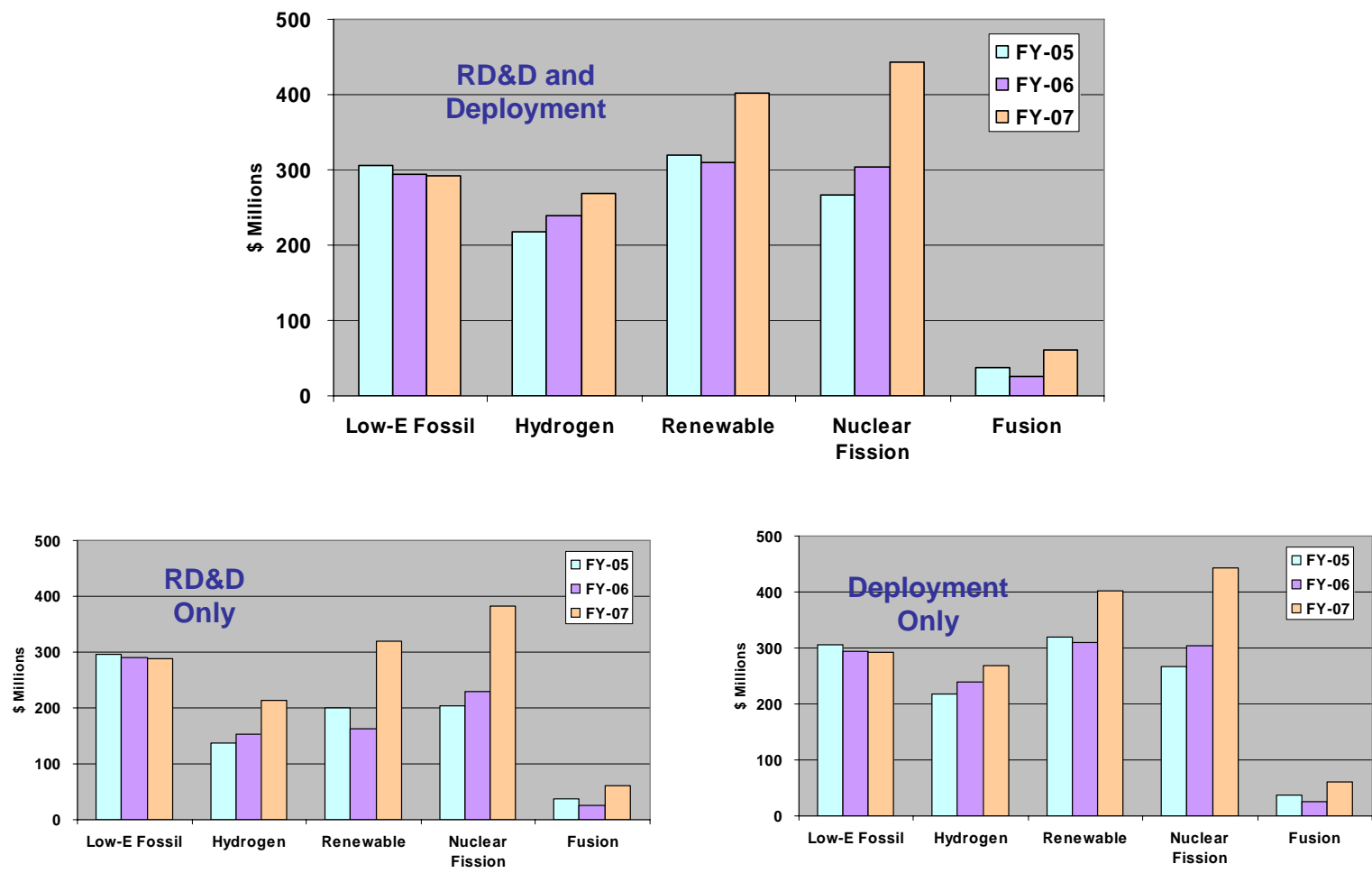


\section{CCTP Budget Summary: Capture and Sequester Carbon Dioxide}
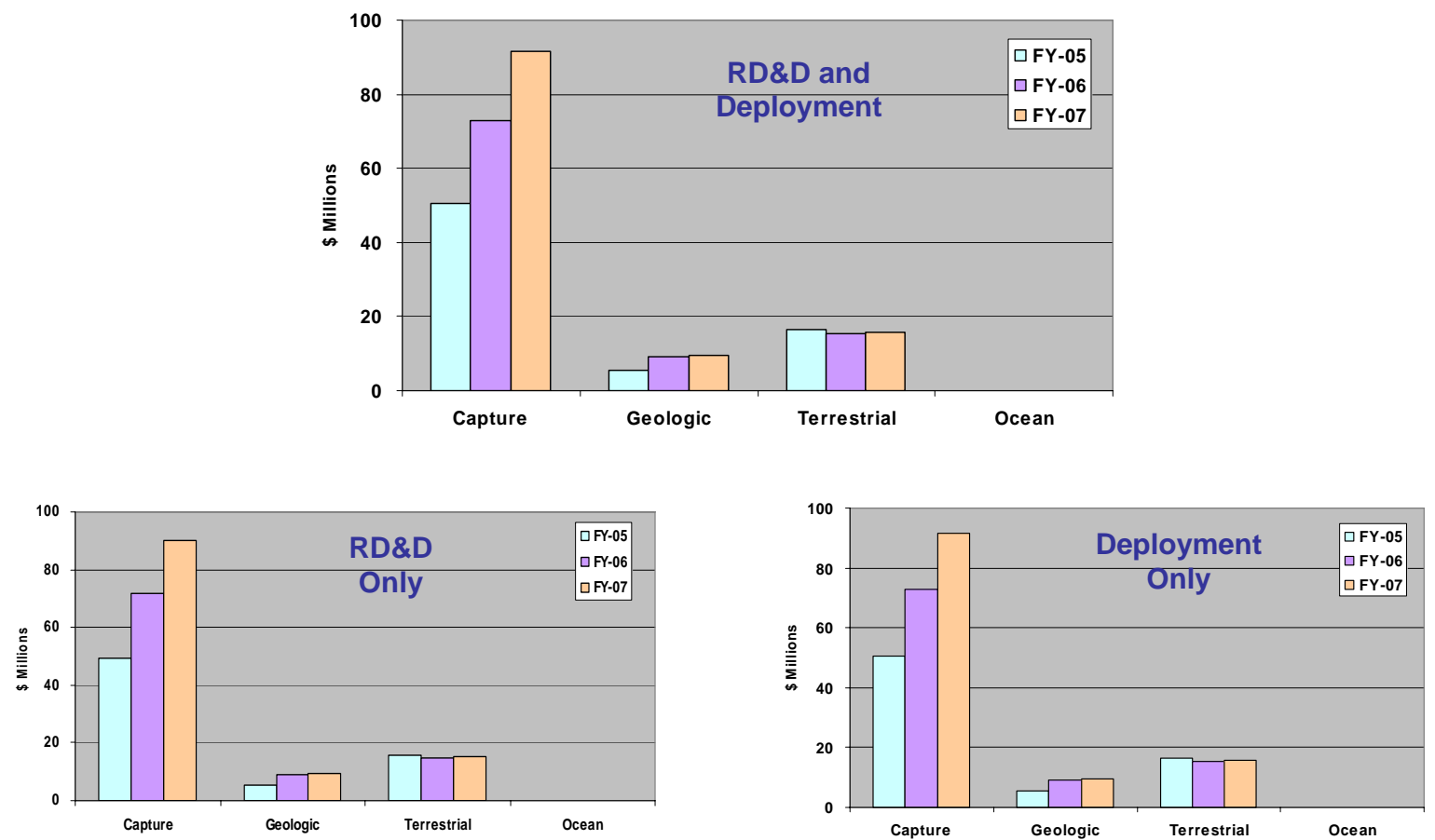

CCTP Budget Summary: Reduce Emissions of Non- $\mathrm{CO}_{2}$ Greenhouse Gases
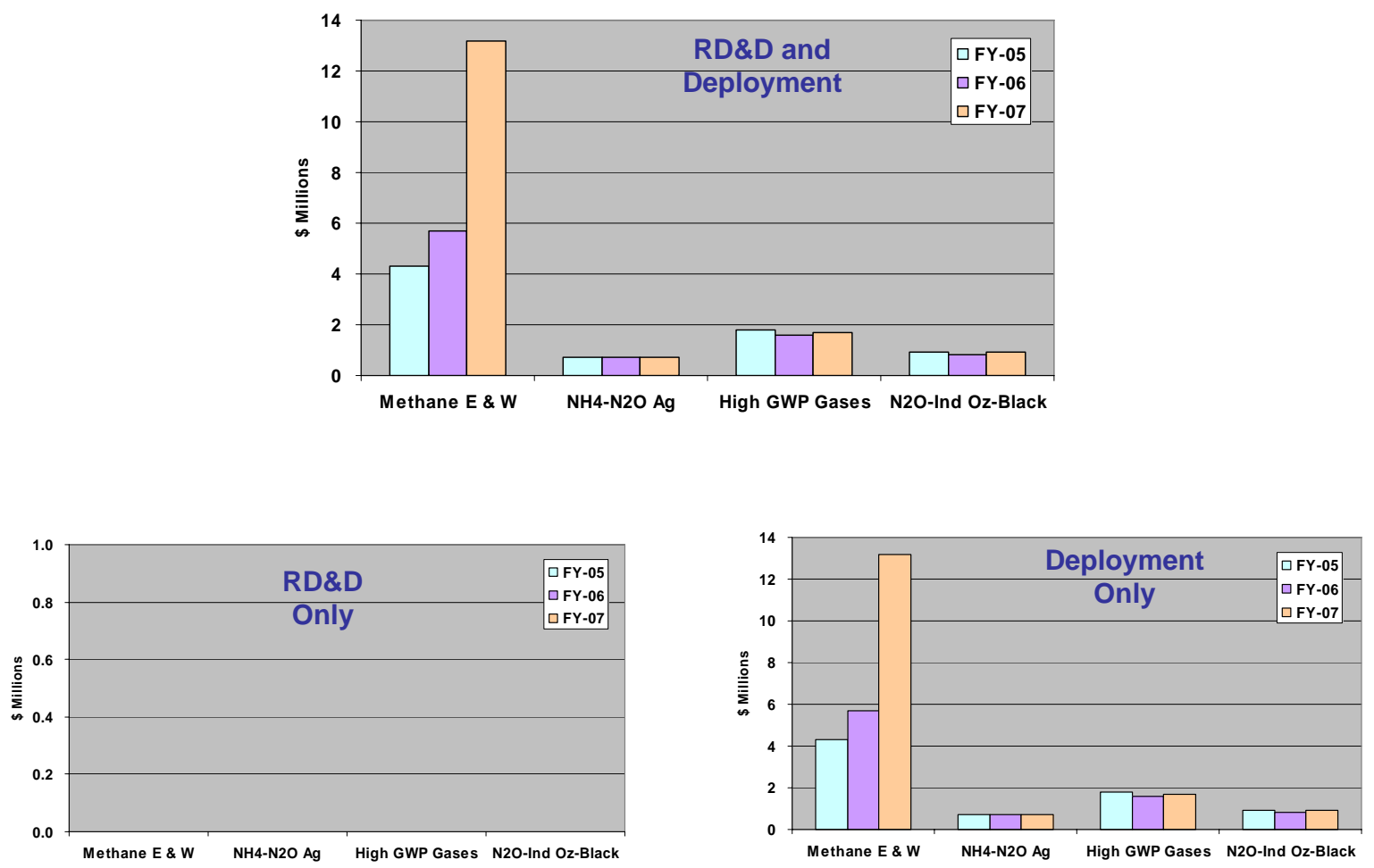


\section{CCTP Budget Summary: Improve Capabilities to Measure}

and Monitor GHG Emissions
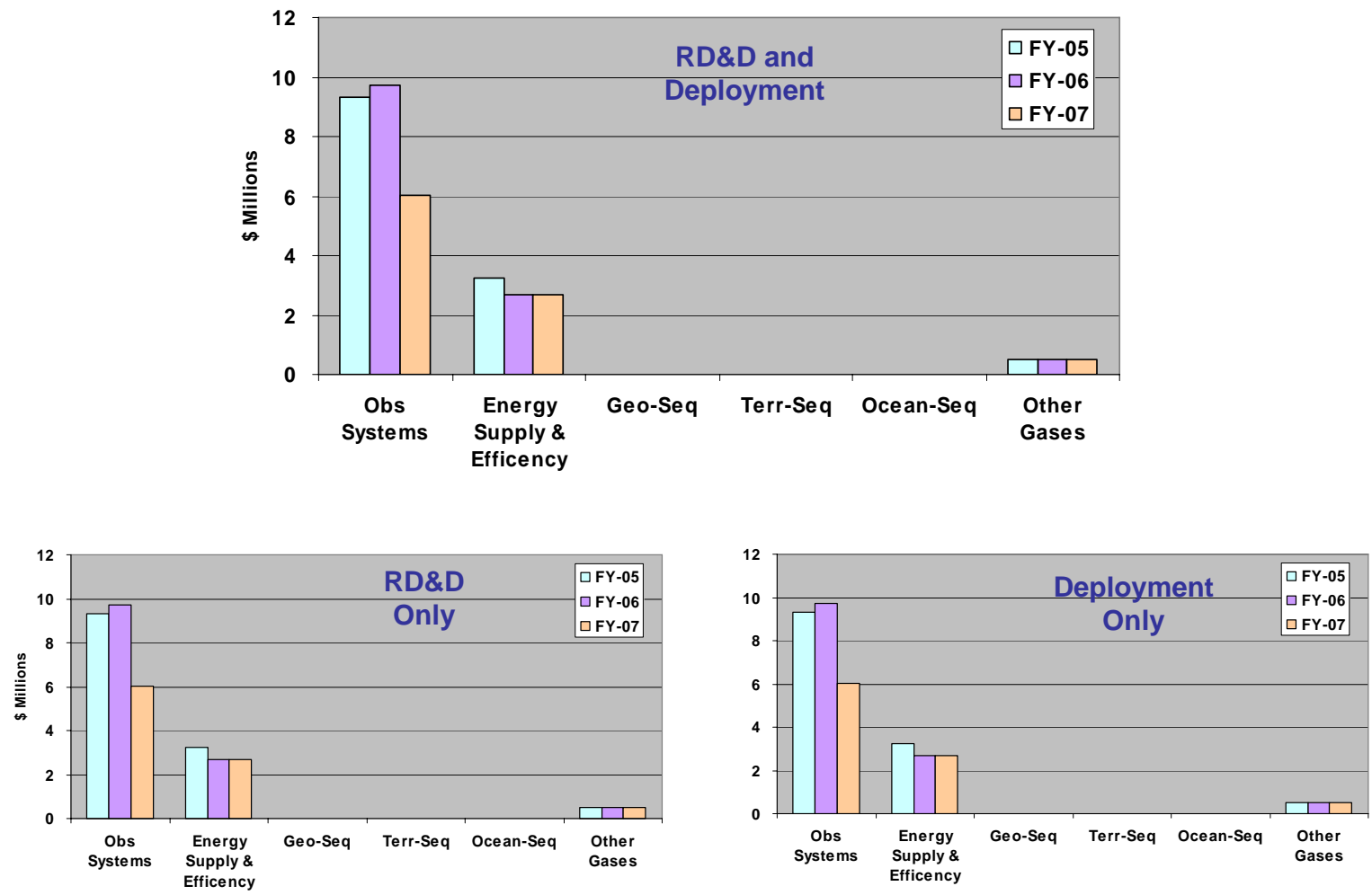

\section{CCTP Budget Summary: Bolster Basic Science Contributions} to Technology Development
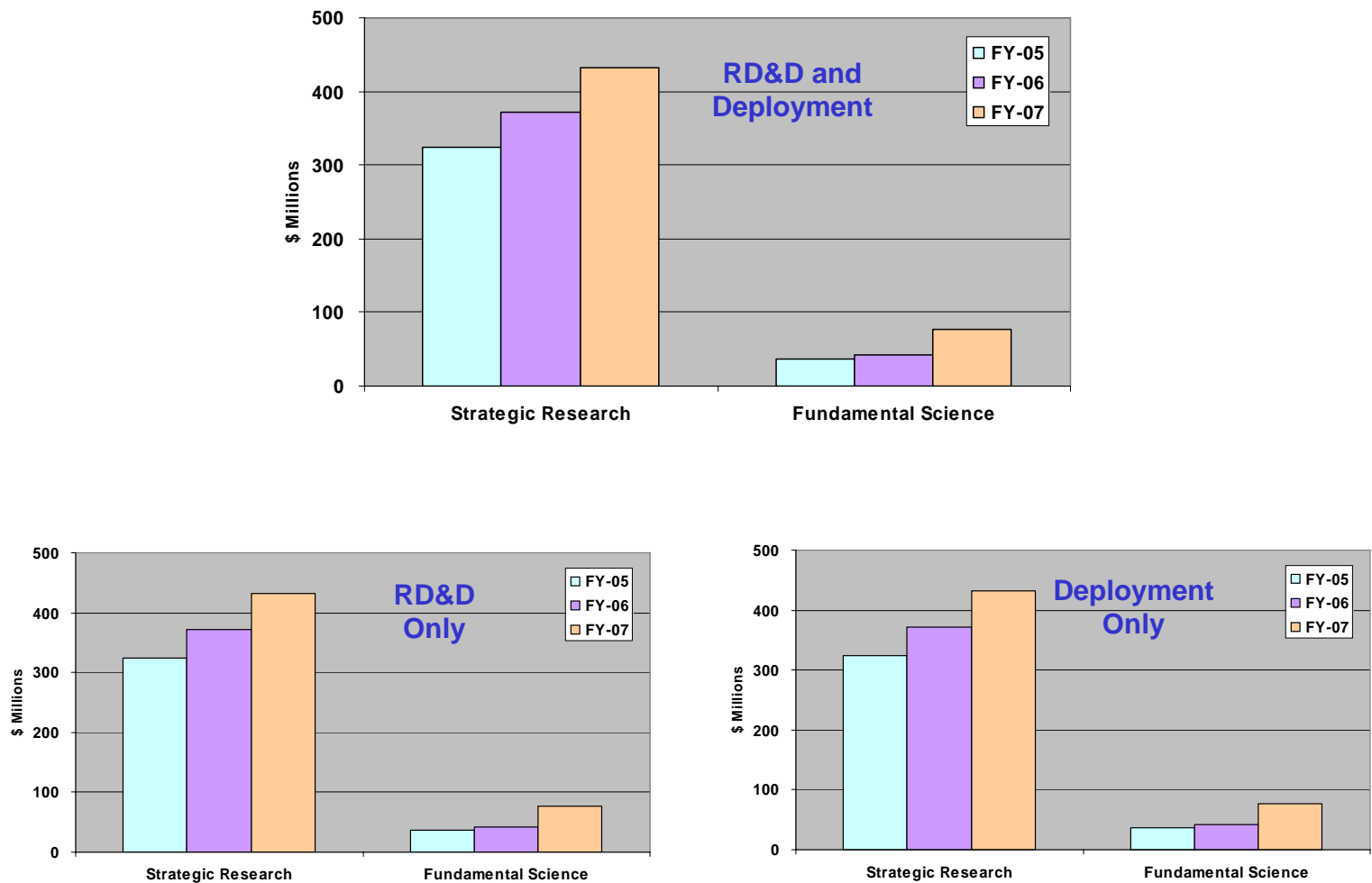
- Beyond the standard suite: Novel and advanced technologies (fusion, large scale solar and bio$\mathrm{X}$, low-resistivity inter-connected grid, etc.) emerge to play major roles, complementing the standard suite.

Two conclusions from these scenarios were emphasized. First, the actions and technologies needed to stabilize GHG concentrations at an acceptable level (based, for instance, on goals set by the United Nations Framework Convention on Climate Change) are large-scale and challenging. For instance, it is estimated that annual $\mathrm{CO}_{2}$ reductions worldwide by the end of the century need to be as high as 14.5 gigatons. Second the PNNL scenarios show that a diversified technology portfolio is needed in all four CCTP emissions-reduction goals.

The following figure displays the cumulative contributions between 2000 and 2100 to emission reductions underlying varying carbon constraints for each of the scenarios. The thick bars show the contributions under the high emission constraint and the thinner, semi-transparent bars show the variation in the contribution between the very high emissions constraint and the low emissions constraint. On the one hand, it shows that no single technology option is able to provide enough emissions reductions to meet the goal of carbon stabilization. On the other hand the figure shows that under a wide range of differing assumptions, advanced technologies associated with energy end-use, energy supply, carbon capture and storage, and other GHG gases could all contribute significantly, underscoring the importance of a diversified approach to technology R\&D.

\section{Potential Contributions to Emissions Reduction}

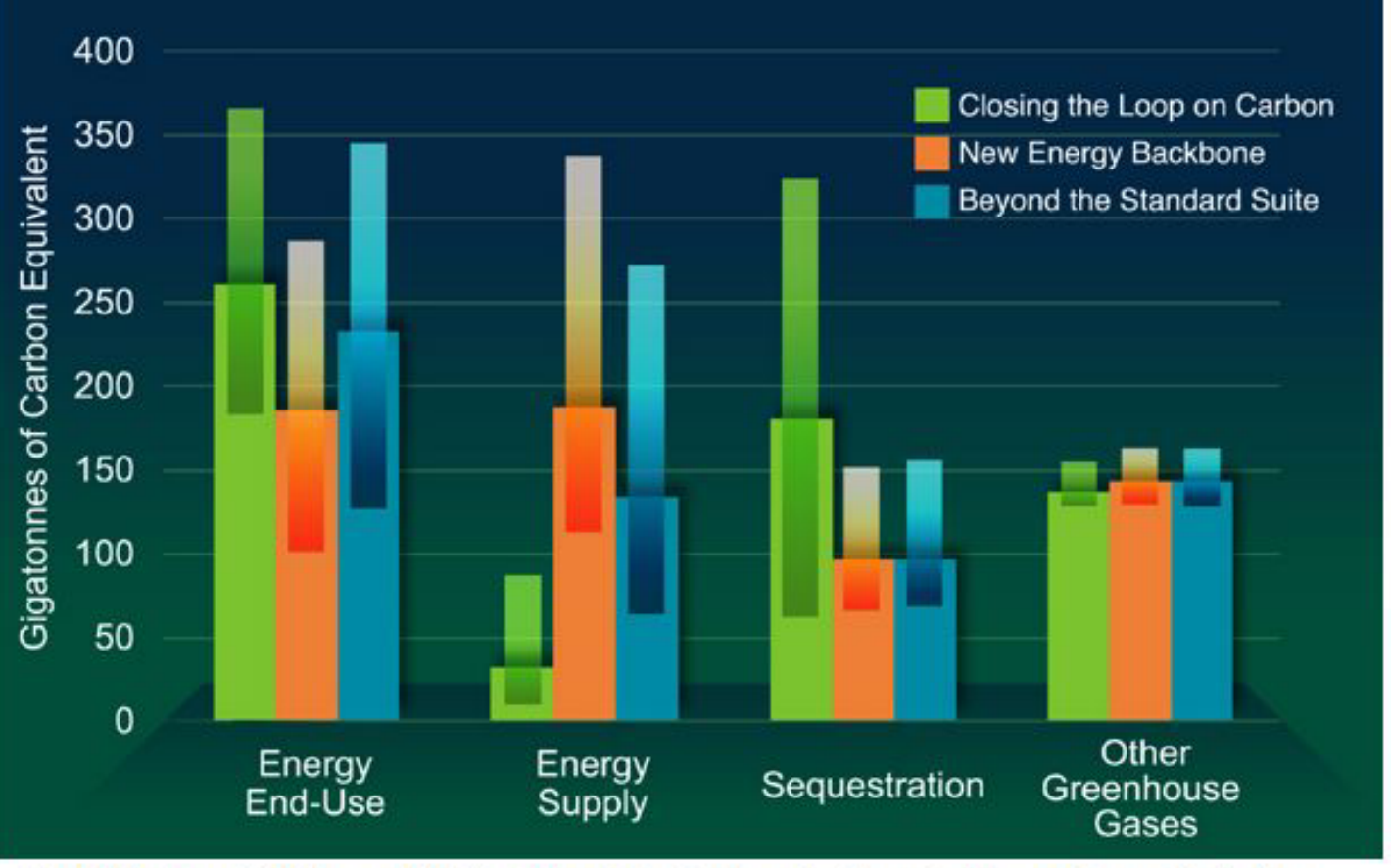

Source: Placet, Humphreys, and Mahasenan, 2004. 


\section{Results: Gaps and Opportunities}

The results of the workshops are summarized here using a series of graphs and tables. In each case the graphs and tables represent the results of a Delphi process through which workshop participants assessed the CCTP R\&D portfolio.

The first graphic is a timeline of representative technologies that could arise over time from ongoing and future research investments. The focus of these timelines is more on the chronology of technology performance milestones and less on the R\&D needed to achieve these levels of performance. Preliminary drafts of six technology timelines (one for each of the five technology goals and a sixth integrating chart) were reviewed by participants at the workshops and comments were collected. The technologies presented in the timeline represent CCTP's current R\&D portfolio and future research directions that were proposed by the workshop participants.

The second graphic is an X-Y plot that portrays a preliminary list of gaps and opportunities in terms of the magnitude of their potential impact and the probability of success. "Impact" was defined as progress toward the particular goal and "probability of success" reflects the level of certainty that the R\&D gap or opportunity could achieve the estimated impact. These plots were produced during each of the five goal workshops. Participants in the portfolio review itemized more than 90 possible R\&D gaps and opportunities. These X-Y plots were an important step in the process of identifying the gaps and opportunities of highest priority for CCTP. The preliminary lists of gaps and opportunities and the plots were reviewed at the "portfolio integration and basic research needs" workshop.

The third graphic is a table listing current portfolio strengths as well as the final list of gaps and opportunities. The final lists of gaps and opportunities were selected by CCTP staff based on the results of the five goal-oriented workshops and the final integration workshop. High priority gaps and opportunities are highlighted in blue; these designations resulted from the workshop deliberations combined with views of the CCTP program staff.

Each of the one-page matrices of information completed by participants was subsequently converted into one-page descriptions of gaps and opportunities. These are reproduced in Appendix C. In some cases, participants provided only a few sentences or a paragraph of information on a particular gap or opportunity. These were compiled into a list of "other technologies." The five tables of gaps and opportunities provide a link to the one-pagers where supplemental information can be found.

\section{Goal 1 - Reduce Emissions from Energy End-Use and Infrastructure}

Background. Emissions of carbon dioxide from energy consumption in the end-use sectors (industry, residential and commercial buildings, and transportation) can be lowered through energy conservation practices, technological and other economic productivity improvements that lead to increased energy efficiency, and shifts in the composition of output in the economy. Historically, global energy productivity, loosely measured in terms of economic output per unit of energy input, has shown steady increases, averaging gains of about 0.9 percent per year over

\section{Energy End-Use Potential Contributions to Emissions Reduction}

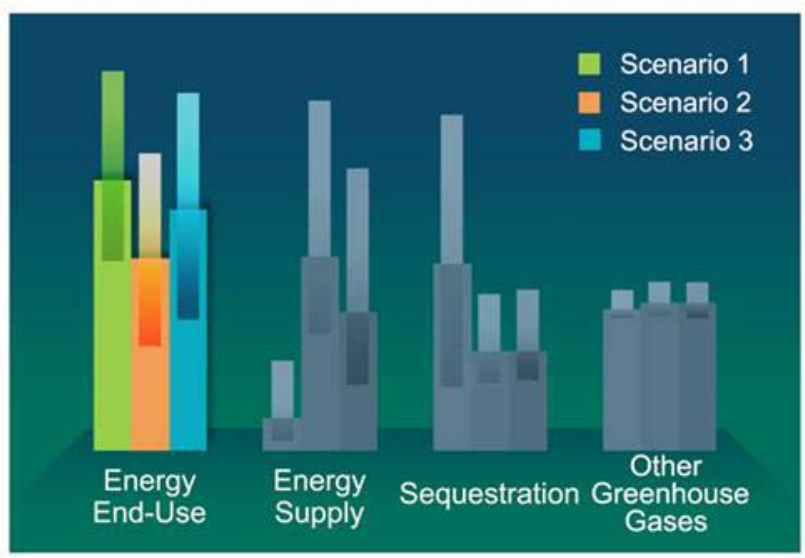

Potential contributions of Energy End Use reduction to cumulative GHC emissions reductions to 2100, across a range of uncertainties, for three advanced technology scenarios. 
the period 1971 to 2002 (EIA, 2004a). Use of more energy-efficient processes and replacement of older, less-efficient capital stock have been important contributors to these gains. Another factor especially in industrialized countries has been a shift over the past several decades in the composition of economic output toward less energy-intensive goods and services.

In the absence of GHG emissions constraints, most forecasts anticipate a future of population and economic growth that drives increasing demand for energy services and increasing $\mathrm{CO}_{2}$ emissions. Many studies suggest that the long-term potential of advanced end-use and infrastructure technologies is significant, both in reducing emissions and in reducing the costs if abatement. As an illustration, in one of many cases analyzed in the Draft CCTP Strategic Plan, ${ }^{1}$ GHG emissions were hypothetically constrained over the course of the 21st century in such a way that a stabilized GHG concentration level of about 550 ppm could ultimately be attained. The lowest-cost arrays of advanced technology in end-use and infrastructure, when compared to a reference case, resulted in reduced or avoided emissions of roughly between 190 and $210 \mathrm{GtC}$. This amounted to between approximately 30 and 35 percent of all GHG emissions reduced, avoided, captured and stored, or otherwise withdrawn and sequestered to attain this level. Similarly, the costs for achieving such emissions reductions, when compared to the reference case, were reduced by roughly a factor of 3 .

In the United States, the largest end-use sources of $\mathrm{CO}_{2}$ emissions are the following:

- Transportation fuels

- Electricity and fuel use in buildings

- Electricity and fuel use in industry

- Non-combustion industrial processes including cement, lime, coking, and soda ash

Technology strategies for the electric grid and infrastructure can also facilitate $\mathrm{CO}_{2}$ emissions reductions. Descriptions of technologies relevant to this goal can be found in the report Technology Options in the Near and Long Term (CCTP, 2005c).

World transportation energy use is expected to grow substantially, and low-emission technology would have significant leverage in helping to transform that sector. Representative near-term technologies include fuel-switching such as hybrid electric vehicles, clean diesel, fuel-flexible vehicles, and efficiency improvements such as light-weight materials, and waste heat recovery. In the long-run, zero-emission verhicle systems are possible with technologies such as hydrogen fuel cells, and significant reductions in vehicle miles of travel could occur through engineered urban designs and regional planning.

Another challenge is to reduce emissions from buildings and industrial processes using new technologies, fuels, and energy forms derived from low- or near-net-zero $\mathrm{CO}_{2}$ emitting sources. In the buildings sector, net-zero homes in the near-term are complemented by net-zero energy office buildings in the mid-term and net-zero energy communities in the long-term. In industry, improved recyclability and greater use of byproducts in the near-term evolve into closed-cycle products and materials in the long-term. Energy storage could become cost-effective for load leveling of the electric grid in the mid-term, and wireless transmission of electricity could become possible in the long-term.

\footnotetext{
${ }^{1}$ In Chapter 3, various advanced technology scenarios were analyzed for cases where global emissions of GHGs were hypothetically constrained. Over the course of the $21^{\text {st }}$ century, growth in emissions was assumed to slow, then stop, and eventually reverse in order to ultimately stabilize GHG concentrations in the Earth's atmosphere at levels ranging from 450 to $750 \mathrm{ppm}$. In each case, technologies competed within the emissions-constrained market, and the results were compared in terms of energy (or other metric), emissions, and costs (CCTP, 2005b).
} 
Results. The following timeline presents a set of representative end-use technologies that could emerge over time from ongoing and future research investments. The timeline illustrates the technology advances that, if realized, would enable sizeable improvements in end-use efficiency throughout the century and across all sectors of the economy.

A number of the transitions embodied in this timeline suggest that in the mid- and long-term, order of magnitude improvements in efficiency could be produced partly by wholesale technology displacement rather than by further optimization of current approaches. Examples include the transition from incandescent to fluorescent and ultimately to solid state lighting. Other possible technology changeovers include the move from internal combustion engines to hydrogen fuel cells; substitutes for steel, cement, limestone, and other high-GHG products; and the possible shift from low-resistance conductors to wireless power transmission.

\section{Technology Timeline: Reduce Emissions from Energy End-Use and Infrastructure}

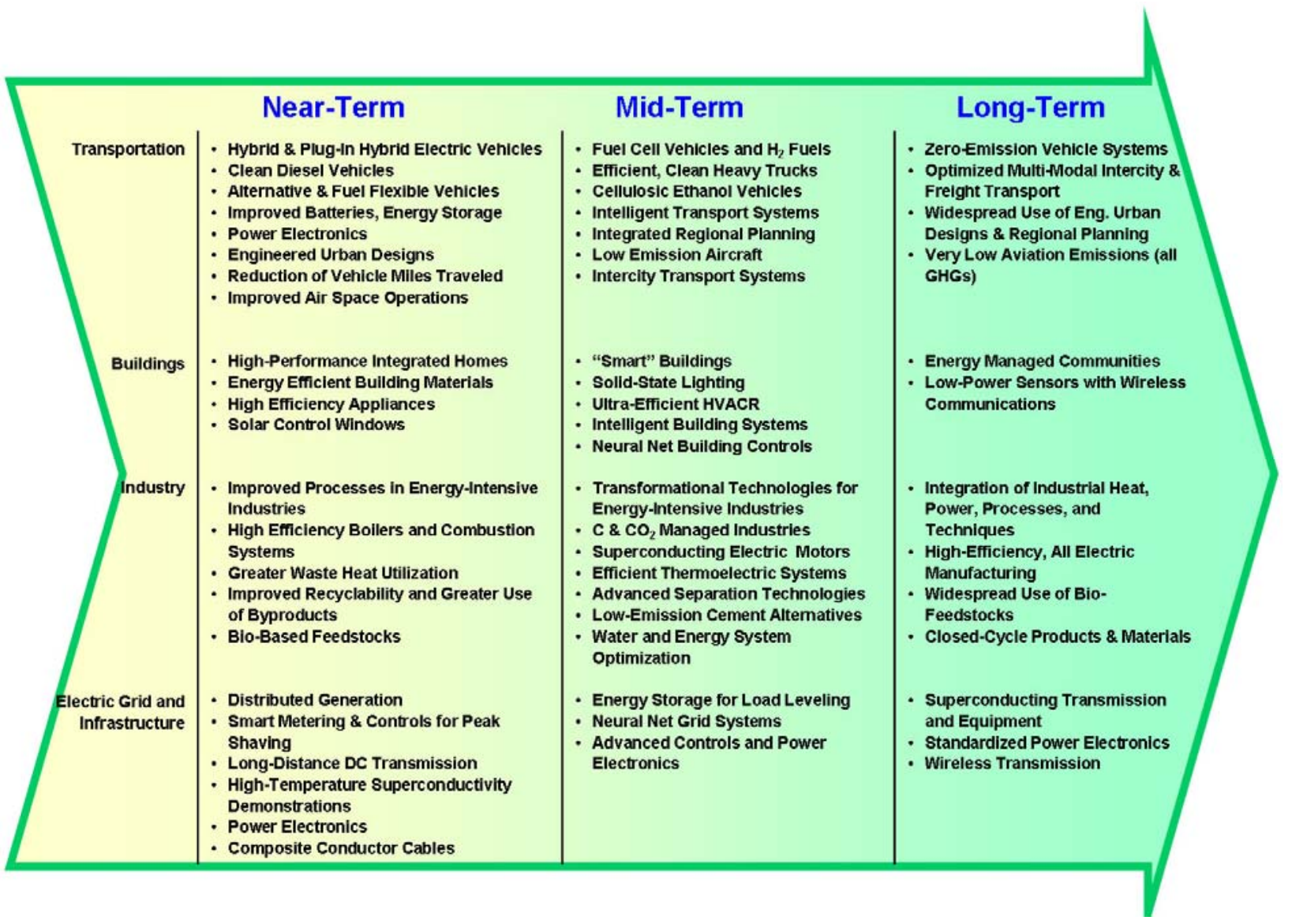

Note: With some overlap, "near-term" envisions significant technology adoption by 10 to 20 years from present, "mid-term" in a following period of 20 to 40 years, and "long-term" in a following period of 40 to 60 years. 
The following figure lists the gaps and opportunities identified by workshop participants with respect to Goal 1. The X-Y plot describes the participants' views of each gap and opportunity in terms of its potential impact on goal attainment and its probability of success.

\section{Impact vs. Probability of Success: Reduce Emissions from Energy End-Use and Infrastructure}

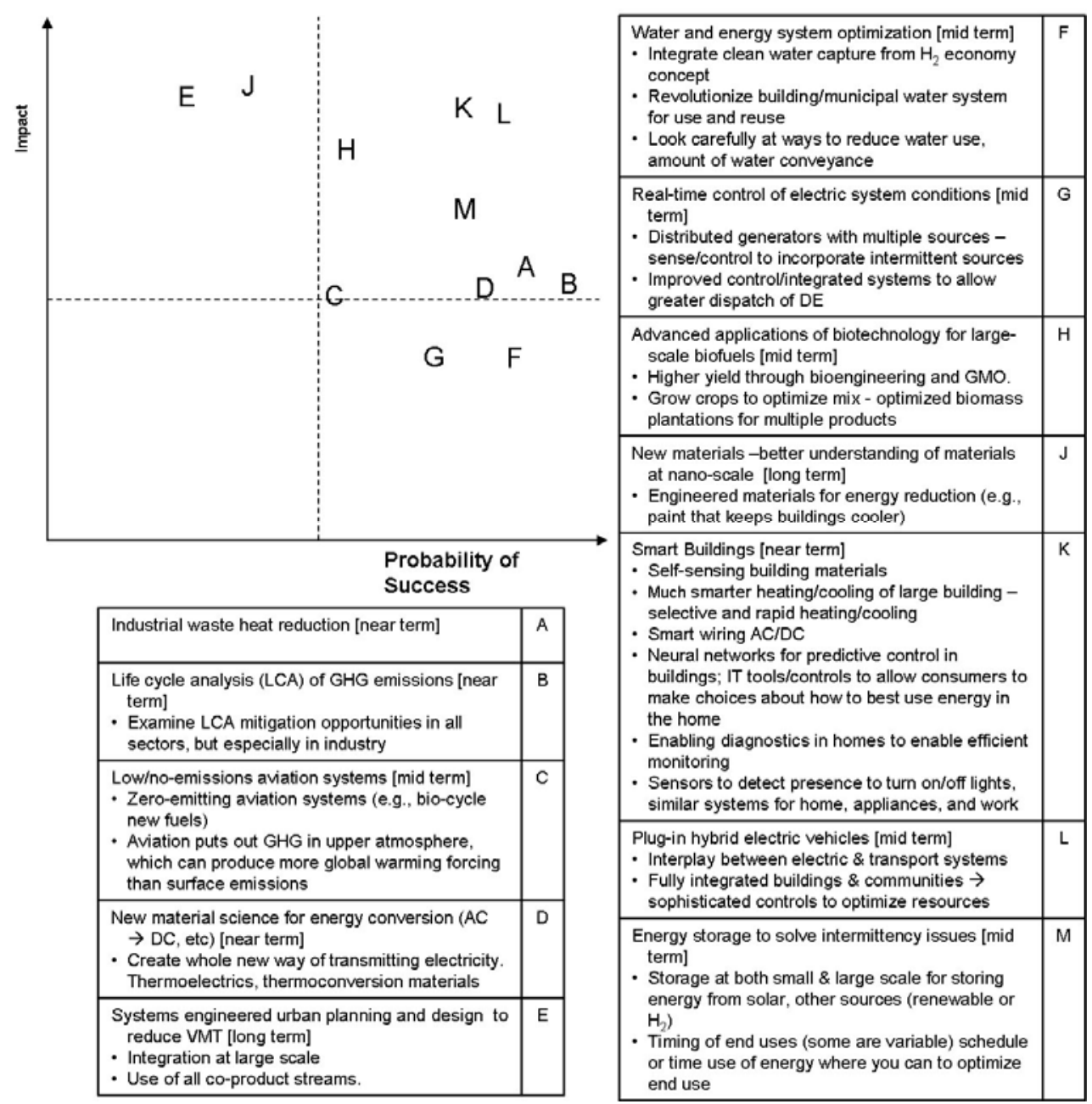

The idea that appears in the uppermost right corner (indicating the highest combination of impact and probability of success) is the plug-in hybrid electric vehicle (HEV) (Item L). In the mid-term, workshop participants felt that the integration of plug-in HEVs with zero energy buildings and utility peak-shaving could dramatically reduce GHGs from vehicles if recharging is done principally with low-carbon forms of electricity such as nuclear or renewable resources. This technology could also help optimize the use of intermittent energy sources such as solar and wind.

Another high-impact/high-probability idea is smart buildings (Item K). This technology opportunity is multi-faceted involving self-sensing building materials, smarter Heating Ventilating AC (HVAC) systems and smart AC/DC wiring, as well as enabling sensors and diagnostics to detect conditions where energy services could be reduced. 
Another concept judged by workshop participants to have potentially high impact is advanced applications of biotechnology for large-scale biofuels (Item $\mathrm{H}$ ). This includes higher biomass yields per acre through genetically engineered organisms, optimization of biomass plantations for multiple bioproducts, and plant engineering to greatly increase lipid synthesis to increase the production of biodiesel from plants. Biotechnology concepts constitute a crosscutting theme that received considerable focus by all of the workshops. "Biomass genomics for alternative fuels, materials, and chemicals" was designated a high priority gap in the Energy Supply workshop and was not repeated as a high priority gap elsewhere because it seemed most central to the supply goal.

The upper right hand quadrant also includes energy storage to reduce costs associated with intermittency and seasonal swings in energy production, to shave peaks, and to enable better use of base-load plants. Other high-potential/low-risk concepts include industrial waste heat reduction, life cycle analysis of GHG emissions, and new material science for energy conversion including thermoelectrics.

Current portfolio strengths and gaps and opportunities for Goal 1 are outlined in the following table, by sub-area. High priority gaps and opportunities are highlighted in blue.

One of the high priority concepts for low-emissions fossil-based power and fuels involved "Integration with carbon capture and storage.” In addition to the conventional approach of combining IGCC technology with geologic storage, the experts also noted the potential for in-situ refining to reduce environmental emissions. This was mentioned in particular with respect to the production of shale oil, but is also applicable to coal mining, where underground refining allows $\mathrm{CO}_{2}$, particulate materials and other pollutants to remain underground where the refined product is produced. Other approaches to addressing the environmental challenges of shale oil production were also noted, such as in situ gasification or the use of oxygen-rich air in the combustion of coal for power production. Workshop participants were aware that meeting the nation's oil security goals with shale oil production would require advances in the production of clean power because the electricity required for heating shale oil formations will be large. 


\section{Current Portfolio Strengths and Gaps \& Opportunities: Reduce Emissions from Energy End-Use and Infrastructure}

\begin{tabular}{|c|c|c|c|}
\hline Goal Sub-Area & Current Portfolio Strengths & Gaps \& Opportunities & App C Link* \\
\hline $\begin{array}{l}\text { Transportation } \\
\text { (SP- 4.1) }\end{array}$ & $\begin{array}{l}\text { - Light Vehicles/Hybrids } \\
\text { - Heavy Vehicles } \\
\text { - } \text { Alternative Fuel Vehicles } \\
\text { - Intelligent Transport } \\
\text { - Systems } \\
\text { - } \text { Aviation Fuel Efficiency }\end{array}$ & $\begin{array}{l}\text { - Enabling Technologies for Low-GHG } \\
\text { Plug-in Hybrid Electric Vehicles } \\
\text { - Advanced Thermoelectric Concepts } \\
\text { to Convert Temperature Differentials } \\
\text { - Studies of Advanced Urban- } \\
\text { Engineering Concepts to Reduce } \\
\text { VMT } \\
\text { - Advanced Freight and Low-Emission } \\
\text { Aviation Systems } \\
\text { - New Combustion Regimes with Fuel } \\
\text { Flexibility, Near-Zero Regulated } \\
\text { Emissions }\end{array}$ & $\begin{array}{l}\text { EU11 \& ES3\&7 } \\
\text { EU4 } \\
\text { EU5 } \\
\text { EU3 }\end{array}$ \\
\hline $\begin{array}{l}\text { Buildings } \\
\text { (SP- 4.2) }\end{array}$ & $\begin{array}{ll}\text { - } & \text { Building Envelope } \\
\text { - } & \text { Building Equipment } \\
\text { - Integrated } \\
\text { Design/Operation } \\
\text { - } \text { Albedo/Urban Heat Island } \\
\text { (EPA) }\end{array}$ & $\begin{array}{l}\text { - Advanced Sensors, Communications } \\
\text { and Controls for Smart Buildings } \\
\text { - Smart Roofs, Walls and Insulation } \\
\text { - Integration of Distributed } \\
\text { Energy/Renewables } \\
\text { - Ultra-Efficient HVACR }\end{array}$ & $\begin{array}{l}\text { EU10 } \\
\text { EU10 } \\
\text { EU7 } \\
\text { EU10 }\end{array}$ \\
\hline $\begin{array}{l}\text { Industry } \\
\text { (SP- 4.3) }\end{array}$ & $\begin{array}{ll}\text { - } & \text { Energy Conversion \& } \\
& \text { Utilization } \\
\text { - } & \text { Resource Recovery \& } \\
\text { Utilization } \\
\text { - Industrial Process } \\
\text { Efficiency } \\
\text { - Enabling Technologies }\end{array}$ & $\begin{array}{l}\text { - Advanced Applications of } \\
\text { Biotechnology } \\
\text { - Substitutes for Steel, Cement, } \\
\text { Limestone, and Other High-GHG } \\
\text { Products } \\
\text { - Greater Waste Heat Utilization } \\
\text { - Computational Modeling and Process } \\
\text { Simulation for System Optimization } \\
\text { - Water and Energy System } \\
\text { Optimization } \\
\text { - Life-Cycle Analysis for GHG } \\
\text { Emissions } \\
\end{array}$ & $\begin{array}{l}\text { EU1 } \\
\text { EU6 } \\
\text { EU2 }\end{array}$ \\
\hline $\begin{array}{l}\text { Infrastructure } \\
\text { (SP- 4.4) }\end{array}$ & $\begin{array}{l}\text { - High Temperature } \\
\text { Superconductivity } \\
\text { - Transmission \& } \\
\text { Distribution } \\
\text { - Distributed Generation } \\
\text { - Energy Storage } \\
\text { - Sensors/Controls } \\
\text { - Power Electronics }\end{array}$ & $\begin{array}{l}\text { - Large-Scale Energy Storage } \\
\text { - } \text { Materials Science for Efficient AC/DC } \\
\text { Conversion } \\
\text { - Nanotechnology for Efficient } \\
\text { Transmission of Energy } \\
\text { - Real-Time Observability, Monitoring } \\
\text { and Control of Electric System } \\
\text { Conditions }\end{array}$ & $\begin{array}{l}\text { EU12 \& ES4\&5 } \\
\text { EU4 }\end{array}$ \\
\hline
\end{tabular}

*Further details for each of the gaps and opportunities listed in the table above are provided in Appendix C as noted by the code in the column "App C Link." 


\section{Goal 2 - Reduce Emissions from Energy Supply}

Background. Global energy demand is projected to grow significantly by the year 2100 . Some projections show energy demand over the century growing by a factor of six or more, and mid-range scenarios project an increase of about a factor of three or more from today's level, even under scenarios in which energy efficiency is assumed to improve steadily over time. Of this growth, global demand for electricity is projected to increase faster than direct use of fuels in enduse applications.

Today, a range of technologies using fossil fuels, nuclear power, hydroelectric power, and a relatively small (but fast growing) amount of renewable energy, supplies the world's electricity demand. Most of global transportation demand is met with petroleum products.

The development of advanced technologies that can significantly reduce emissions of carbon dioxide from energy supply is a central component of the overall climate change technology strategy. Many opportunities exist for pursuing technological options for energy supply that are characterized by low or near-net-zero emissions and whose development can be facilitated by a coordinated Federal R\&D investment plan.

Some advanced energy supply technologies build on the existing energy infrastructure, which is currently dominated by coal and other fossil fuels. One set of technologies that would allow continued use of coal and other fossil fuels, even under scenarios calling for substantial $\mathrm{CO}_{2}$ emission limitations, is contained in an advanced coal-based production facility, based on coal gasification and production of syngas, which can generate electricity, hydrogen, and other valued fuels and chemicals and would be combined with $\mathrm{CO}_{2}$ capture and storage and have very low emissions of other pollutants. Some of the examined emissions reduction scenarios project that if $\mathrm{CO}_{2}$ capture and storage and improvements in fossil energy conversion efficiencies are achieved, fossil-based energy could continue to supply a large percentage of total energy and electricity in the future even under a high carbon constraint. In addition to this mid- to long-term opportunity, lowering $\mathrm{CO}_{2}$ emissions from fossil fuel combustion in the near term can be achieved by increasing the energy efficiency of combustion technology and by increasing the use of combined heat and power.

Advances in low- and zero-emission technologies have also been identified in a number of scenario analyses as important for reducing GHG emissions. These technologies include advanced forms of renewable energy, such as wind, photovoltaics, solar thermal applications, and others; biologically based open and closed energy cycles, such as enhanced systems for biomass combustion, biomass conversion to biofuels and other forms of bioenergy; refuse-derived fuels and energy. Technologies suggested for nuclear energy include advanced reactors, use of plutonium and transuranics in reactor fuel, spent fuel 
recycling to address repository limitations, and advanced proliferation-resistant gas centrifuges. Radiation resistant materials are a priority for both fission reactors and future fusion energy systems. Applications of all these carbon-free sources of energy to the production of hydrogen would enable the reduction of emissions from the transportation sector and electricity production.

The Draft CCTP Strategic Plan (CCTP, 2005b) is organized around the following five energy supply technology areas:

- Low-Emission, Fossil-Based Fuels and Power

- Hydrogen as an Energy Carrier

- Renewable Energy and Fuels

- Nuclear Fission

- Fusion Energy

Individual technology descriptions are provided in the CCTP report, Technology Options for the Near and Long-Term (CCTP, 2005c).

Results. The following timeline presents a set of representative energy supply technologies that could arise over time from ongoing and future research investments. The timeline illustrates the technology advances that, if realized, would produce the energy supply options needed for a future of near-net-zero GHG emissions. Meeting the expected growth in world energy demand over the span of the $21^{\text {st }}$ century will likely be challenging enough. Meeting such demand, while simultaneously reducing emissions and maintaining economic prosperity, will be doubly challenging. Advanced energy supply technologies as outlined in this timeline are critical to meeting these challenges.

Over the next century, the timeline portrays a transition beginning with the commercialization of integrated gasification combined cycle (IGCC) coal plants in the short-term, which facilitate the capture of $\mathrm{CO}_{2}$ emissions. In the next 20 to 40 years (the mid-term) the timeline indicates the market penetration of zero emission coal plants where $\mathrm{CO}_{2}$ is captured and sequestered. By the end of the century, zeroemission fossil energy could dominate.

Regarding the transition to hydrogen, the timeline portrays stationary hydrogen fuel cells in the shortterm, possibly involving natural gas reforming to produce hydrogen. This could transition to renewablehydrogen-powered fuel cell vehicles in the mid-term, and an integrated hydrogen-electricity economy in the long-term.

The potential development of renewables is illustrated by the near-term market penetration of buildingintegrated photovoltaic systems, the mid-term introduction of community-scale solar power, and the widespread use of renewable energy in the long-term.

Widespread use of nuclear power in the long term is seen in the timeline as being enabled by the nearterm development of advanced fuel cycle technology and the subsequent development of closed, proliferation resistant cycles in the mid-term. The first pilot plant for commercial fusion energy is anticipated in the mid-term with wider deployment of fusion power plants in the long-term. 


\section{Technology Timeline: Reduce Emissions from Energy Supply}

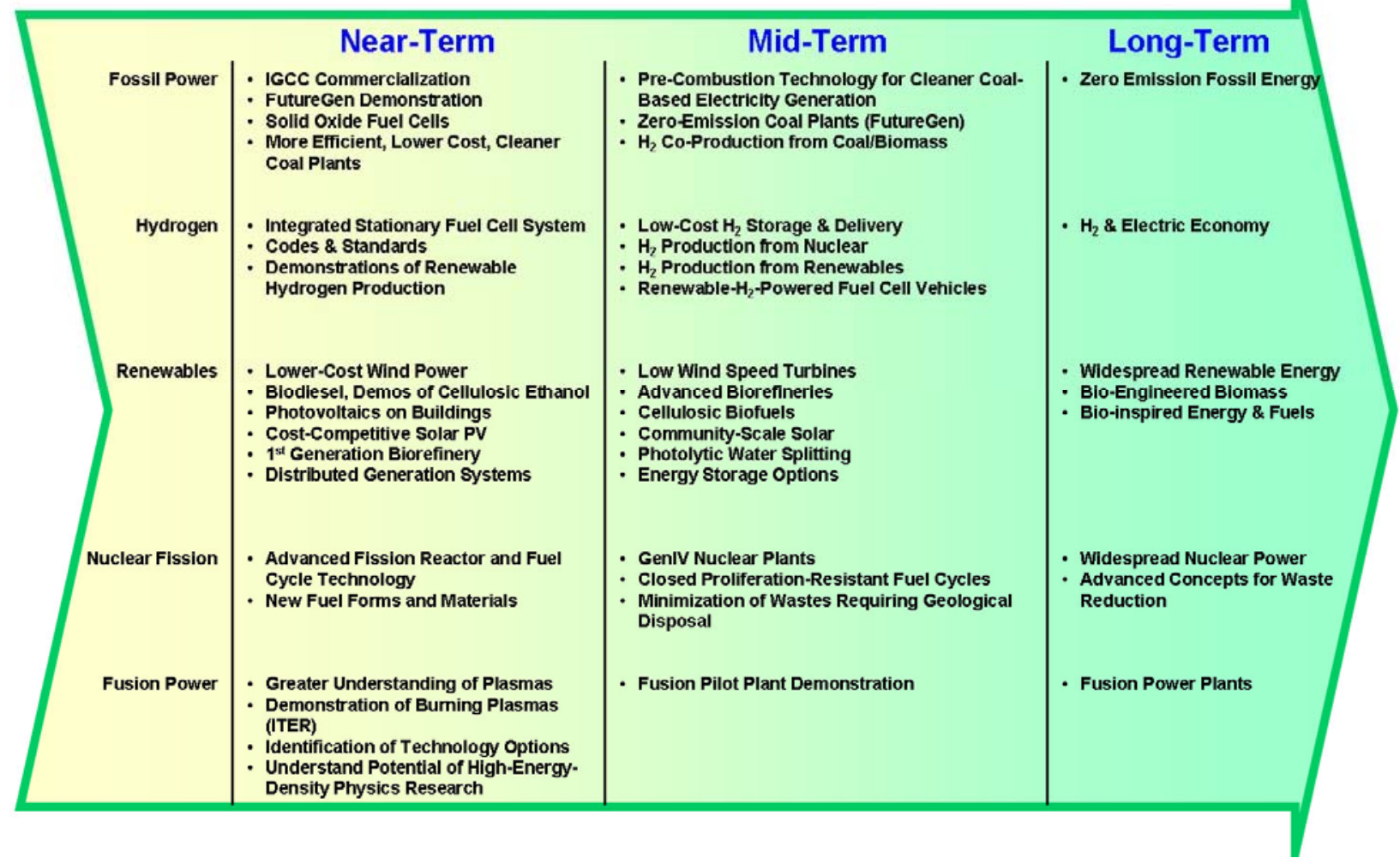

Note: With some overlap, "near-term" envisions significant technology adoption by 10 to 20 years from present, "mid-term" in a following period of 20 to 40 years, and "long-term" in a following period of 40 to 60 years.

The following figure lists the gaps and opportunities identified by workshop participants with respect to Goal 2. The X-Y grid describes the participants' views of each gap and opportunity in terms of its potential impact on goal attainment and its probability of success.

The gaps and opportunities appearing in the upper right quadrant of the figure illustrate some of the more high-impact, high-probability ideas that emerged. Several of these ideas (Items D, E, and F) are fairly exploratory in nature, i.e., nanotechnology for transmission and conversion of energy, high altitude wind kites, and liquid photovoltaics. Ideas $\mathrm{G}$ and $\mathrm{H}$, which are seen as having a fairly significant potential impact and probability of success, address the need for next-generation transmission materials (e.g., hightemperature superconducting materials and nanotechnology for highly conducting superconductors).

The remaining upper right quadrant idea refers to the development of personalized power systems for home and work. These systems refer to miniature space conditioning systems that meet comfort requirements with minimal energy expenditure.

Participants in both the Energy Supply and End-Use Energy and Infrastructure Workshops identified plug-in hybrid electric vehicles (HEVs) as an R\&D gap and opportunity, but the probability of success was seen as less likely by the experts in Energy Supply. The benefits of plug-in HEVs is highly dependent upon the fuel used to produce the electricity that recharges the HEV batteries. If the fuel is low in carbon content as would be the case with renewable or nuclear power, then plug-in HEVs could deliver sizable emission reductions relative to petroleum-based transportation fuels. If the fuels used to produce 
electricity in the mid- and long-term are not transformed and if $\mathrm{CO}_{2}$ is not sequestered by coal plants, then it is not clear that plug-in HEVs would be beneficial as a climate change technology. Similar contingencies were discussed with respect to the trend toward electro-technologies in the industrial sector such as infrared drying and induction heating.

\section{Impact vs. Probability of Success: Reduce Emissions from Energy Supply}

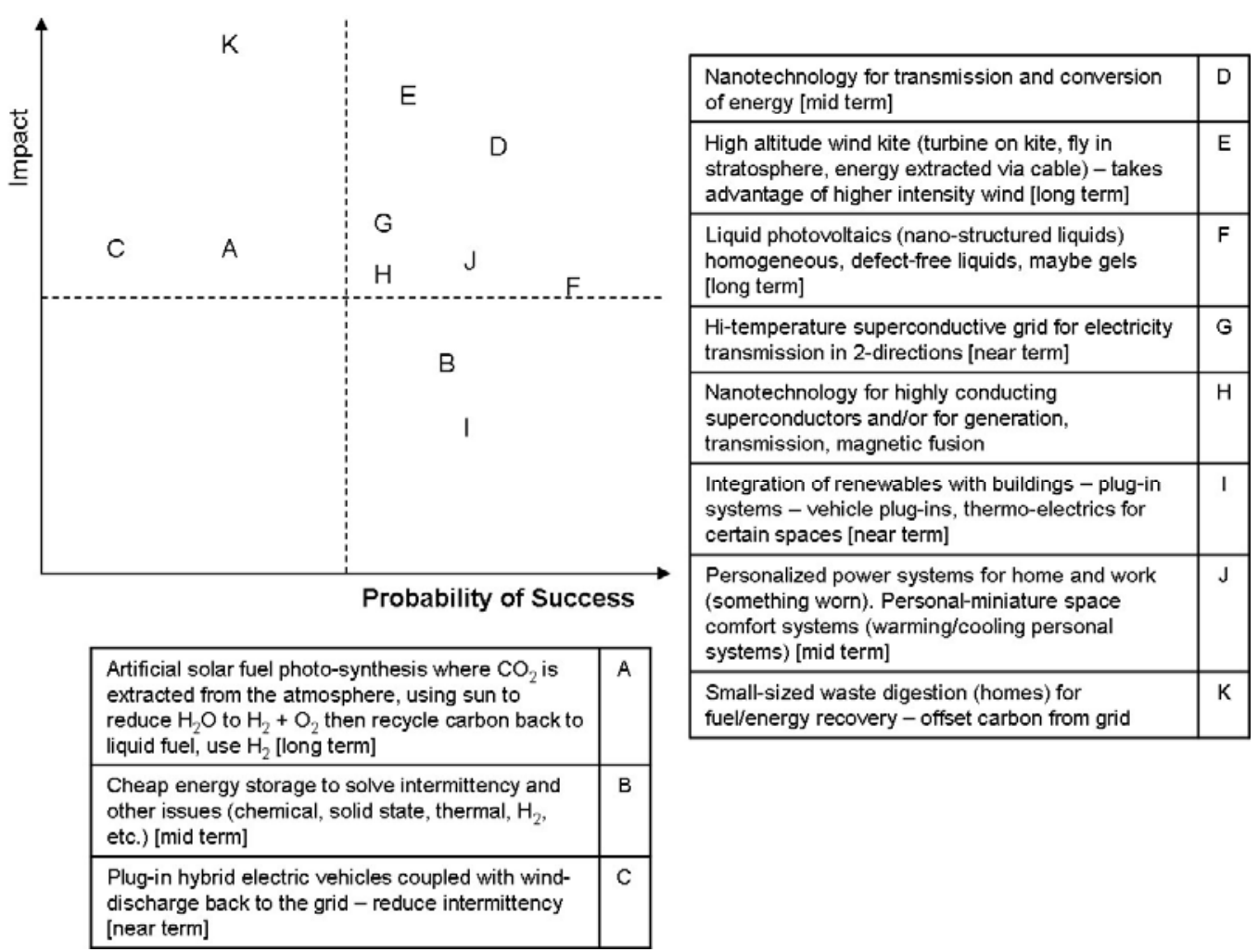

Current portfolio strengths and gaps and opportunities for Goal 2 are outlined in the following table, by sub-area. High priority gaps and opportunities are highlighted in blue.

Among the high-priority gaps and opportunities in the renewable energy and fuels sub-area is the development of a systems approach to waste management, including waste-to-energy. This concept refers to a multi-faceted approach that could reduce the magnitude of landfill waste, could ultimately eliminate new landfill waste, and could reduce uncontrolled landfill gas emissions. Possible features of such a system include:

- Designing products to tag and identify for recycling

- Distributed waste processing: on-site conversion (e.g., home, industrial) of waste to hydrogen, other fuels, or electricity.

- Sorting the entire waste stream into processing categories (recyclables, organics, inerts/toxics, etc.) for more complete recycling

- Using engineered bacteria that breakdown and process waste without producing methane: one approach would be to reduce $\mathrm{CH}_{4}$ to hydrogen and carbon that is sequestered in the soil 


\section{Current Portfolio Strengths and Gaps \& Opportunities: Reduce Emissions from Energy Supply}

\begin{tabular}{|c|c|c|c|}
\hline Goal Sub-Area & $\begin{array}{l}\text { Current Portfolio } \\
\text { Strengths }\end{array}$ & Gaps \& Opportunities & $\begin{array}{c}\text { Appendix C } \\
\text { Link }^{*}\end{array}$ \\
\hline $\begin{array}{l}\text { Low-Emissions } \\
\text { Fossil-Based } \\
\text { Power \& Fuels } \\
\text { (SP- 5.1) }\end{array}$ & $\begin{array}{l}\text { - Advanced Power } \\
\text { Systems } \\
\text { - Distributed } \\
\text { Generation - Fuel } \\
\text { Cells } \\
\text { - Co-Production } \\
\text { Hydrogen } \\
\end{array}$ & $\begin{array}{l}\text { - Integration with Carbon Capture and } \\
\text { Storage } \\
\text { - Methane Hydrates }\end{array}$ & CCS7 \\
\hline $\begin{array}{l}\text { Hydrogen } \\
\text { (SP- 5.2) }\end{array}$ & 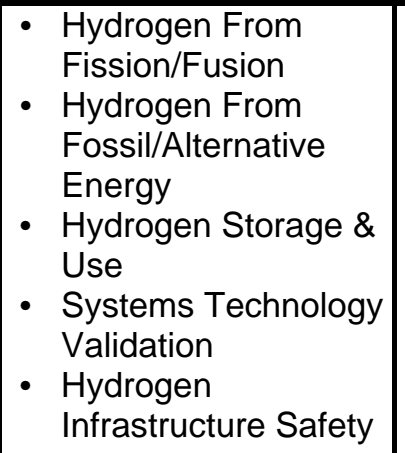 & $\begin{array}{l}\text { - Integration of Electricity and } \mathrm{H}_{2} \text { with the } \\
\text { Transportation Sector } \\
\text { - Advanced Concepts in Hydrogen Storage } \\
\text { - Hydrogen Co-Production and Integration } \\
\text { with } \mathrm{CO}_{2} \text { Capture }\end{array}$ & $\begin{array}{l}\text { EU11 } \\
\text { EU12 }\end{array}$ \\
\hline $\begin{array}{l}\text { Renewable } \\
\text { Energy \& Fuels } \\
\text { (SP- 5.3) }\end{array}$ & \begin{tabular}{ll|} 
- & Wind Energy \\
- Photovoltaics, \\
Photoconversion \\
- Solar, Concentrating \\
- Bio-Fuels/ Biomass
\end{tabular} & $\begin{array}{l}\text { Biomass Genomics and Alternative Fuels, } \\
\text { Materials, and Chemicals } \\
\text { - Systems Approach to Waste Management, } \\
\text { Including Waste-to-Energy } \\
\text { - Solar Fuels (Artificial Photosynthesis) } \\
\text { - Advanced Solid-State Thermoelectrics } \\
\text { - Wave Energy and Tidal Dams }\end{array}$ & $\begin{array}{l}\text { EU8 \& Terr } 2 \\
\text { OG3 } \\
\text { ES6 }\end{array}$ \\
\hline $\begin{array}{l}\text { Nuclear Fission } \\
\text { (SP- 5.4) }\end{array}$ & \begin{tabular}{ll|} 
- & Nuclear: Near-Term \\
& Deployment \\
- & GenIV \\
- & Advanced Fuel Cycle \\
& initiative (Global \\
& Nuclear Energy \\
& Partnership)
\end{tabular} & $\begin{array}{l}\text { - Advanced Fuel Resources and Fuel } \\
\text { Cycles for Fission } \\
\text { - Nano-Engineered Materials and Heat } \\
\text { Transfer Technology } \\
\text { - Next-Generation Nuclear Reactors } \\
\text { Including Dry Cycle Nuclear Plants } \\
\text { - Integrated Models of Reactor and Fuel } \\
\text { Performance }\end{array}$ & ES1 \\
\hline $\begin{array}{l}\text { Fusion Energy } \\
\text { (SP- 5.5) }\end{array}$ & $\begin{array}{ll}\text { - } & \text { Fusion Sciences } \\
\text { - ITER }\end{array}$ & $\begin{array}{l}\text { Radiation Resistant Structural Materials for } \\
\text { Fusion and Fission Systems } \\
\text { - Advanced Sensors for Measurement of } \\
\text { Plasma and Optical Parameters } \\
\text { - Inertial Fusion Energy } \\
\text { - Superconducting Materials that Function in } \\
\text { High Magnetic Fields }\end{array}$ & ES1 \\
\hline
\end{tabular}

*Further details for each of the gaps and opportunities listed in the table above are provided in Appendix C as noted by the code in the column "App C Link." 
Potential technology options include sort and weight recognition technology; tagging and tracking technology; small-scale waste conversion to fuels, power, and products; and genetically engineered bacteria. Numerous other gaps and opportunities are listed in the table.

\section{Goal 3 - Capture and Sequester Carbon Dioxide}

Background. Technologies and improved management systems for carbon capture, transport, storage, and sequestration can help to reduce carbon dioxide emissions and growth in atmospheric $\mathrm{CO}_{2}$ concentrations. The main focus areas for R\&D related to carbon cycle management include (1) the capture of $\mathrm{CO}_{2}$ emissions from large point sources, such as power plants, oil refineries, and industrial processes, and its storage in geologic formations or other storage media; (2) enhanced carbon uptake and storage by terrestrial biotic systems; and (3) improved understanding of the potential for ocean storage and sequestration methodologies.

If current world energy production and consumption patterns persist into the foreseeable future, fossil
Sequestration Potential Contributions to Emissions Reduction

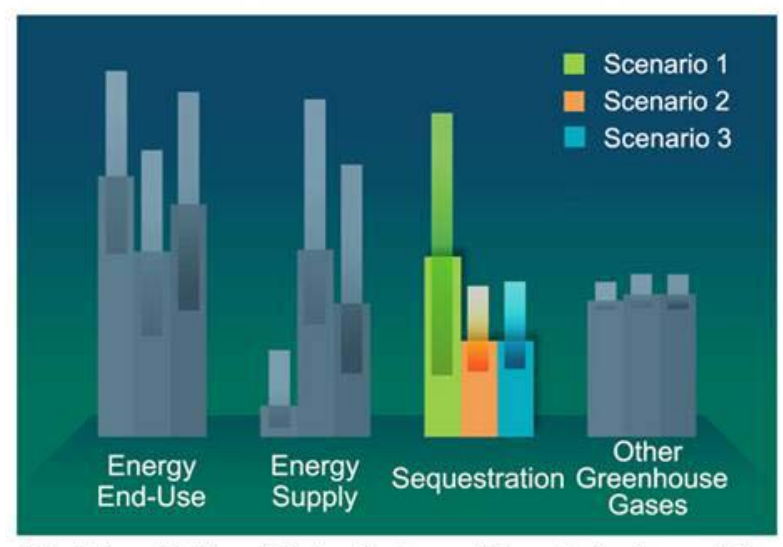

Potential contributions of Carbon Capture and Sequestration to cumulative GHG emissions reductions to 2100, across a range of uncertainties, for three advanced technology scenarios.

fuels will remain the mainstay of global energy production well into the 21st century. The Energy Information Administration projects that by 2025 about 88 percent of global energy demand will be met by fossil fuels, because fossil fuels will likely continue to yield competitive advantages relative to other alternatives (EIA, 2004b). In the United States, the use of fossil fuels in the electric power industry accounted for 39 percent of total energy-related $\mathrm{CO}_{2}$ emissions in 2003, and this share is expected to slightly increase to 41 percent in 2025. In 2025, coal is projected to account for 50 percent of U.S. electricity generation and for an estimated 81 percent of electricity-generated $\mathrm{CO}_{2}$ emissions. Natural gas is projected to account for 24 percent of electricity generation and about 15 percent of electricity-related $\mathrm{CO}_{2}$ emissions in 2025 (EIA, 2005).

Human activities related to land conversion and agricultural practices have also contributed to the buildup of carbon dioxide to the atmosphere. Past $\mathrm{CO}_{2}$ emissions from land-use activities are potentially reversible, and improved land-management practices can actually restore depleted carbon stocks. Therefore, there are potentially large opportunities to increase terrestrial carbon sequestration.

Carbon capture, transport, storage, and sequestration technologies have become a high priority R\&D focus under CCTP because they hold the potential to reduce $\mathrm{CO}_{2}$ emissions from point sources, as well as from the atmosphere, and to enable continued use of coal and other fossil fuels well into the future. Nearterm R\&D opportunities include optimizing carbon sequestration and management technologies and practices in terrestrial systems, and accelerating the development of technologies for capturing and geologically storing $\mathrm{CO}_{2}$ for enhanced oil recovery. Additional $\mathrm{R} \& \mathrm{D}$ opportunities include further development of other types of geologic storage and terrestrial sequestration options, as well as better understanding of the role oceans might play in storing carbon and the potential unintended consequences of using the oceans for carbon sequestration. 
Results. The following timeline presents a set of representative technologies for capturing, storing and sequestering carbon that could arise over time from ongoing and future research investments. Advanced technologies are seen entering the marketplace in the near, mid, and long terms, where the long term is sustained indefinitely. The timeline illustrates the technology advances that, if realized, would allow fossil fuels to continue to play an important role as a primary energy supply. Since the current energy infrastructure is designed around fossil fuels, the viability of carbon capture and storage preserves a number of options for an energy future. Additionally, the ability to cost-effectively and safely sequester carbon in terrestrial systems could have potentially profound implications for the dynamics of food, fiber, and land use.

\section{Technology Timeline: Capture and Sequester Carbon Dioxide}

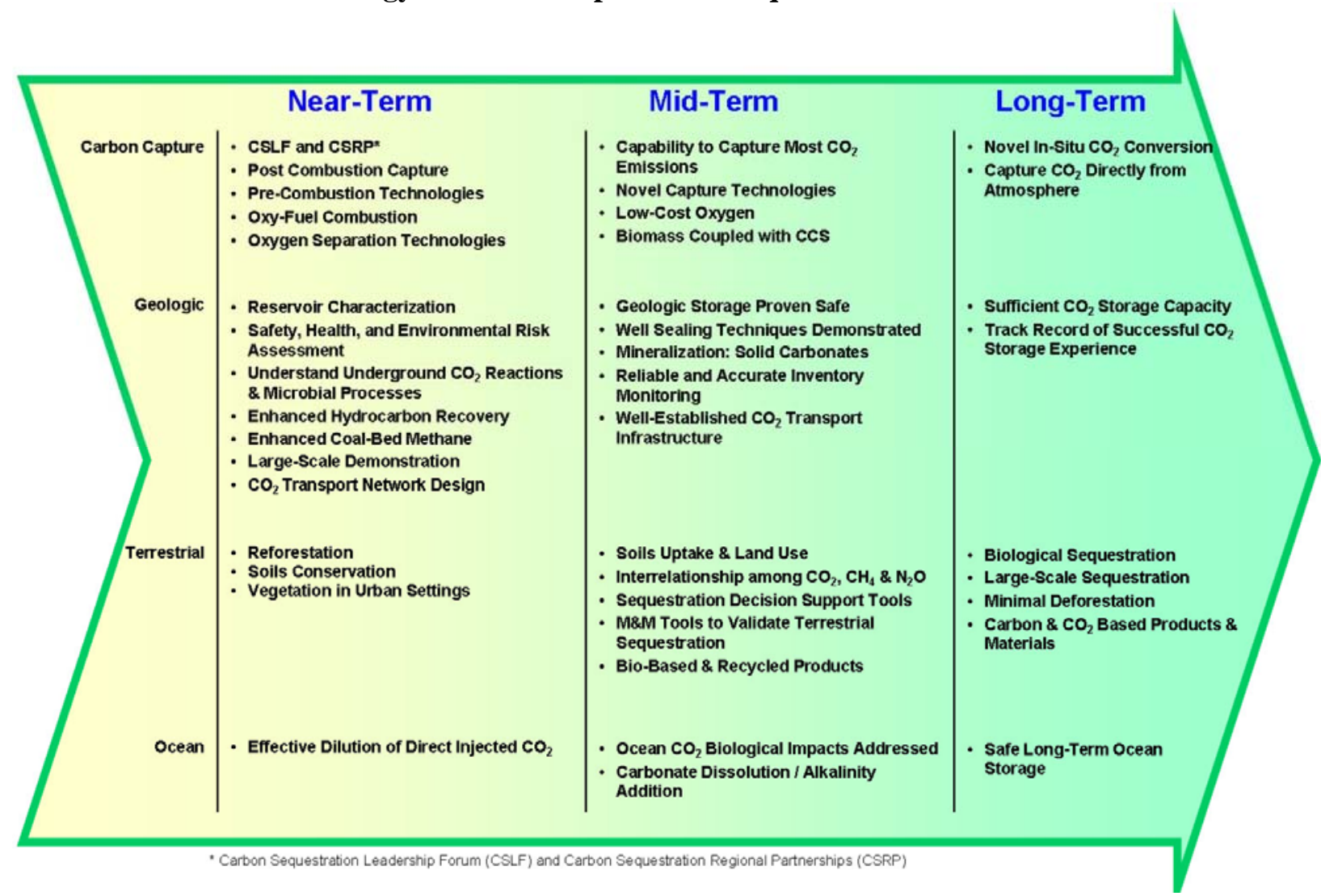

Note: With some overlap, "near-term" envisions significant technology adoption by 10 to 20 years from present, "mid-term" in a following period of 20 to 40 years, and "long-term" in a following period of 40 to 60 years.

There was a great deal of discussion about the inclusion of "carbon and $\mathrm{CO}_{2}$ based products and materials" as a long-term milestone; there was disagreement about the viability of producing carbon products with market value. The International Panel of Climate Change has concluded that society needs to absorb the cost of carbon capture and sequestration; as a result, some participants wanted to remove this item from the timeline. Nevertheless, several concepts were discussed that could sequester carbon and produce marketable products. One possibility mentioned by participants is biomass char produced by pyrolyzing biomass residues. This process could produce a long-lived fertilizer for soil conditioning. By putting the char back into the soil, it could act as a long-time release fertilizer to enhance agriculture production. A second idea expands on the use of carbon dioxide for enhanced oil recovery (EOR). Many existing hydrocarbon reservoirs have unfavorable economics for EOR. By putting $\mathrm{CO}_{2}$ underground to soak for several decades or a century, it may be possible to rejuvenate or regenerate an underground reservoir while the $\mathrm{CO}_{2}$ is simultaneously being stored. On a more conceptual note, if carbon dioxide 
were sequestered underground by a microbial process, it could possibly be converted into high-value products using the pressure and temperature differentials that exist underground.

Representative near-term carbon capture technologies include post combustion, pre-combustion, and oxyfuel facilities. While near-term research in this area focuses on separating $\mathrm{CO}_{2}$ at large point-source facilities - such as power plants - the mid-term and long-term technologies seek capabilities to capture most $\mathrm{CO}_{2}$ emissions from a wide range of sources, including capture directly from the atmosphere. Once captured, $\mathrm{CO}_{2}$ theoretically could be stored in underground geologic formations or sequestered in the deep ocean. Representative technologies for $\mathrm{CO}_{2}$ injection and storage in the near-term include further research on reservoir characterization and on potential underground reactions to ensure safe, long-lasting storage. Through the mid-term and long-term, representative scenarios for geologic storage and ocean storage will have undergone sufficient demonstrations and established safe and effective track records.

Terrestrial sequestration can help achieve the objectives of this goal in the near-term by reforestation, soils conservation, and vegetation in urban settings. In the mid- and long-term domains, bio-based and recycled products and technologies for large-scale terrestrial sequestration may emerge over time.

A number of mid and long-term technologies presented in the timeline suggest that an integrated approach may be essential to meeting gigaton order of magnitude reductions for this goal area. For example, biomass combined with CCS, in-situ $\mathrm{CO}_{2}$ conversion, inter-relationships among GHGs in terrestrial sequestration, and carbon-based products all involve combining multiple R\&D areas.

Although energy infrastructures later in this century presumably will be different from those of today, without the options that carbon capture and sequestration provide, infrastructure changes must occur sooner and much more dramatically than would otherwise be the case. A more gradual transition that continues the use of fossil fuels, particularly coal, could avoid potentially disruptive consequences that might occur if a rapid change to non-fossil energy sources is required.

The following figure shows the gaps and opportunities identified by workshop participants with respect to carbon capture, geologic storage, and ocean sequestration (terrestrial sequestration was not evaluated in this workshop; instead, it was considered as part of Workshop 4, which involved land use practices and non- $\mathrm{CO}_{2} \mathrm{GHGs}$ ). During the workshops several preliminary X-Y plots were generated by the participants covering several workshop activities based on ideas for new research opportunities not covered in CCTP's current R\&D portfolio. Each of these preliminary X-Y plots described the participants' views of each gap and opportunity in terms of its potential impact on goal attainment and its probability of success. This $\mathrm{X}-\mathrm{Y}$ plot summarizes the preliminary plots of key gaps and opportunities for further evaluation.

In the uppermost right corner of the X-Y plot (indicating the highest combination of impact and probability of success) are demonstrations of large-scale geologic storage to characterize performance (Item A) for the near term. Participants noted that the urgency of being able to display the feasibility of CCS as a practical climate change mitigation tool, along with the need for collecting empirical data from an actual storage site, pushed this item to its high priority location on the plot. Advanced geologic storage technology (Item E) is a related item also in the upper right quadrant of the plot. This idea includes accurate, reliable, real-time data on measuring and monitoring injected $\mathrm{CO}_{2}$.

Workshop participants felt that exploring policy and environmental, health, and safety implications of CCS (Item B), was the second highest impact idea. Recognizing that public perception is vital for the success of CCS, this item seeks to address managing transport and storage risk over a long time period. Similarly, for environmental impacts of ocean storage, participants tagged item $\mathrm{C}$ - quantify and mitigate effects of $\mathrm{CO}_{2}$ on marine ecosystems - as a high-impact/high-probability idea. 


\section{Impact vs. Probability of Success: Capture and Sequester Carbon Dioxide}

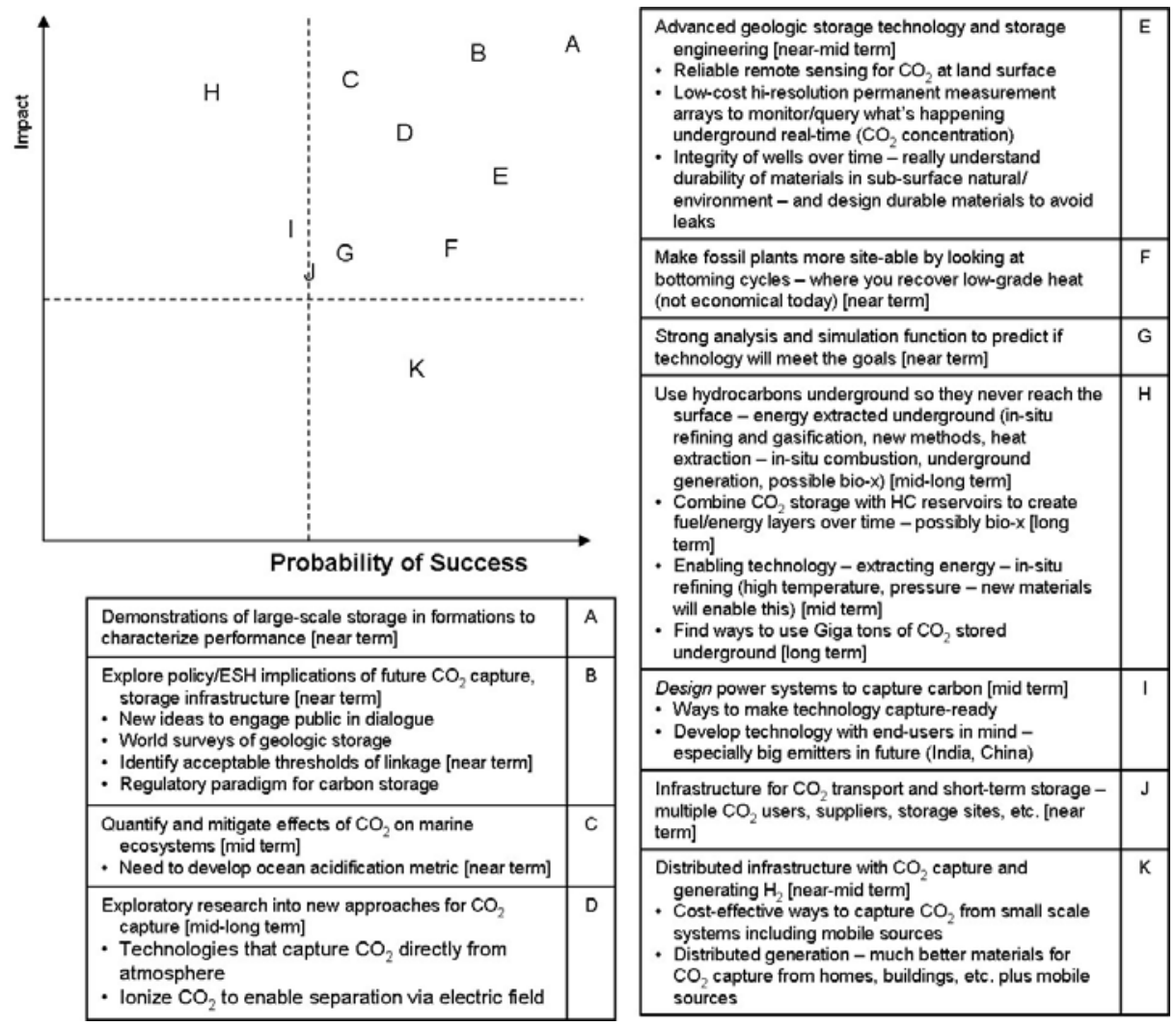

In the mid to long-term timeframes, participants placed importance on exploratory research into new approaches for $\mathrm{CO}_{2}$ capture (Item D). Noting the difficulty in forecasting research pathways 20 years or more into the future, workshop experts suggested exploring a few technologies that could revolutionize CCS, such as capturing $\mathrm{CO}_{2}$ directly from the atmosphere or ionizing $\mathrm{CO}_{2}$ to separate and capture $\mathrm{CO}_{2}$.

Making fossil plants more site-able by evaluating bottoming cycles (Item F) was also seen as a high priority by workshop participants. In some states cooling water cannot be used anymore, and as a result plants must rely on air cooling. To make this economic, fossil plants need to use bottoming cycles to capture some of the low-grade heat. The challenge is to identify ways to trade-off the additional capital requirements to make plants more efficient and to reduce their cooling needs. This R\&D gap is related to the "water and energy optimization" that was discussed in several of the other workshops and was identified as a gap and opportunity in Workshop 1. The energy used by water infrastructure and the water used in power plants and fuel supply systems are both emerging as important factors in public policy debates and will likely impact climate change mitigation options.

Other ideas located in the upper right quadrant of the X-Y plot include investing in tools for strong analysis and modeling simulations of CCS (Item G) and funding infrastructure for $\mathrm{CO}_{2}$ storage (Item J), which involves collaboration of multiple $\mathrm{CO}_{2}$ users, suppliers, storage sites, etc. These two ideas were estimated by workshop participants to be potentially functional and marketable in the near term.

Current portfolio strengths and gaps and opportunities for Goal 3 are outlined in the following table, by sub-area. The strengths represent the current portfolio as described in the Strategic Plan. These portfolio strengths are the focus of current RDD\&D activities by the private, State and Federal sectors and, in many 
cases, are the result of many years of investment. High priority gaps and opportunities are highlighted in blue.

High priority gaps and opportunities shown in the table for the carbon capture subarea focus on improving capture efficiency by evaluating currently available CCS technologies through an integrated modeling framework, and by emphasizing further innovation of capture techniques through advanced materials such as membranes. Geologic and ocean storage high priority areas illustrate the need for further scientific understanding of subsurface $\mathrm{CO}_{2}$ movements, reactions, and impacts.

High priority areas for terrestrial sequestration focus on maximizing climate change mitigation impacts by utilizing a systems approach across multiple sectors (power generation, agriculture, manufacturing industry) and gases $\left(\mathrm{CO}_{2}, \mathrm{CH}_{4}, \mathrm{~N}_{2} \mathrm{O}\right)$, and on the enormous potential from land-use management deploying current best practices as well as continuing to investigate better methods. 


\section{Current Portfolio Strengths ands Gaps \& Opportunities: Capture and Sequester Carbon Dioxide}

\begin{tabular}{|c|c|c|c|}
\hline Goal Sub-Area & $\begin{array}{l}\text { Current Portfolio } \\
\text { Strengths }\end{array}$ & Gaps \& Opportunities & App C Link* \\
\hline $\begin{array}{l}\text { Carbon Capture } \\
\text { (SP- 6.1) }\end{array}$ & $\begin{array}{l}\text { - Carbon Capture } \\
\text { - } \mathrm{CO}_{2} \text { Separation }\end{array}$ & $\begin{array}{l}\text { Advanced Materials, Including Membranes for } \\
\mathrm{CO}_{2} \text { Separations, Transport, and Storage } \\
\text { - Integrated Modeling Framework to Evaluate } \\
\text { CCS Technologies } \\
\text { - Technologies that Capture } \mathrm{CO}_{2} \text { Directly from } \\
\text { Atmosphere } \\
\text { - Ionize } \mathrm{CO}_{2} \text { to Enable Separation via Electric } \\
\text { Field } \\
\text { - Oxygen Separation Technologies: Oxyfuels }\end{array}$ & $\begin{array}{l}\text { CCS2 \& CCS6 } \\
\text { CCS6 } \\
\text { ccs6 }\end{array}$ \\
\hline $\begin{array}{l}\text { Geologic } \\
\text { Storage } \\
\text { (SP- 6.2) }\end{array}$ & 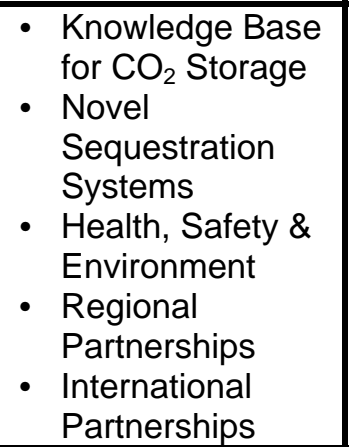 & $\begin{array}{l}\text { - Understand } \mathrm{CO}_{2} \text { Movement in Hydrocarbon- } \\
\text { Bearing Formations } \\
\text { - Understand Underground } \mathrm{CO}_{2} \text { Geochemical } \\
\text { and Microbial Processes } \\
\text { - } \mathrm{CO}_{2} \text { Geologic Storage Engineering (Pore Size, } \\
\text { Mineral Trapping, Leak Detection) } \\
\text { - Large-Scale Demonstration of } \mathrm{CO}_{2} \text { Storage } \\
\text { - Combine } \mathrm{CO}_{2} \text { Storage, In-Situ Refining, } \\
\text { Gasification, Power Generation, etc }\end{array}$ & $\begin{array}{l}\operatorname{ccs} 4 \\
\operatorname{ccs} 7 \\
\operatorname{ccs} 4\end{array}$ \\
\hline $\begin{array}{l}\text { Terrestrial } \\
\text { Sequestration } \\
\text { (SP- 6.3) }\end{array}$ & $\begin{array}{ll}\text { - } & \text { Land } \\
& \text { Management } \\
\text { - } & \text { Biotechnology } \\
& \text { (Soil Carbon) } \\
\text { - } & \text { Improved M\&M }\end{array}$ & $\begin{array}{l}\text { - Systems Approach across Sectors and Gases } \\
\text { (Energy Crops, Seq., Nitrogen) } \\
\text { - Potential from Land-Use Management (e.g., } \\
\text { Sustainable Forestry vs. Deforestation) } \\
\text { - Optimize Biomass Genomics for Fuels, } \\
\text { Materials, Chemicals, \& } \mathrm{CO}_{2} \text { Storage } \\
\text { - Vegetation in Urban Settings (Sequestration } \\
\text { and Heat Island Effect) }\end{array}$ & $\begin{array}{l}\text { Terr } 1 \\
\text { Terr } 6 \\
\text { EU8 \& Terr } 2\end{array}$ \\
\hline $\begin{array}{l}\text { Ocean } \\
\text { Sequestration } \\
\text { (SP-6.4) }\end{array}$ & $\begin{array}{l}\text { Direct Injection of } \\
\mathrm{CO}_{2} \text { in Hydrates }\end{array}$ & $\begin{array}{l}\text { - } \text { Basic Research in Ocean Chemistry and } \\
\text { Biological Cycles } \\
\text { - Ocean Acidification Issues } \\
\text { - Ocean Direct Injection }\end{array}$ & $\begin{array}{l}\operatorname{ccs} 1 \\
\operatorname{ccs} 1\end{array}$ \\
\hline
\end{tabular}

*Further details for each of the gaps and opportunities listed in the table above are provided in Appendix C as noted by the code in the column "App C Link."

\section{Goal 4 - Reduce Emissions of Non-CO $\mathrm{CO}_{2}$ Greenhouse Gases}

Background: Several gases other than carbon dioxide are known to have greenhouse gas warming effects. When concentrated in the Earth's atmosphere, these non- $\mathrm{CO}_{2} \mathrm{GHGs}$ can contribute to climate change. The more significant of these are methane $\left(\mathrm{CH}_{4}\right)$ from natural gas production, transportation and distribution systems, bio-degradation of waste in landfills, coal mining, and agricultural production; nitrous oxide $\left(\mathrm{N}_{2} \mathrm{O}\right)$ from industrial and agricultural activities; and certain fluorine-containing substances, such as hydrofluorocarbons (HFCs), perfluorocarbons (PFCs), and sulfur hexafluoride $\left(\mathrm{SF}_{6}\right)$ from industrial sources. 
The Intergovernmental Panel on Climate Change's (IPCC’s) Third Assessment Report (IPCC, 2001) states that "well-mixed" non- $\mathrm{CO}_{2}$ gases with high global warming potentials (GWPs) may be responsible for as much as 40 percent of the estimated increase in radiative climate forcing between the years 1750 and 2000. In addition, emissions of black carbon (soot), organic carbon and other aerosols, as well as tropospheric ozone and ozone precursors, have important effects on the Earth's overall energy balance.

Developing technologies for commercial readiness that can reduce emissions of these non- $\mathrm{CO}_{2} \mathrm{GHGs}$ is an important component of a comprehensive strategy to address concerns about climate change. A recent modeling study (Placet et al., 2004) showed that there is a considerable amount of uncertainty about future rates of growth of non-
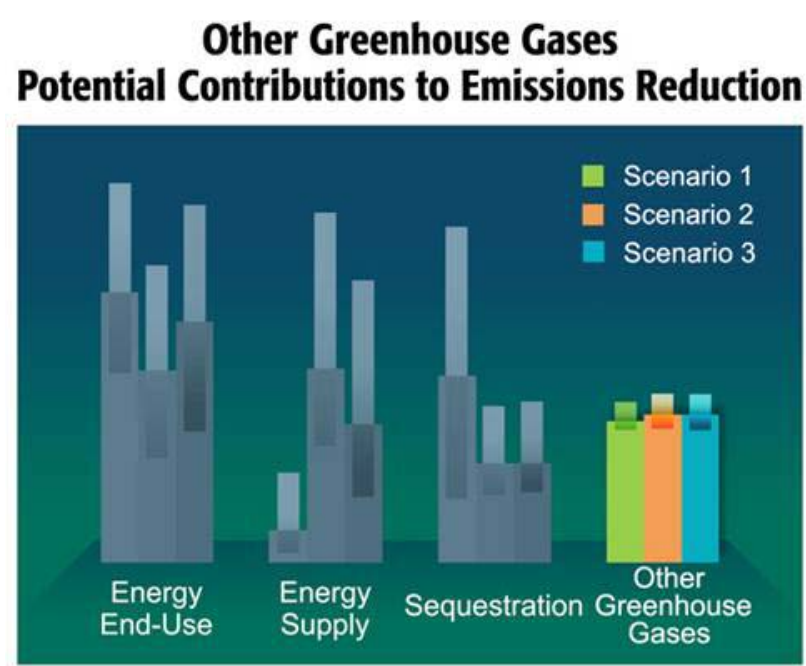

Potential contributions of Other Greenhouse Gases to cumulative CHC emissions reductions to 2100 , across a range of uncertainties, for three advanced technology scenarios.

$\mathrm{CO}_{2}$ emissions, but most models project that emissions will increase over time in the absence of constraints.

Achieving significant reductions in the emissions of non- $\mathrm{CO}_{2}$ GHGs is possible, taking into account the current achievements in reducing emissions as well as the results of detailed analyses of the technical and economic potential to reduce emissions from particular sources and sectors. It may be possible to achieve $\mathrm{CH}_{4}$ emission reductions of 40 to 60 percent by 2050, and 45 to 70 percent by 2100 . Emissions of $\mathrm{N}_{2} \mathrm{O}$ can be reduced by 25 to 30 percent by 2050, and 50 percent by 2100 (DeAngelo, 2005; Delhotal, 2005). In addition, it is possible to reduce emissions of high-GWP gases by 60 to 80 percent by 2050, and 55 to 75 percent by 2100 (Schaefer, 2005).

The key emission sources of other GHGs can be organized around five broad categories - or "target areas.”

- $\mathrm{CH}_{4}$ Emissions from Energy and Waste

- $\mathrm{CH}_{4}$ and $\mathrm{N}_{2} \mathrm{O}$ Emissions from Agriculture

- Emissions of High GWP Gases

- $\quad \mathrm{N}_{2} \mathrm{O}$ Emissions from Combustion and Industrial Sources

- Emissions of Tropospheric Ozone Precursors and Black Carbon

Results. The following timeline presents a representative set of technologies that could arise over time from ongoing and future research investments. The timeline illustrates the technology advances that, if realized, would be needed for a future of near-net-zero GHG emissions. If successfully developed through R\&D and adopted, such technologies could contribute significantly to the goal of mitigating future increases in radiative climate forcing, in both the near term and long term. 


\section{Technology Timeline: Reduce Emissions of Non- $\mathrm{CO}_{2}$ Greenhouse Gases}

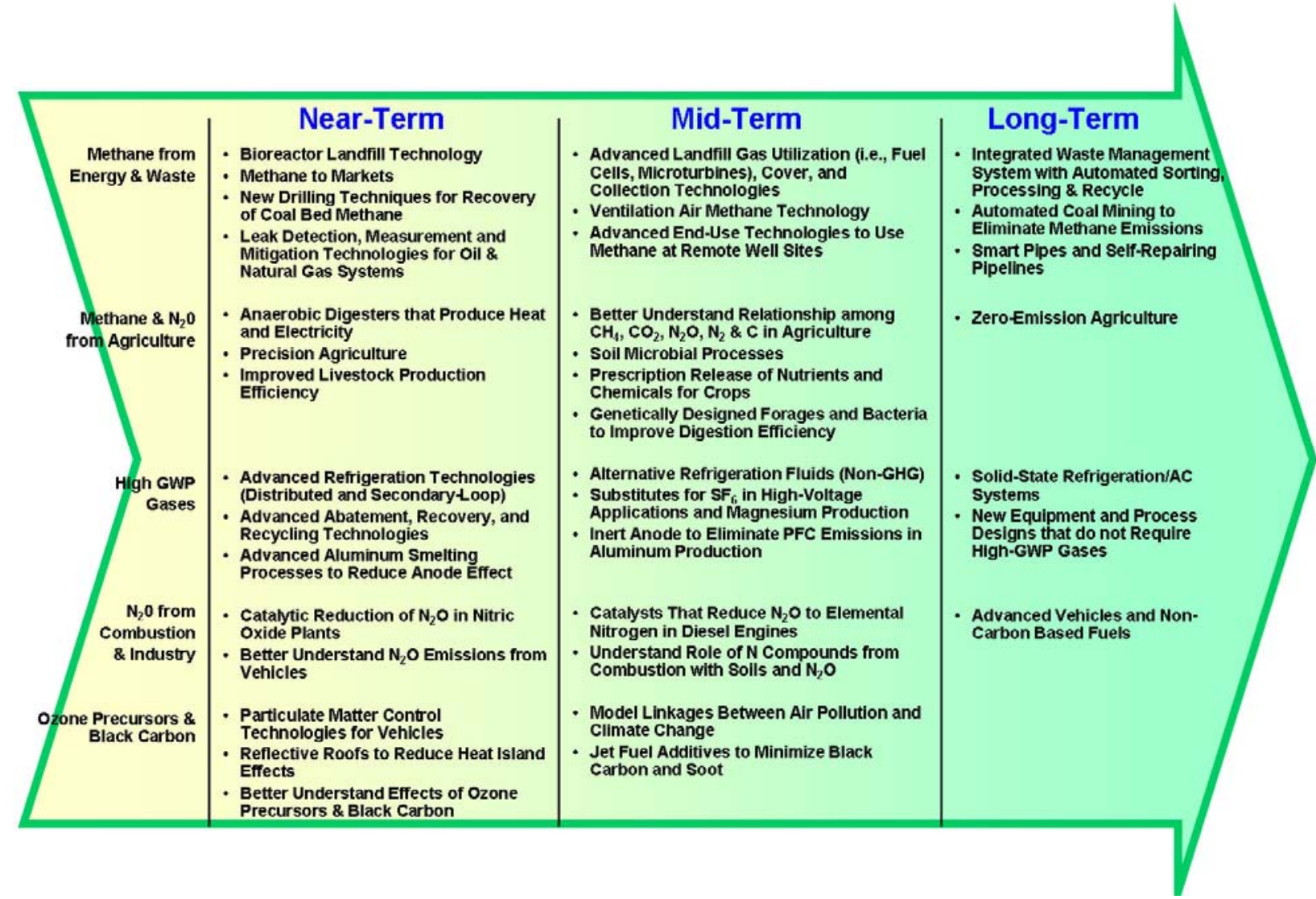

Note: With some overlap, “near-term” envisions significant technology adoption by 10 to 20 years from present, "mid-term" in a following period of 20 to 40 years, and "long-term” in a following period of 40 to 60 years.

Advanced technologies are seen entering the marketplace in the near, mid, and long terms, where the long term is sustained indefinitely. Such a progression, if successfully realized worldwide, would be consistent with attaining the potential for reducing emissions of non- $\mathrm{CO}_{2}$ greenhouse gases portrayed at the beginning of this section. Note that the timing and pace of technology adoption are uncertain and must be guided by science and supported by appropriate policies.

As shown in the timeline, sustained R\&D investments in technologies to reduce emissions of non- $\mathrm{CO}_{2}$ greenhouse gases over the near, mid, and long term will enhance our ability to optimize agricultural land use, reduce methane emissions from energy and waste, produce substitutes for high global warming potential gases, and model the role of ozone precursors and black carbon. These capabilities will facilitate pathways for reducing and mitigating non- $\mathrm{CO}_{2}$ GHG emissions.

The following figure lists the gaps and opportunities identified by workshop participants with respect to terrestrial sequestration (a sub-area of Goal 3) and GHG emission reductions from agricultural and land use practices (sub-areas of Goal 4). The X-Y plot describes the participants' views of each gap and opportunity in terms of its potential impact on goal attainment and its probability of success. 


\section{Impact vs. Probability of Success: Reduce Emissions of Non- $\mathrm{CO}_{2}$ Greenhouse Gases (Terrestrial Sequestration, Agriculture, and Land Use)}

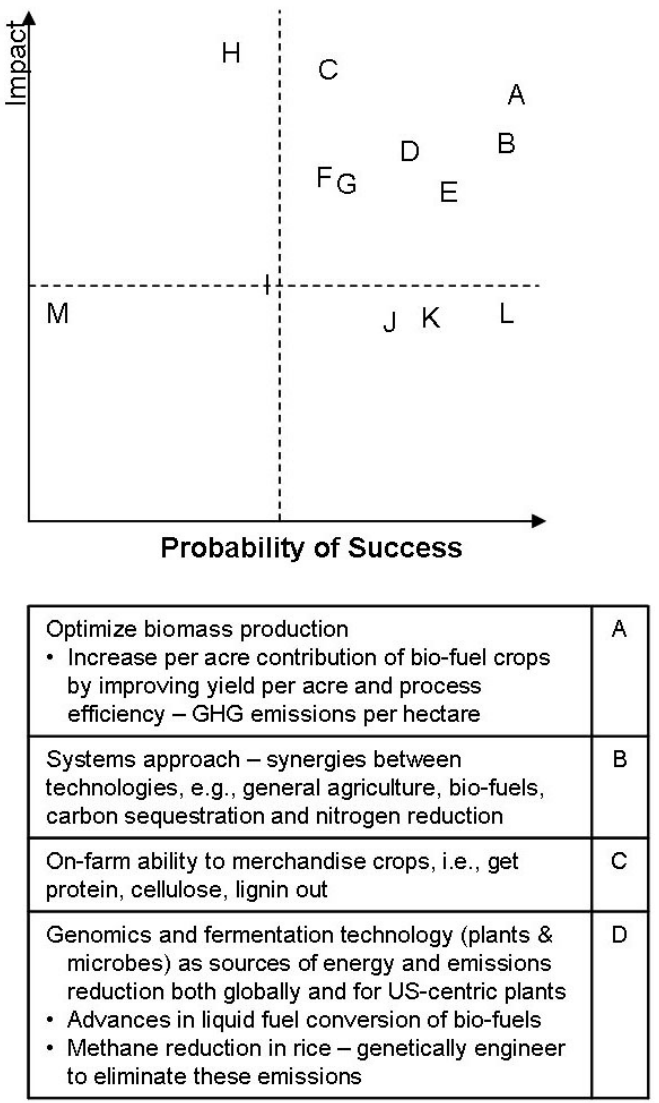

\begin{tabular}{|c|c|}
\hline $\begin{array}{l}\text { In rice and other agriculture, use crop residues in } \\
\text { different ways to reduce energy use on the farm }\end{array}$ & $E$ \\
\hline $\begin{array}{l}\text { Precision agriculture } \\
\text { - Reduction of nitrous oxide emissions from } \\
\text { agricultural sources by manipulating nitrogen } \\
\text { fertilizer } \\
\text { - Advances in nutrient efficiencies in agricultural } \\
\text { soils from fertilizer }\end{array}$ & $\mathrm{F}$ \\
\hline $\begin{array}{l}\text { Create incentives for maintaining carbon stocks } \\
\text { and to avoid de-forestation }\end{array}$ & G \\
\hline $\begin{array}{l}\text { - Green re-revolution - produce more protein on a } \\
\text { lot less land } \\
\text { - Bio-sensors - engineered plants that indicate } \\
\text { when they need nitrogen and water }\end{array}$ & $\mathrm{H}$ \\
\hline $\begin{array}{l}\text { Improved understanding of specific soil microbial } \\
\text { processes } \\
\text { - Is there a way to stabilize carbon in the slow soil } \\
\text { pool (retain } \mathrm{CO}_{2} \text { in roots and soil) } \\
\text { - Develop ability to enhance transport of carbon to } \\
\text { deep soil depths }\end{array}$ & 1 \\
\hline $\begin{array}{l}\text { Improved understanding of rumen microbial } \\
\text { processes and nutrient needs } \\
\text { - Change rumen chemistry of livestock } \\
\text { - Advances in nutrient efficiencies of feed } \\
\text { utilization in animals }\end{array}$ & $\mathrm{J}$ \\
\hline Better technologies for on-farm handling of waste & $\mathrm{K}$ \\
\hline $\begin{array}{l}\text { Improve transportation of agricultural materials } \\
\text { (tractor, rail, barge, pipelines) }\end{array}$ & $\mathrm{L}$ \\
\hline $\begin{array}{l}\text { - Optimize tradeoff between albedo and } \\
\text { absorption } \\
\text { - Manipulate reflectivity of forests and crops to } \\
\text { sequester more carbon }\end{array}$ & M \\
\hline
\end{tabular}

The idea that appears in the uppermost right corner (indicating the highest combination of impact and probability of success) entails optimization of biomass production by increasing yield and bio-fuel process efficiency (Item A). This idea focuses on biomass being used as an alternative to petroleum and natural gas and theoretically providing a net-zero GHG energy resource. Technological advancements would be needed in biotechnology, bioengineering, and possibly nanotechnology to optimize biomass production and conversion to bio-fuels. Genomics and fermentation technology (Item D) is a related idea that could advance the liquid fuel conversion process of biomass to bio-fuels. On-farm ability to merchandise crops (Item C) such that the protein, cellulose, and lignin, for example, could be extracted onsite would also contribute to optimizing biomass production and utilization.

The idea of applying a systems approach across sectors and gases (Item B) was also considered a highimpact, high-probability of success idea by the team of participants at the workshop. This idea encompasses a wide range of economic areas and technologies such as bio-fuels combined with carbon capture and sequestration and agriculture land use to reduce $\mathrm{CO}_{2}$ while simultaneously reducing methane and other GHGs. The focus relies less on further technological innovation, but rather on optimizing what knowledge and technology we currently possess, and determining via a systems approach how existing technologies can be deployed and configured to work together.

The remaining upper right quadrant ideas include investigating methods to use crop residues from farms to reduce overall energy use (Item E), more efficient use of fertilizers through advances in fertilizer 
technology and/or advances in soil nutrient efficiencies (Item F), and avoiding worldwide deforestation (Item G), which includes research into creating sustainable forest systems and increasing productivity from existing forestland.

The following figure lists the gaps and opportunities identified by workshop participants with respect to reducing emissions of high global warming potential gases (mostly from industrial gases, a sub-area of Goal 4). The X-Y plot describes the participants' views of each gap and opportunity in terms of its potential impact on goal attainment and its probability of success.

\section{Impact vs. Probability of Success: Reduce Emissions of Non- $\mathrm{CO}_{2}$ Greenhouse Gases (Industrial Gases)}

\begin{tabular}{|c|c|c|c|c|}
\hline & & \multirow{2}{*}{$\begin{array}{l}\text { Military uses of } \mathrm{SF}_{6}-\text { redesign of system to eliminate } \\
\text { venting of } \mathrm{SF}_{6} \text { and utilities [mid term] } \\
\text { Elimination of working fluids all together - solid state } \\
\text { refrigeration, } \mathrm{AVC} \\
\text { Completely new ways of capturing/recovering/reusing } \\
\text { refrigerants or elimination of } \mathrm{GHG} \text { refrigerants [long } \\
\text { term] }\end{array}$} & \multirow[t]{2}{*}{ C } \\
\hline & & & & \\
\hline & & & $\begin{array}{l}\text { Elimination of AC production by Hall-Heroult cell or } \\
\text { eliminate PFCs or eliminate use of AC (High - Long) }\end{array}$ & $\mathrm{E}$ \\
\hline & \multirow[b]{2}{*}{ E } & & $\begin{array}{l}\text { Replace semi-conductors with alternative materials that } \\
\text { do not require toxic processing, e.g., DNA - memory } \\
\text { chips (High - Mid) }\end{array}$ & $\mathrm{F}$ \\
\hline & & & $\begin{array}{l}\text { Tagging and sorting technologies to convert waste to } \\
\text { useful products } \\
\text { - Entirely closed, } 100 \% \text { recovery of landfill and } \\
\text { conversion to viable fuels and high value products } \\
\text { sustainable (energy) [near term] } \\
\text { - Eliminate/Significantly reduce flows into landfills thru } \\
\text { perfect sorting and recovery, conversion of all waste }\end{array}$ & G \\
\hline & \multirow{2}{*}{\multicolumn{2}{|c|}{ Probability of Success }} & $\begin{array}{l}\text { into useful products, and tagging of manufacturing } \\
\text { parts }\end{array}$ & \\
\hline & & & $\begin{array}{l}\text { Genetically engineered organisms that could be injected } \\
\text { into landfills (bioreactor landfills) [mid term] }\end{array}$ & $\mathrm{H}$ \\
\hline & $\begin{array}{l}\text { Self-repairing, leak free gas pipelines and LNG } \\
\text { conversion systems } \\
\text { - Smart materials that detect and seal leaks [mid term] } \\
\text { - Self-repairing systems, gas-pipelines/LNG conversion } \\
\text { systems, perfect seals, injection of leak-seal, leak- } \\
\text { activated pipes, self-sensing pipes }\end{array}$ & A & $\begin{array}{l}\text { Better understand the formation and life of nitrous } \\
\text { oxides } \\
\text { - Nitrous oxide from combustion (utilities and industry) } \\
\text { (Near) }\end{array}$ & I \\
\hline & \multirow{2}{*}{$\begin{array}{l}\text { Alternatives to } S_{6} \text { and PFCs } \\
\text { - Photovoltaic }-C V \text { Dep. to replace the part of the } \\
\text { semiconductor process that emits GHGs } \\
\text { - Direct use of fluorine generation - semiconductor } \\
\text { CVD, photovoltaic or replace use of fluorine (maybe in } \\
\text { conjunction with HC for plasma etching) }\end{array}$} & \multirow[t]{2}{*}{$B$} & $\begin{array}{l}\text { Longer term solutions are to eliminate the source (don't } \\
\text { use coal, etc.) don't combustion fuels (near) } \\
\text { - black carbon tropospheric ozone (basic) }\end{array}$ & $J$ \\
\hline & & & $\begin{array}{l}\text { Elimination of the source over the long term (for } \\
\text { combustion sources) (basic) } \\
\text { - hi-warming potential gases (High) }\end{array}$ & $\mathrm{K}$ \\
\hline
\end{tabular}

Participants felt that smart materials that detect and self-repair leaks in pipelines (Item A) represent the idea with the highest impact and probability of success for the Industrial Gas sub-goal area. Advances in materials, seals and valve technology could eliminate or reduce fugitive pipeline emissions, particularly for methane pipelines. Another idea to reduce methane emissions involves genetically engineered organisms that breakdown and process waste in landfills without emitting methane (Item H). Potentially, genetically engineered bacteria would convert the waste to fuels, power, and products.

The remaining idea in the upper right quadrant of the X-Y plot entails eliminating emissions of high global warming potential gases used as refrigerants (Item D). Research into replacements of current hydrofluorocarbons with alternate non-GWP gases and replacing traditional refrigeration fluids with solid state refrigeration and air conditioning were listed as possible approaches. Solid state devices would eliminate the need for working fluids altogether.

Current portfolio strengths and gaps and opportunities for Goal 4 are outlined in the following table, by subarea. High priority gaps and opportunities are highlighted in blue. 


\section{Current Portfolio Strengths and Gaps \& Opportunities Reduce Emissions of Non- $\mathrm{CO}_{2}$ Greenhouse Gases}

\begin{tabular}{|c|c|c|c|}
\hline Goal Sub-Area & $\begin{array}{l}\text { Current Portfolio } \\
\text { Strengths }\end{array}$ & Gaps \& Opportunities & App C Link* \\
\hline $\begin{array}{l}\text { Methane } \\
\text { Emissions } \\
\text { From Energy \& } \\
\text { Waste } \\
\text { (SP- 7.1) }\end{array}$ & $\begin{array}{ll}\text { - } & \text { Landfill Gas } \\
& \text { Programs (EPA +) } \\
\text { - } & \text { Coal Mine/Bed } \\
& \text { Methane (EPA +) } \\
\text { - } & \text { Methane to } \\
& \text { Markets (EPA +) }\end{array}$ & $\begin{array}{l}\text { - } \text { Automated Mining Systems that Eliminate } \\
\text { Methane Emissions } \\
\text { - Tagging and Sorting Technologies to Convert } \\
\text { Waste to Useful Products } \\
\text { - Distributed Waste Management Systems: } \\
\text { Waste to Fuels or Electricity } \\
\text { - Improved Combustion in Natural Gas Flaring } \\
\text { - Bioreactor Landfills Using Genetically } \\
\text { Engineered Organisms } \\
\text { - Self-Repairing, Leak-Free Gas Pipelines and } \\
\text { LNG Conversion Systems }\end{array}$ & $\begin{array}{l}\text { OG3 } \\
\text { OG3 } \\
\text { OG3 } \\
\text { OG1 }\end{array}$ \\
\hline \begin{tabular}{l|} 
Methane and \\
$\mathrm{N}_{2} \mathrm{O}$ Emissions \\
from Agriculture \\
(SP- 7.2)
\end{tabular} & $\begin{array}{ll}- & \text { Advanced AG - } \\
& \mathrm{N}_{2} \mathrm{O} \text { Reduction } \\
\text { - } & \text { Manure } \\
& \text { Management } \\
\text { - Enteric Emissions } \\
\text { Reductions }\end{array}$ & $\begin{array}{l}\text { - Precision Agriculture and Biosensors } \\
\text { - Improved Understanding of Rumen Microbial } \\
\text { Processes and Nutrient Needs } \\
\text { - Improved Separation Processes and } \\
\text { Stabilization \& New Types of Digestors, (e.g., } \\
\text { small scale) } \\
\text { - Improved Understanding of Specific Soil } \\
\text { Microbial Processes }\end{array}$ & \\
\hline $\begin{array}{l}\text { Emissions of } \\
\text { High GWP } \\
\text { Gases } \\
\text { (SP- 7.3) }\end{array}$ & $\begin{array}{l}\text { - } \text { Substitutes for } \\
\text { High GWP Gases } \\
\text { - } \text { Substitutes for } \\
\text { SF }_{6} \\
\text { - } \text { Refrigeration - } \\
\text { HFC Reduction }\end{array}$ & $\begin{array}{l}\text { - } \text { Alternatives to } \mathrm{SF}_{6} \text { in HV Electric } \\
\text { Transformers, Circuit Breakers, etc. } \\
\text { - Eliminate GHG-Emitting Working Fluids in } \\
\text { Refrigeration and Air-Conditioning } \\
\text { - } \text { Alternatives to } \mathrm{SF}_{6} \text { \& PFCs in Chem. Vapor } \\
\text { Deposition, Cleaning, Etching, etc } \\
\text { - } \text { Alternative Cover Gases to Replace } \mathrm{SF}_{6} \text { for } \\
\text { Magnesium Melt Protection } \\
\text { - New Technologies \& Controls to Reduce } \\
\text { Aluminum Smelting PFC Emissions } \\
\end{array}$ & $\begin{array}{l}\text { OG6 } \\
\text { OG4 } \\
\text { OG5 }\end{array}$ \\
\hline $\begin{array}{l}\mathrm{N}_{2} \mathrm{O} \text { Emissions } \\
\text { from } \\
\text { Combustion \& } \\
\text { Industry } \\
\text { (SP- 7.4) } \\
\end{array}$ & $\begin{array}{ll} & \mathrm{N}_{2} \mathrm{O} \text { Abatement - } \\
& \text { Nitric Acid } \\
\text { - } & \mathrm{N}_{2} \mathrm{O} \text { Abatement - } \\
\text { Transportation }\end{array}$ & $\begin{array}{l}\text { - Understanding of Formation and Life of Nitrous } \\
\text { Oxide from Combustion } \\
\text { - Advanced Catalytic Reduction of } \mathrm{N}_{2} \mathrm{O} \text { from } \\
\text { Combustion Sources }\end{array}$ & \\
\hline $\begin{array}{l}\text { Tropospheric } \\
\text { Ozone } \\
\text { Precursors \& } \\
\text { Black Carbon } \\
\text { (SP- } 7.5) \\
\end{array}$ & $\begin{array}{l}\text { - } \text { Abatement - } \\
\text { TOPs \& BC }\end{array}$ & $\begin{array}{l}\text { - Analysis of Role of Black \& Organic Carbon } \\
\text { and Tropospheric Ozone Precursors } \\
\text { - Diesel Engine Emission Reduction and Control } \\
\text { - Jet Fuel Additives } \\
\text { - Computational Models of Soot Formation }\end{array}$ & \\
\hline
\end{tabular}

*Further details for each of the gaps and opportunities listed in the table above are provided in Appendix $\mathrm{C}$ as noted by the code in the column "App C Link."

As shown in the table above, the gaps and opportunities cover a wide range of economic sectors and technological solutions. In the highest priority gaps and opportunities the mining industry, landfill waste management, crop agriculture, livestock, electronics, HVAC, and power generation/combustion all play key roles for reducing GHG emissions in this goal area. The applied technology R\&D of the high priority 
ideas ranges from mechanical automation to genetic science to electronics. Basic science is especially important in the high priority gaps and opportunities for Goal 4, specifically by gaining understanding of nitrous oxide characterization, life, and formation from combustion and analyzing the role of black and organic carbon and tropospheric precursors.

\section{Goal 5 - Improve Capabilities to Measure and Monitor GHG Emissions}

Background: The sources of greenhouse gas emissions are varied and complex, as are the potential mitigation strategies afforded by advanced climate change technologies, such as those presented in the previous chapters. Measurement and monitoring systems will be needed to complement these technologies in order to assess their efficacy and sustainability and guide future enhancements. If a carbon management regime is going to recognize energy end-use efficiencies, low-carbon energy supplies, carbon capture and sequestration, and efforts to reduce emissions of non- $\mathrm{CO}_{2}$ GHGs, then verification is required. A global enterprise requires a mechanism by which a large set of parties are involved in a policing function, using common standards for collecting and processing data.

Measurement and monitoring systems need to cover a wide array of GHG sensors, measurement platforms, monitoring and inventorying systems, and associated analytical tools, including databases, models and inference methods. Development and application of such systems can provide accurate characterizations of advanced technologies, enable increased understanding of performance, guide further research, reduce costs, and improve effectiveness. Research and development on these systems is required to increase their capabilities and facilitate and accelerate their adoption.

Observations using measurement and monitoring technologies can be used to establish informational baselines necessary for analytical comparisons, and to measure carbon storage and GHG fluxes across a range of scales, from individual locations to large geographic regions. If such baselines are established, the effectiveness of implemented GHG-reduction technologies can be assessed against a background of prior or existing conditions and other natural indicators.

Ideally, an integrated observation system strategy would be employed to measure and monitor the sources and sinks of all gases that have an impact on climate change, using the most cost-effective mix of techniques ranging from local in situ sensors to global remote sensing satellites. This would involve technologies aimed at a spectrum of applications, including $\mathrm{CO}_{2}$ from energy-related activities (such as transportation and fossil plants); GHGs other than $\mathrm{CO}_{2}$ (including methane, nitrous oxide, fluorocarbons, ozone); and other GHG-related substances (such as black carbon aerosol). An integrated system architecture serves as a guide for many of the step-by-step development activities required in these areas. It could establish a framework for $R \& D$ that places measurement and monitoring technologies in context with the Integrated Earth Observation System (IEOS) and other CCTP technologies.

In the near term, opportunities for advancing GHG measuring and monitoring systems present themselves as integral elements of the CCTP R\&D programs and initiatives. Efforts must focus on the significant emission sources and sinks, and on measurement and monitoring of carbon sequestration and storage.

Technology can be developed to address knowledge gaps in GHG emissions and to improve inventories. In some cases, it is not necessary or cost-effective to measure emissions directly. In such cases, emissions can be measured indirectly by measuring other parameters as proxies, such as feedstock, fuel, or energy flows (referred to as "parametric" or "accounting-based" estimates); or by measuring changes in carbon stocks. Under CCTP, there is a benefit to undertaking research to test, validate, quantify uncertainties, and certify such uses of proxy measurements. The long-term approach is to evaluate data needs and pursue the development of an integrated and overarching system architecture that focuses on the most critical and supplementary data needs. 
Results. The following timeline presents a set of representative measurement and monitoring technologies that could arise over time from ongoing and future research investments. The resulting timeline illustrates the technology advances that, if realized, would produce continuing progress in GHG measuring and monitoring systems. Such systems are needed to support the design and implementation of strategies to ensure a future of near-net-zero GHG emissions.

\section{Technology Timeline: Improve Capabilities to Measure and Monitor GHG Emissions}

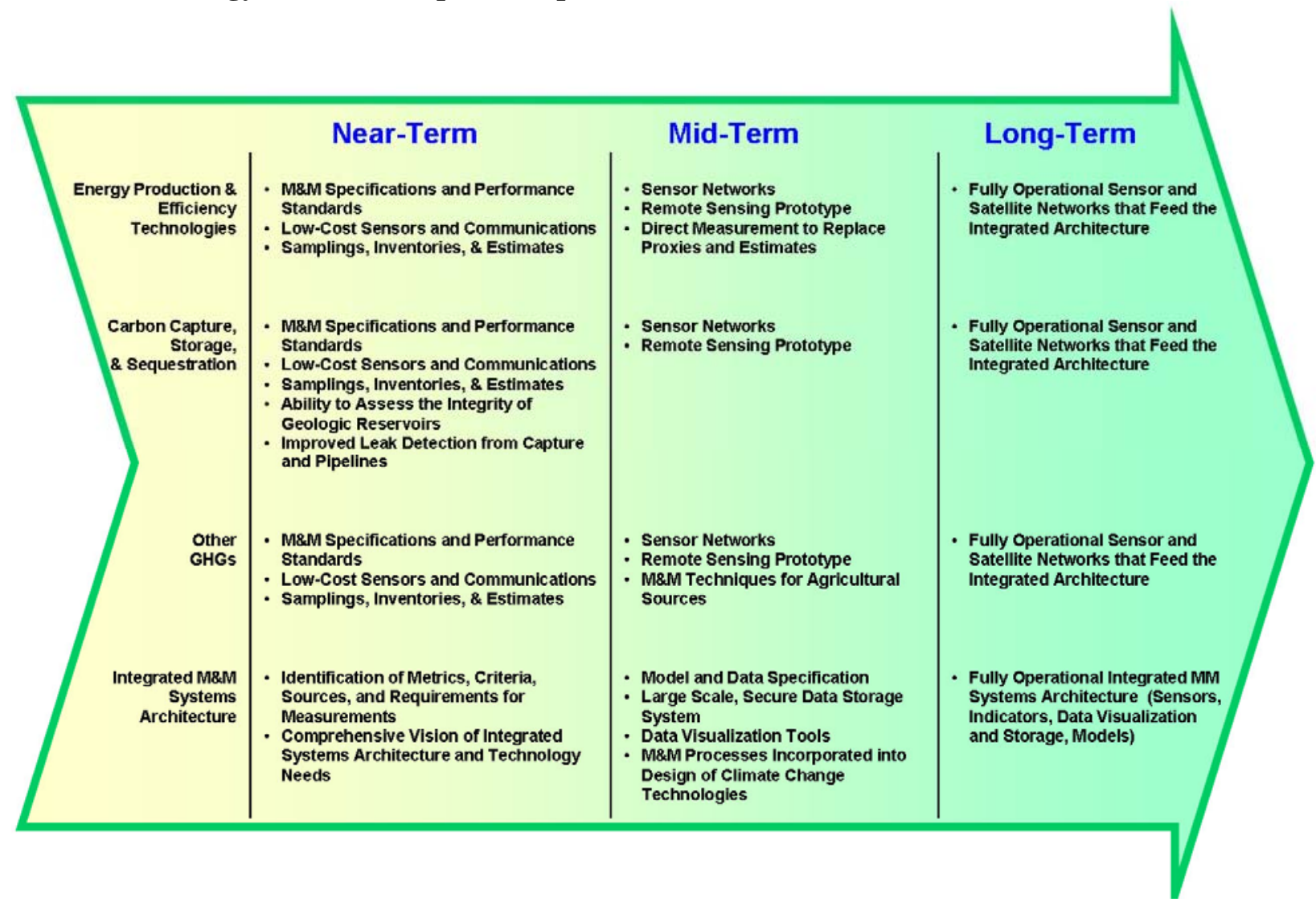

Note: With some overlap, “near-term” envisions significant technology adoption by 10 to 20 years from present, "mid-term" in a following period of 20 to 40 years, and "long-term” in a following period of 40 to 60 years.

The technologies presented in the timeline represent a combination of ongoing research directions in CCTP's current R\&D portfolio and future research directions proposed by participants at the portfolio review workshop. Near-term opportunities for R\&D include (1) measurement and monitoring systems, performance standards, and sampling to support emission reductions in the energy supply and end-user sectors, including carbon dioxide as well as other gases; (2) improved technologies to support carbon sequestration and capture; (3) and integrated systems for measuring and monitoring atmospheric concentrations and surface emissions of GHGs.

As shown in the timeline, sustained R\&D investments in monitoring and measurement capabilities over the mid- and long-term will enhance our ability to model GHG emissions, simulate atmospheric physical and chemical processes, and enable a fully integrated space-borne, airborne, and surface-based scanning and remote sensing system to provide 3D, real-time mapping of atmospheric GHG concentrations. These 
capabilities will not only facilitate the monitoring of climate change parameters, but will also provide pathways for reducing and mitigating GHG emissions.

The following figure lists the gaps and opportunities identified by workshop participants with respect to Goal 5. The X-Y plot describes the participants' views of each gap and opportunity in terms of its potential impact on goal attainment and its probability of success.

\section{Impact vs. Probability of Success: Improve Capabilities to Measure and Monitor GHG Emissions}

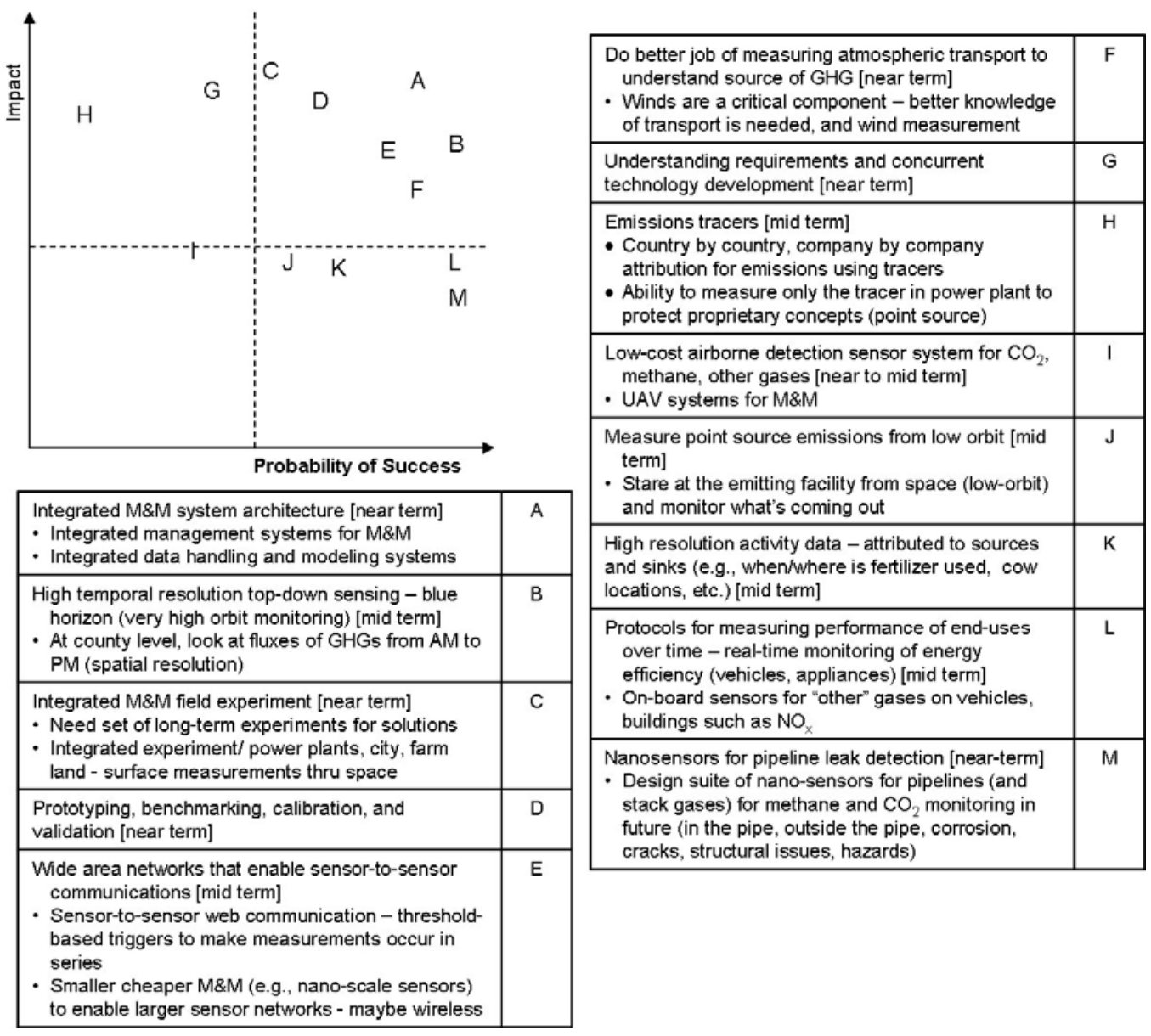

The gaps and opportunities in the upper right hand quadrant of the figure illustrate some of the more highimpact, high-probability ideas that emerged. Several of these ideas (Items A, B, D, E) support the notion of an integrated systems approach to measuring and monitoring of GHGs that include fully operational sensor and satellite networks with integrated data collection, management and retrieval systems. These systems would have wide-area capabilities (surface) as well as top-down sensing (high orbit). Both of these features are seen as mid-term capabilities, while the system architecture and prototyping could occur in the near term.

The remaining upper right quadrant ideas include understanding the sources and fate of GHGs (Item F) and integrated field experiments to demonstrate potential climate change solutions (Item C). The first will require more fundamental scientific research, while the latter will be accomplished through a combination of development and demonstration projects. 
Current portfolio strengths and gaps and opportunities for Goal 5 are listed in the following table, by subarea. High priority gaps and opportunities are highlighted in blue.

Current Portfolio Strengths and Gaps \& Opportunities: Improve Capabilities to Measure and Monitor GHG Emissions

\begin{tabular}{|c|c|c|c|}
\hline Goal Sub-Area & $\begin{array}{l}\text { Current Portfolio } \\
\text { Strengths }\end{array}$ & Gaps \& Opportunities & App C Link* \\
\hline $\begin{array}{l}\text { Energy } \\
\text { Production/ } \\
\text { Efficiency } \\
\text { (SP- 8.2) }\end{array}$ & $\begin{array}{l}\text { M\&M for Energy } \\
\text { Production \& } \\
\text { Efficiency }\end{array}$ & $\begin{array}{l}\text { - Protocols for Multiple Assessments of } \\
\text { Performance of Energy End-Uses } \\
\text { - Improvements in Temporal and Spatial } \\
\text { Resolution Measurements } \\
\text { - Satellite-Based Sensors for Direct } \\
\text { Measurement of } \mathrm{CO}_{2} \text { and Other Gases } \\
\text { - Wireless Micro-Sensor Networks for } \\
\text { Migration, Uptake, and Distribution of GHGs }\end{array}$ & $\begin{array}{l}\text { MM3 } \\
\text { MM3 } \\
\text { MM5 \& } 6 \\
\text { MM3 }\end{array}$ \\
\hline $\begin{array}{l}\mathrm{CO}_{2} \text { Capture \& } \\
\text { Sequestration } \\
\text { (SP- 8.3.1) }\end{array}$ & $\begin{array}{l}\text { M\&M for Geologic } \\
\text { Storage }\end{array}$ & $\begin{array}{l}\text { - Remote Subsurface/Near Surface } \mathrm{CO}_{2} \\
\text { Monitoring } \\
\text { - Improvements in Leak Detection from } \\
\text { Separation and Capture and Pipeline } \\
\text { Systems }\end{array}$ & CCS7 \\
\hline $\begin{array}{l}\text { Terrestrial } \\
\text { Sequestration } \\
\text { (SP- 8.3.2) }\end{array}$ & $\begin{array}{l}\text { - M\&M for } \\
\text { Terrestrial Seq. }\end{array}$ & $\begin{array}{l}\text { - Global Network Monitoring and Measurement } \\
\text { of Terrestrial Carbon }\end{array}$ & MM8 \\
\hline $\begin{array}{l}\text { Oceanic } \\
\text { Sequestration } \\
\text { (SP- 8.3.3) }\end{array}$ & $\begin{array}{l}\text { - M\&M for Ocean } \\
\text { Seq. }\end{array}$ & - Measurement and Tracking of Injected $\mathrm{CO}_{2}$ & \\
\hline $\begin{array}{l}\text { Other Gases } \\
\text { (SP- 8.4) }\end{array}$ & $\begin{array}{l}\text { - M\&M for Other } \\
\text { Gases }\end{array}$ & $\begin{array}{l}\text { Space-Based Technologies for Long-Term } \\
\text { Monitoring of GHGs and Aerosols } \\
\text { - } \mathrm{N}_{2} \mathrm{O} \text { Measurement Techniques for Emerging } \\
\text { Gasoline and Diesel Engines } \\
\text { - Advanced, Real-Time Measurement for Fine } \\
\text { Particulate Matter and Soot } \\
\text { - Nanosensors for Pipeline Leak Detection } \\
\end{array}$ & MM2 \\
\hline $\begin{array}{l}\text { Integrated M\&M } \\
\text { System } \\
\text { Architecture } \\
\text { (SP- 8.5) }\end{array}$ & $\begin{array}{l}\text { M\&M Observation } \\
\text { System }\end{array}$ & $\begin{array}{l}\text { - Integrated M\&M System Architecture } \\
\text { - Wide Area Networks that Provide Robust } \\
\text { - } \text { (Sensor to Sensor) Communications } \\
\text { Platorms for Spatial Scales and } \\
\text { - Reasurement Layers (Ground, Air, \& Space) } \\
\text { Existing Integrated System Components } \\
\text { - Integrated M\&M Field Experiment }\end{array}$ & $\begin{array}{l}\text { MM5 \& } 6 \\
\text { MM4 } \\
\text { MM5 \& } 6 \\
\text { MM7 } \\
\text { MM8 }\end{array}$ \\
\hline
\end{tabular}

*Further details for each of the gaps and opportunities listed in the table above are provided in Appendix C as noted by the code in the column "App C Link."

As shown in the table above, the gaps and opportunities cover measuring and monitoring technology for energy supply and end-use as well as capture and sequestration strategies. In energy supply and end-use, the highest priority gaps and opportunities focus on better measurement of end-use emissions to enable assessment of performance as well as impacts on climate change. Advanced satellite and wireless technologies are possible approaches. 
In the area of capture and sequestration, gaps and opportunities were identified to support the concepts of geologic storage and terrestrial, ocean and surface sequestration. The primary focus is on better technology for monitoring the fate of sequestered carbon over time, and potential detection of leaks.

The development of an integrated M\&M system emerged as a high priority for the future. This system would encompass a variety of technologies to enable robust measuring and monitoring of atmospheric as well as surface carbon emissions. Development of this system will require a combination of fundamental scientific research, technology development (sensors, platforms, models), and demonstration (prototyping, benchmarking of system components, field experiments).

Measuring and monitoring of other gases will require space-based technologies to determine long-term fate, as well as techniques for measuring the emissions of other gases from end-uses (transportation).

Further details for each of the gaps and opportunities listed in the table above are provided in Appendix C as noted by the code in the column "App C Link". For example, gaps and opportunities with "MM3" adjacent to it indicate that there is one-page write-up of this idea in Appendix $\mathrm{C}$ with title beginning MM3. "MM $-2^{\text {nd }}$ Tier" indicates that there are a couple of sentences describing the idea in the section entitled "Other New Technologies for Measuring and Monitoring" immediately following the one-page write-ups in Appendix C. 


\section{Goal 6 - Bolster Basic Science Contributions to Technology Development}

The participants in this sixth workshop contributed to the development of a combined CCTP technology timeline highlighting some of the key technology milestones that could make a difference over the 100year planning horizon.

\section{Summary Technology Timeline}

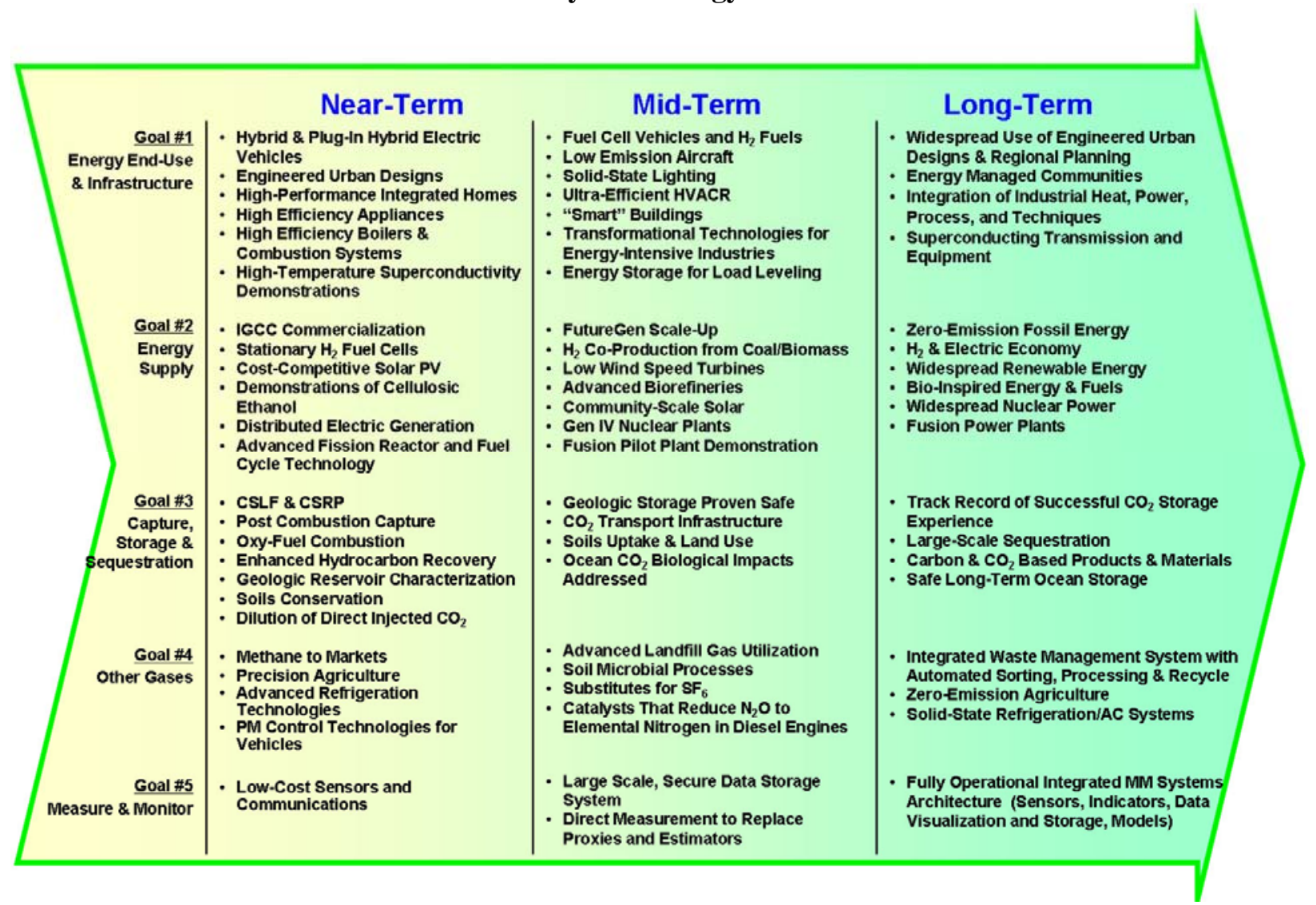

Note: With some overlap, "near-term" envisions significant technology adoption by 10 to 20 years from present, "mid-term" in a following period of 20 to 40 years, and "long-term" in a following period of 40 to 60 years.

Participants also reviewed the results of the five technology goal workshops in order to provide an integrative perspective on the relative importance of alternative technology pathways. These results were factored back into the tables of gaps and opportunities and technology timelines shown in the five previous sections. The priority gaps from these five technology goal areas are listed below. 


\section{Priority R\&D Gaps and Opportunities}

\begin{tabular}{|c|c|}
\hline Goal & Priority Gaps \& Opportunities \\
\hline $\begin{array}{l}\text { Reduce Emissions } \\
\text { from Energy End- } \\
\text { Use and } \\
\text { Infrastructure }\end{array}$ & $\begin{array}{l}\text { Enabling Technologies for Low-GHG Plug-in Hybrid Electric Vehicles } \\
\text { Advanced Thermoelectric Concepts to Convert Temperature Differentials } \\
\text { Advanced Sensors, Communications and Controls for Smart Buildings } \\
\text { Advanced Applications of Biotechnology } \\
\text { Large-Scale Energy Storage }\end{array}$ \\
\hline $\begin{array}{l}\text { Reduce Emissions } \\
\text { From Energy Supply }\end{array}$ & $\begin{array}{l}\text { Integration with Carbon Capture and Storage } \\
\text { Integration of Electricity and } \mathrm{H}_{2} \text { Production with the Transportation Sector } \\
\text { Biomass Genomics and Alternative Fuels, Materials, and Chemicals } \\
\text { Systems Approach to Waste Management, Including Waste-to-Energy } \\
\text { Advanced Fuel Resources and Fuel Cycles for Fission } \\
\text { Radiation Resistant Structural Materials for Fusion and Fission Systems }\end{array}$ \\
\hline $\begin{array}{l}\text { Capture and } \\
\text { Sequester Carbon } \\
\text { Dioxide }\end{array}$ & $\begin{array}{l}\text { Advanced Materials, incl. Membranes for } \mathrm{CO}_{2} \text { Separations, Transport, \& Storage } \\
\text { Integrated Modeling Framework to Evaluate CCS Technologies } \\
\text { Understand } \mathrm{CO}_{2} \text { Movement in Hydrocarbon-Bearing Formations } \\
\text { Systems Approach across Sectors and Gases (Energy Crops, Seq., Nitrogen) } \\
\text { Potential from Land-Use Mgt (e.g., Sustainable Forestry vs. Deforestation) } \\
\text { Basic Research in Ocean Chemistry and Biological Cycles }\end{array}$ \\
\hline $\begin{array}{l}\text { Reduce Emissions } \\
\text { Of Non- } \mathrm{CO}_{2} \\
\text { Greenhouse Gases }\end{array}$ & $\begin{array}{l}\text { Automated Mining Systems that Eliminate Methane Emissions } \\
\text { Tagging and Sorting Technologies to Convert Waste to Useful Products } \\
\text { Precision Agriculture and Biosensors } \\
\text { Improved Understanding of Rumen Microbial Processes and Nutrient Needs } \\
\text { Alternatives to SF } 6 \text { in HV Electric Transformers, Circuit Breakers, etc. } \\
\text { Eliminate GHG-Emitting Working Fluids in Refrigeration and Air-Conditioning } \\
\text { Understanding of Formation and Life of Nitrous Oxide from Combustion } \\
\text { Analysis of Role of Black \& Organic Carbon and Tropospheric Ozone Precursors }\end{array}$ \\
\hline $\begin{array}{l}\text { Improve Capabilities } \\
\text { To Measure and } \\
\text { Monitor GHG } \\
\text { Emissions }\end{array}$ & $\begin{array}{l}\text { Protocols for Multiple Assessments of Performance of Energy End-Uses } \\
\text { Improvements in Temporal and Spatial Resolution Measurements } \\
\text { Remote Subsurface/Near Surface } \mathrm{CO}_{2} \text { Monitoring } \\
\text { Measurement and Tracking of Injected } \mathrm{CO}_{2} \\
\text { Space-Based Technologies for Long-Term Monitoring of GHGs and Aerosols } \\
\text { Integrated M\&M System Architecture } \\
\text { Wide Area Networks that Provide Robust (Sensor to Sensor) Communications } \\
\text { Platforms for Spatial Scales and Measurement Layers (Ground, Air, \& Space) }\end{array}$ \\
\hline
\end{tabular}

The large number of gaps and opportunities in the goal 4 and 5 areas reflects the small budgets in these areas. The Federal government spends about $\$ 3$ billion/year on climate change technology development, but very little of this is spent on R\&D to reduce emissions of non- $\mathrm{CO}_{2}$ GHGs and less than $\$ 20$ million is spent to improve capabilities to measure and monitor GHG emissions. 
Another feature of this table is the large number of gaps and opportunities that address mid- and longterm R\&D including many novel concepts and exploratory R\&D (e.g., advanced thermoelectric concepts and basic research in ocean chemistry and biological cycles); enabling research and technologies (e.g., large-scale energy storage and biomass genomics); and integrative concepts (e.g., integration of electricity and hydrogen transportation sectors).

Finally, participants in all of the workshops were asked to prioritize the basic science contributions needed to advance climate change technologies. The results were reviewed and expanded by participants in the "Research Integration and Basic Science Workshop." One of the outcomes of this effort was a crosswalk between fundamental research areas and CCTP’s five technology goals.

Dissimilar technologies often require similar scientific advances to succeed. For example, degradationresistant materials that perform well under high temperature conditions are essential to improving the energy efficiency of industrial processes; they are also needed to advance to a next generation of fossil and nuclear power plants, and are essential to realizing fusion energy. Similarly, plant and microbial genomics are central to advancing biofuels and biobased chemicals, improving terrestrial sequestration of carbon dioxide, and reducing methane emissions from landfills and livestock.

The following table was produced using the results of the integration workshop. It describes twenty crosscutting strategic research areas and identifies the climate change technology goals that depend on their success. This broad agenda of strategic research is inspired by the technical challenges of specific climate change technologies. If adequately funded, it may successfully convert many of today's emerging technologies into cost-competitive and attractive products and practices. However, to address the century-scale problem of climate change, scientific breakthroughs will be needed to broaden the range of today's options. 


\section{Crosscutting Fundamental Research Areas}

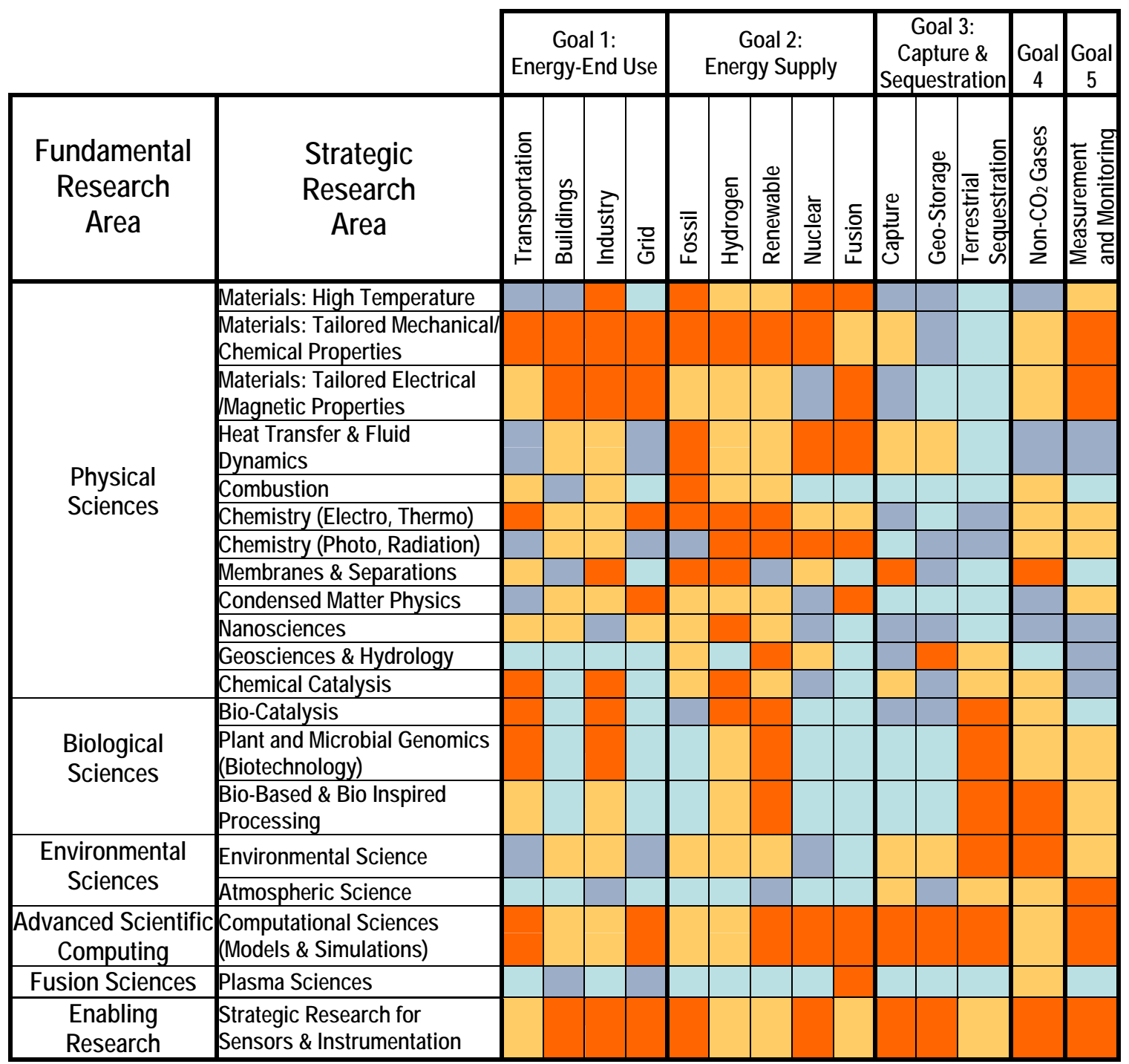

A strategic research area that is central to advancing the technology approach

A strategic research area that is expected to contribute significantly to the technology approach

A strategic research area that has the potential to contribute significantly to the technology approach

A strategic research area that is not expected to contribute significantly to the technology approach 


\section{Results: Crosscutting Themes}

A number of themes emerged that cut across the six R\&D Portfolio Assessment Workshops. These are discussed below.

\section{Stronger Long-Term Focus}

Participants generally concluded that the CCTP $\mathrm{R} \& \mathrm{D}$ portfolio is strong and relatively wellbalanced to meet near-term objectives. However, in each of the six workshops, participants expressed the view that the current CCTP portfolio lacks an adequate long-term focus.

In order to strengthen the mid- and long-term focus of the CCTP R\&D portfolio, participants recommended greater emphasis on exploratory research addressing novel concepts to uncover "breakthrough technology," to strengthen the research community, and to broaden the R\&D portfolio. In addition, there was a strong sentiment that enabling R\&D and integrative concepts (combinations of systems and technologies across sectors) needed more attention. Workshop suggestions for these three research thrusts (novel concepts and exploratory $R \& D$, enabling $R \& D$, and integrative concepts) are described below.

Selected Quotes from Workshop Participants

- "Too little basic $R \& D$; portfolio is short/medium heavy"

- "Need greater percentage of dollars to go to potential breakthrough technology vs. incremental improvements"

- "More emphasis on long-term, revolutionary technologies”

- "Too little emphasis in most programs on really innovative, unconventional approaches"

- "Emphasize small-scale, high-risk, high payoff research"

- "Greater stress on exploratory research"

- "Need more funding for basic, academic research"

- "Need set of long-term experiments for solutions

\section{Novel Concepts and Exploratory R\&D}

In order to make important advances in reducing GHG emissions, novel technology concepts are needed. "Atypical" or "out-of-the-box" novel concepts often do not fit within the boundaries of traditional R\&D. These ideas may require scientific disciplines outside the usual fields, involve application of previously unexplored methods, and offer approaches that compete with more traditional practices. Novel approaches should be considered because they may lead to innovative ways of reducing GHG emissions and GHG concentrations, or otherwise address the effects of climate change.

Novel concepts recommended at the workshops for future investigation include the following:

- Innovative ways to capture and sequester carbon:

$>$ Direct capture of carbon dioxide from the atmosphere

$>$ Ionize $\mathrm{CO}_{2}$ to enable separation via electric fields

$>$ Microbial fixation of carbon in geologic formations

$>$ Soil enhancing carbon sequestration from biomass pyrolysis char

- Innovative concepts based on bio-X (biosciences combined with fields such as nanotechnology, chemistry, and computers):

$>$ Use of "enzyme machines" 
New materials (organic-inorganic hybrids) that could replace traditional technology (e.g., fusing a bio-based light harvesting antennae onto an inorganic framework)

- Innovative and renewable ways to produce or convert energy:

$>$ High-altitude wind kites - kites tethered at high altitude capture the intensity of the wind in the jetstream and convert it to energy via turbines

$>$ Harvesting fugitive energy in buildings to operate ubiquitous low-power sensors and controls with built-in communications

$>$ Tidal dams based on using a barrage (artificial dam) at a bay or estuary with a large tidal range, generating power primarily at ebb tides as the barrage creates a significant head of water, much like a hydroelectric dam

$>$ Ocean thermal energy generation using the thermal gradients in the ocean to generate electricity, hydrogen, or cooling

- Low-loss energy transport:

$>$ Power beaming or wireless power transmission to enable remote terrestrial power systems as well as geosynchronous orbital satellites with solar reflectors for collecting and concentrating power

$>$ “Thermal wires" that move heat in one direction without dispersing heat in the opposite direction

- Novel modes for mitigation of GHG concentrations:

$>$ Geo-engineering the earth's rate of solar insolation (e.g., using nano-particles of aluminum)

$>$ Increasing the earth's surface albedo, especially in urban areas to reduce temperatures and reduce $\mathrm{NO}_{\mathrm{x}}$ production

\section{Enabling R\&D}

Enabling R\&D contributes indirectly to CCTP goals by facilitating the development, deployment, and use of complementary or ancillary technologies that are necessary to the success of mainstream climate change technologies. Enabling technologies often represent the scientific and engineering breakthroughs needed to move next-generation concepts forward along the development cycle. In addition, by cutting across multiple disciplines, enabling technologies can lead to the diffusion of new concepts in multiple areas.

Enabling R\&D emphasized at the workshops includes:

- Energy storage (both small- and large-scale) including the development of electrochemical, kinetic, thermal, and electromagnetic storage systems to reduce costs associated with intermittency and seasonal swings in energy production from most renewables, and to enable plug-in hybrid electric vehicles and hydrogen fuel cell vehicles

- Sensors, communications, and controls to enable smart buildings using ubiquitous low-power sensors to monitor emissions, to detect precursors of failure (i.e., sentinels) in systems that emit high GWP gases, to measure soil carbon fast and cheap, to optimize industrial processes, and to provide electric grid sensor webs (i.e., sensor-to-sensor communications) that use local sensors to trigger alarms to initiate measurements over a larger area

- New materials discovery, design, development, and fabrication for energy use reduction through light-weighting vehicles and equipment, for performance under extreme conditions, for improved thermal management, and other novel properties 
- Innovative designer catalysts, membranes and separations for gas purification, carbon capture from flue gases, high-efficiency chemical processing, cost-competitive fuel cell membranes, and low-energy desalination

- Low-loss power transmission and distribution via nanotubes or other materials that enable lowresistance power transmission without the use of cryogenics or wireless transmission of electricity (i.e., power beaming) to enable space-based solar farms to supply energy to earth, or for wireless power on earth using microwave or laser energy

- Low-cost power electronics for AC-DC conversion to enable cost-competitive solar photovoltaics and microgrids, power conditioning, rapid fault response, and hybrid electric vehicles

- Methods to "control” photon, electron, ion, and phonon transport in materials for next-generation energy technologies including thermoelectric materials that can produce electricity from temperature differentials

- Revolutionary analytical instruments that enable atmospheric GHG imaging, theoretical modeling and visualization, nanoscale materials characterization, and other enabling applications

- Bio-materials and bio-chemical interfaces, especially at the nanoscale where soft matter and hard matter can be joined

\section{Integrative Concepts}

Integrative concepts combine systems and cut across technologies, disciplines, and sometimes sectors of the economy. Developing such integrative concepts is an inter-disciplinary, complex undertaking that requires new partnerships and alliances. The combination of concepts into integrated, more efficiently functioning systems could have potentially large implications for climate change and should be encouraged.

Integrative concepts recommended at the workshops:

- Plug-in hybrid electric vehicles (HEVs): Integration of plug-in HEVs with zero energy buildings and utility peak-shaving could dramatically reduce GHGs from vehicles if recharging is done principally with low-carbon forms of electricity such as nuclear or renewable resources. This technology could also help optimize the use of intermittent energy sources such as solar and wind.

- Systems engineered urban planning and design: Land use can be designed to reduce vehicle mile requirements and allow co-location of activities with common needs for energy, water, and other resources. GHGs could be reduced through co-location of energy sources and sinks.

- Systems approach to integrated waste management: Reduce the magnitude of landfill waste through tagging and sorting technologies, distributed waste processing for conversion to power and fuels, and using engineered bacteria to process waste without producing methane.

- Integrated measurement and monitoring: Design integrated system architecture that fuses instrumentation platforms, data, new models and decision-support tools.

- Water - energy nexus: More efficient use of energy to support the water distribution and treatment infrastructure, and more efficient use of water to support energy supply. Technologies to minimize energy requirements for water use could include buildings designed to reduce use and conveyance of water, grey-water re-use, efficient desalination technology, and integration of water storage and treatment with intermittent renewable energy supplies. Adaptation of nuclear power plants to "dry" closed-loop systems is an example of a technology to minimize the use of water in power production. 
- Underground energy extraction: Extract energy underground from hydrocarbons (oil and coal) so that heat and power can be brought to the surface. Approaches might include in-situ refining, which will require materials for high-temperature and pressure or underground in-situ gasification.

Other examples merge suites of technologies into holistic approaches that have limited adverse climate effects. For instance, biomass gasification could be used to produce electricity with carbon sequestration to produce clean diesel (dimethyl ether) as an alternative transportation fuel. Integrated systems approaches can help reduce overall GHG emissions as when agriculture and forestry practices are jointly optimized.

\section{Science to Technology Workshops}

A number of science and technology workshops have been sponsored by the DOE Office of Science's Basic Energy Science (BES) Office to identify basic science needs to support DOE's energy goals. These workshops have resulted in comprehensive reports that outline future research needs in energy technology areas important to CCTP, including nuclear, solar, and hydrogen. In addition, a number of new workshops are planned to continue to elucidate basic science needed to support technologies for addressing climate change.

A number of areas where research in the basic sciences will be needed in the future were identified during the Integration Workshop. These cover a range of new technology areas from thermoelectrics to bio-X to energy storage. Most of the areas identified were crosscutting and could have a broad impact across many sectors. 


\section{Science to Technology Workshops}

\section{Results of Portfolio Review:}

- Electric grid challenges - system architecture, control systems, and power electronics

- Thermoelectrics by application (e.g., refrigeration, power generation)

- Solid state lighting

- Bio-X - combination of nanoscience and genomics

- Plant genetic engineering

- Measuring and monitoring of climate change mitigation - international focus

- Sensors, controls, communication

- Energy storage - basic science and requirements of integrated systems

- Batteries - power \& energy (basic chemistry)

- Heat Transfer - material insulation, cryogenics, thermal conducting coolants

- Ocean sequestration \& methane hydrates
BES/BER "BRN" Workshops To Date:

- Biomass to Biofuels

December 2005

- Genomics:GTL Roadmap

August 2005

- The Path to Sustainable Nuclear Energy September 2005

- Solar Energy Utilization April 18-21, 2005

- Advanced Computational Materials Science: Application to Fusion and Generation IV Fission Reactors

March 31-April 2, 2004

- Nanoscience Research for Energy Needs March 16-18, 2004

- Hydrogen Economy May 13-15, 2003

- Assure a Secure Energy Future October 21-25, 2002

BES/BER "BRN" Workshops Planned:

- Superconductivity May 2006

- Solid-State Lighting May 2006

- Advanced Nuclear Systems mid FY 2007

- Energy Storage mid FY 2007

BRN = Basic Research Needs 


\section{Summary}

The current CCTP R\&D portfolio has a number of strengths, especially in near-term technology development. Given the potential impacts on climate over a 100-year time horizon, the CCTP R\&D portfolio review suggested a need for accelerating R\&D on technologies that could provide more midand long-term technology solutions to climate change. The integration workshop underscored the importance of strengthening the basic sciences to better understand and reduce sources of GHG emissions while sustaining economic growth.

Integration workshop participants also reiterated that success will require the pursuit of multiple technology pathways to address the CCTP goals; no single technology is sufficient to address the impacts of climate change.

The CCTP portfolio review concluded that there is a particular need to augment research on mitigating non- $\mathrm{CO}_{2}$ GHGs and on measuring and monitoring systems. The Federal government spends about $\$ 3$ billion/year on climate change technology development, but very little of this is spent on R\&D to reduce emissions of non- $\mathrm{CO}_{2} \mathrm{GHGs}$, and less than $\$ 20$ million is spent to improve capabilities to measure and monitor GHG emissions.

The first three goal areas (emission reductions from end-use and infrastructure, emission reductions from energy supply, and carbon capture and sequestration) have historically been relatively well-supported, albeit with a more near-term focus. Many of the gaps and opportunities shown for these goals reflect technologies that should receive greater emphasis in the mid- and long-term. The large number of gaps and opportunities identified for goals 4 and 5 (emission reductions from non- $\mathrm{CO}_{2}$ GHGs and measurement and monitoring of GHG emissions) reflect current and historically low budgets for R\&D in these areas.

In addition to mainstream CCTP technology development activities, research should be conducted in a number of cross-cutting areas, specifically:

- Novel concepts and exploratory R\&D (e.g., innovative ways to capture/sequester carbon, combining biosciences with nanotechnology and other emerging fields; new ways to convert energy; novel GHG mitigation strategies)

- Enabling R\&D (e.g., generic, widely-applicable developments in energy storage, sensors, communications, materials, nanotechnology, and instrumentation)

- Integrative concepts (systems combined to provide unique advantages, e.g., integration of plug-in vehicles with zero energy buildings, integrated waste management, engineered urban planning for low GHG emissions, energy systems designed to support water supply)

These research activities need to be complemented by strategically focused research in the basic sciences. Achieving the CCTP vision will likely require discoveries and innovations well beyond the capabilities of today's science and technology. Better integration of basic scientific research with applied technology development may be the key to achieving CCTP's goals related to energy efficiency, energy supply, carbon capture and sequestration, reducing emissions of non- $\mathrm{CO}_{2}$ gases, and measurement and monitoring. Basic science research is likely to provide the underlying knowledge base on which new technologies are built. Such technological progress will create new, better, and more affordable solutions and will facility the means for change and a smooth transition to a near-zero emission future. 


\section{Next Steps for FY 2008 and Beyond}

Several next steps should be undertaken so that the CCTP R\&D portfolio can be strengthened in FY 2008 and beyond.

For CCTP's applied R\&D programs, Federal agencies should evaluate the high priority gaps and opportunities identified in this portfolio review. Following technology roadmapping and other R\&D planning activities, the validated high priorities should be funded.

For basic research programs, additional strategic planning workshops (modeled after the DOE/BES and BER workshops) should be held, focusing on the basic science needed to meet the CCTP applied R\&D goals. These would set the stage for funding follow-on solicitations in key areas.

For the Federal agencies that sponsor CCTP R\&D activities - including DOE, NSF, NIST, EPA, USDA, and others - a number of follow-on activities are recommended. First, the CCTP goals and approaches need to be integrated into the American Competitiveness Initiative. Second, tractable means should be established for addressing crosscutting and integrative needs - those that combine technologies and ideas across sectors and disciplines, that will be essential to addressing climate change over the long term. Finally, mechanisms should be strengthened and formalized for stimulating novel concepts and enabling exploratory R\&D. The assessment reiterated the value of pursuing exploratory, out-of-the-box concepts that may be outside the realm of traditional thinking but that could potentially have large impacts for climate change. To support exploratory concepts as well as mainstream technologies, more research in the basic sciences and enabling disciplines of materials, biology, physical sciences, computational sciences, nanotechnology and others will be required. This will produce the scientific knowledge and discovery needed for a revolutionary change in the way we produce and use energy. 


\section{References}

DeAngelo, B., F. de la Chesnaye, R. Beach, A. Sommer, and B. Murray, 2005. Methane and Nitrous Oxide Mitigation in Agriculture. Energy Journal.

Delhotal, K. Casey, F. C. de la Chesnaye, A. Gardiner, J. Bates, and A. Sankovski, 2005. Mitigation of Methane and Nitrous Oxide Emissions from Waste, Energy and Industry. Energy Journal.

Energy Information Administration (EIA). 2004a. Annual energy outlook 2004: With projections to 2025, DOE/EIA-0383(2004). Washington, DC: U.S. Department of Energy.

Energy Information Administration (EIA). 2004b. International energy outlook 2004. Washington, D.C: U.S. Department of Energy. http://www.eia.doe.gov/oiaf/ieo/pdf/0484(2004).pdf

Energy Information Administration (EIA). 2005. Annual energy outlook 2005. Washington, DC: U.S. Department of Energy. http://www.eia.doe.gov/oiaf/aeo/pdf/0383(2005).pdf

Intergovernmental Panel on Climate Change (IPCC). 2001. Climate change 2001: The scientific basis. Cambridge, UK: Cambridge University Press.

Placet, M., K.K. Humphreys, and N.M. Mahasenan. 2004. Climate Change Technology Scenarios: Energy, Emissions and Economic Implications. Richland, WA: Pacific Northwest National Laboratory. http://www.pnl.gov/energy/climatetechnology.stm

Schaefer, D., D. Godwin, and J. Harnish, 2005. Estimating Future Emissions and Potential Reductions of HFCs, PFCs, and SF6. Energy Journal (forthcoming).

U.S. Climate Change Technology Program. 2005a. Vision and Framework for Strategy and Planning. http://www.climatetechnology.gov/vision2005/index.htm

U.S. Climate Change Technology Program. 2005b. Strategic Plan Draft for Public Comment September 2005. http://www.climatetechnology.gov/stratplan/draft/index.htm

U.S. Climate Change Technology Program. 2005c. Technology Options for the Near and Long-term. http://www.climatetechnology.gov/library/2005/tech-options/index.htm 


\section{Acknowledgement}

This work was sponsored by the U.S. Climate Change Technology Program (CCTP). We wish to acknowledge Dr. Robert Marlay, Director of DOE's Office of Science and Technology Policy and Deputy Director of CCTP, and Dr. Michael Curtis, DOE Project Technical Director, who provided the vision for this portfolio review, contributed to the design and execution of the review, and provided guidance to the effort at numerous critical junctures.

We would also like to acknowledge the participation of the CCTP Working Group chairs who helped to plan and participated in the CCTP portfolio review workshops, including:

Mark Ginsberg, Workshop 1 Chair

John Stamos, Workshop 2 Chair

Jay Braitsch, Workshop 3 Chair

Dina Kruger, Workshop 4 Co-Chair

William Hohenstein, Workshop 4 Co-Chair

Ronald J. Birk, Workshop 5 Chair

Jerry W. Elwood, Workshop 6 Chair

The portfolio review would not have been possible without the willing involvement of the experts who attended the six workshops and whose ideas we strove to capture and summarize in this document. Their names and affiliations are provided in Appendix A. In addition, Bob Hawsey, Acting Director of ORNL's Energy Efficiency and Renewable Energy Program, and Charles Forsberg, ORNL Distinguished R\&D Staff and Senior Reactor Technical Adviser, provided valuable reviews of the report.

Finally, we would like to recognize Melissa Eichner, Energetics, who was the principal workshop facilitator. 
Appendix A

Participant List 



\section{Workshop \#1 - Reduce Emissions from Energy End-Use and Infrastructure}

\begin{tabular}{|c|c|c|c|c|}
\hline FirstName & LastName & Organization Name & e-mail & Role \\
\hline \multicolumn{5}{|c|}{ Workshop Leaders } \\
\hline Mark & Ginsberg & US Departmet of Energy & mark.ginsberg@ee.doe.gov & CCTP Chair \\
\hline Marilyn & Brown & Oak Rige National Laboratory & brownma@ornl.gov & CCTP Integrator \\
\hline \multicolumn{5}{|c|}{ Technical Experts } \\
\hline Douglas & Arent & NREL & douglas_arent@nrel.gov & Expert \\
\hline Terry & Boston & Tennessee Valley Authority & wtboston@tva.gov & Expert \\
\hline Lawrence & Boyd & Energy Industries of Ohio & boyd@energyinohio.org & Expert \\
\hline Chris & Green & McGill University & chris.green@mcgill.ca & Expert \\
\hline Jeff & Harris & Lawrence Berkeley National Lab & JPHarris@lbl.gov & Expert \\
\hline Joan & Ogden & University of California & jmogden@ucdavis.edu & Expert \\
\hline Lori & Perine & American Forest \& Paper Association & lori_perine@afandpa.org & Expert \\
\hline Dale & Steinar & Florida State University & dale@caps.fsu.edu & Expert \\
\hline Chowen Chou & Wey & NASA Glenn Research Center & chowen.c.wey@grc.nasa.gov & Expert \\
\hline \multicolumn{5}{|l|}{ Observers } \\
\hline Dan & Garretson & Office of Science \& Technology Policy & dgarretson@ostp.eop.gov & Expert \\
\hline Kevin & Hurst & Office of Science \& Technology Policy & khurst@ostp.eop.gov & Observer \\
\hline Gordon & Michaels & Oak Ridge National Laboratory & michaelsge@ornl.gov & Observer \\
\hline Randy & Steer & US Department of Energy & randy.steer@ee.doe.gov & Observer \\
\hline \multicolumn{5}{|c|}{ ССТP and Support Staff } \\
\hline Bob & Marlay & US Department of Energy/CCTP & robert.marlay@hq.doe.gov & CCTP Dep. Dir. \\
\hline Mike & Curtis & US Department of Energy/CCTP & michael.curtis@hq.doe.gov & Project Manager \\
\hline Inja & Paik & US Department of Energy/CCTP & inja.paik@hq.doe.gov & Project Manager \\
\hline Burt & Koske & Idaho National Laboratory & burton.koske@inl.gov & CCTP Support \\
\hline \multicolumn{5}{|c|}{ Facilitators and Rapporteurs } \\
\hline Joan & Pellegrino & Energetics & jpellegrino@energetics.com & Facilitator \\
\hline Melissa & Eichner & Energetics & meichner@energetics.com & Facilitator \\
\hline Matt & Antes & Energetics & mantes@energetics.com & Rapporteur \\
\hline Steven & Hellen & Energetics & shellen@energetics.com & Rapporteur \\
\hline
\end{tabular}

\section{Workshop \#2 - Reduce Emissions from Energy Supply}

\begin{tabular}{|c|c|c|c|c|}
\hline FirstName & LastName & Organization Name & e-mail & Role \\
\hline \multicolumn{5}{|c|}{ Workshop Leaders } \\
\hline John & Stamos & U.S. Department of Energy & john.stamos@nuclear.energy.gov & CCTP Chair \\
\hline William & Fulkerson & University of Tennessee, JIEE & wfulk@utk.edu & CCTP Integrator \\
\hline \multicolumn{5}{|c|}{ Technical Experts } \\
\hline Johnathan & Coleman & Solar Turbines, Inc. & jcoleman@solarturbines.com & Expert \\
\hline Bill & Fang & Edison Electric Institute & bfang@eei.org & Expert \\
\hline Robert J. & Goldston & Princeton Plasma Physics Laboratory & rgoldston@pppl.gov & Expert \\
\hline Gordon & Michaels & Oak Ridge National Laboratory & michaelsge@ornl.gov & Expert \\
\hline Nag & Patibandla & New York State Energy R\&D Authority & np1@nyserda.org & Expert \\
\hline Maxine & Savitz & National Academy of Engineering & maxinesavitz@aol.com & Expert \\
\hline Walter & Short & National Renewable Energy Laboratory & walter_short@nrel.gov & Expert \\
\hline Jim & Zucchetto & National Academies & jzucchet@nas.edu & Expert \\
\hline \multicolumn{5}{|l|}{ Observers } \\
\hline Jay & Braitsch & U.S. Department of Energy & jay.braitsch@hq.doe.gov & Observer \\
\hline Dan & Garretson & W.H. Off. Of Science \& Tech. Policy & dgarretson@ostp.eop.gov & EOP Observer \\
\hline Mark & Ginsberg & US Departmet of Energy & mark.ginsberg@ee.doe.gov & Observer \\
\hline Charlie & Hammerline & EERE & charlie.hemmerline@ee.doe.gov & Observer \\
\hline Ehsan & Khan & US Department of Energy & ehsan.khan@science.doe.gov & Observer \\
\hline Steve & Obenshein & Naval Research Laboratory & Steve.Obenschain@nrl.navy.mil & Observer \\
\hline Randy & Steer & US Department of Energy & randy.steer@ee.doe.gov & Observer \\
\hline \multicolumn{5}{|c|}{ CCTP and Support Staff } \\
\hline Bob & Marlay & US Department of Energy/CCTP & |robert.marlay@hq.doe.gov & CCTP Dep. Dir. \\
\hline Mike & Curtis & US Department of Energy/CCTP & michael.curtis@hq.doe.gov & Project Manager \\
\hline Marilyn & Brown & Oak Ridge National Laboratory & BrownMA@ornl.gov & Project Leader \\
\hline Burt & Koske & Idaho National Laboratory & burton.koske@inl.gov & CCTP Support \\
\hline \multicolumn{5}{|c|}{ Facilitators and Rapporteurs } \\
\hline Joan & Pellegrino & Energetics & jpellegrino@energetics.com & Facilitator \\
\hline Melissa & Eichner & Energetics & meichner@energetics.com & Facilitator \\
\hline Matt & Antes & Energetics & mantes@energetics.com & Rapporteur \\
\hline
\end{tabular}




\section{Workshop \#3 -Capture and Sequester Carbon Dioxide}

\begin{tabular}{|c|c|c|c|c|}
\hline FirstName & LastName & Organization Name & e-mail & Role \\
\hline Sally M. & Benson & Lawrence Berkeley National Lab & SMBenson@lbl.gov & CCTP Integrator \\
\hline Eric & Adams & Massachusetts Institute of Technology & eeadams@mit.edu & Expert \\
\hline Ken & Caldeira & Carnegie Institution & kcaldeira@globalecology.stanford.edu & Expert \\
\hline Richard & Doctor & Argonne National Laboratory & rdoctor@anl.gov & Expert \\
\hline Howard & Herzog & Massachusetts Institute of Technology & hjherzog@MIT.EDU & Expert \\
\hline Haroon S. & Kheshgi & Exxon Mobil Research \& Engineering Company & haroon.s.kheshgi@exxonmobil.com & Expert \\
\hline Robert & Kane & US Department of Energy & robert.kane@hq.doe.gov & Expert \\
\hline Arthur & Lee & Chevron Corporation & rlas@chevron.com & Expert \\
\hline \multicolumn{5}{|l|}{ Observers } \\
\hline Ehsan & Khan & US Department of Energy & ehsan.khan@science.doe.gov & Observer \\
\hline Burt & Koske & Idaho National Laboratory & burton.koske@inl.gov & CCTP Support \\
\hline Marilyn & Brown & Oak Ridge National Laboratory & BrownMA@ornl.gov & Project Leader \\
\hline \multicolumn{5}{|c|}{ Facilitators and Rapporteurs } \\
\hline Joan & Pellegrino & Energetics & jpellegrino@energetics.com & Facilitator \\
\hline Matt & Antes & Energetics & mantes@energetics.com & Rapporteur \\
\hline Melissa & Eichner & Energetics & meichner@energetics.com & Rapporteur \\
\hline Melanie & Miller & Energetics & mmiller@energetics.com & Rapporteur \\
\hline
\end{tabular}

\section{Workshop \#4 - Reduce Emissions of Non- $\mathrm{CO}_{2}$ Greenhouse Gases}

\begin{tabular}{|c|c|c|c|c|}
\hline FirstName & LastName & Organization Name & e-mail & Role \\
\hline \multicolumn{5}{|c|}{ Workshop Leaders } \\
\hline Dina W. & Kruger & USEPA Headquarters & kruger.dina@epa.gov & CCTP Chair \\
\hline William & Hohenstein & Global Change Program Office & whohenst@oce.usda.gov & CCTP Chair \\
\hline Paul M. & Gunning & USEPA Headquarters & gunning.paul@epa.gov & CCTP Integrator \\
\hline Brian & Murray & Research Triangle International & bcm@rti.org & CCTP Integrator \\
\hline \multicolumn{5}{|c|}{ Technical Experts } \\
\hline Robin & Graham & Oak Ridge National Laboratory & grahamro@ornl.gov & Expert \\
\hline Kristen & Johnson & Washington State University & johnsoka@wsu.edu & Expert \\
\hline Ravi & Kantamaneni & ICF Consulting Inc. & RKantamaneni@ICFConsulting.com & Expert \\
\hline Aslam & Khalil & Portland State University & khalilm@pdx.edu & Expert \\
\hline Bruce & McCarl & Texas A\&M & mccarl@tamu.edu & Expert \\
\hline Charles & Rice & Kansas State & cwrice@ksu.edu & Expert \\
\hline \multicolumn{5}{|l|}{ Observers } \\
\hline Tom & Morehouse & W.H. Off. Of Science \& Tech. Poli & dtmorehouse@ostp.eop.gov & EOP Observer \\
\hline \multicolumn{5}{|c|}{ CCTP and Support Staff } \\
\hline Bob & Marlay & US Department of Energy/CCTP & robert.marlay@hq.doe.gov & CCTP Dep. Dir. \\
\hline Mike & Curtis & US Department of Energy/CCTP & michael.curtis@hq.doe.gov & Project Manager \\
\hline Marilyn & Brown & Oak Ridge National Laboratory & BrownMA@ornl.gov & Project Leader \\
\hline Burt & Koske & Idaho National Laboratory & burton.koske@inl.gov & CCTP Support \\
\hline \multicolumn{5}{|c|}{ Facilitators and Rapporteurs } \\
\hline Joan & Pellegrino & Energetics & |jpellegrino@energetics.com & Facilitator \\
\hline Matt & Antes & Energetics & mantes@energetics.com & Rapporteurs \\
\hline Melissa & Eichner & Energetics & meichner@energetics.com & Rapporteurs \\
\hline Melanie & Miller & Energetics & mmiller@energetics.com & Rapporteurs \\
\hline
\end{tabular}




\section{Workshop \#5 - Improve Capabilities to Measure and Monitor GHG Emissions}

\begin{tabular}{|c|c|c|c|c|}
\hline FirstName & LastName & Organization Name & e-mail & Role \\
\hline \multicolumn{5}{|c|}{ Workshop Leaders } \\
\hline Gerald & Stokes & Pacific Northwest National Laboratory & stokes@pnl.gov & CCTP Integrator \\
\hline Richard A. & Benson & Los Alamos National Laboratory & rabenson@lanl.gov & Expert \\
\hline Lynn & Beary & National Institute of Standards and Technology & ellyn.beary@nist.gov & Expert \\
\hline Phil & DeCola & NASA Headquarters & pdecola@nasa.gov & Expert \\
\hline Mayra & Montrose & NASA Headquarters & mmontrose@hq.nasa.gov & Expert \\
\hline Keith & Paustian & Colorado State University & Keith.Paustian@ColoState.EDU & Expert \\
\hline \multicolumn{5}{|l|}{ Observers } \\
\hline Ehsan & Khan & US Department of Energy & |ehsan.khan@science.doe.gov & Observer \\
\hline Gordon & Michaels & Oak Ridge National Laboratory & michaelsge@ornl.gov & Observer \\
\hline \multicolumn{5}{|c|}{ CCTP and Support Staff } \\
\hline Joan & Pellegrino & Energetics & |jpellegrino@energetics.com & Facilitator \\
\hline Melissa & Eichner & Energetics & meichner@energetics.com & Facilitator \\
\hline Matt & Antes & Energetics & mantes@energetics.com & Rapporteur \\
\hline Melanie & Miller & Energetics & mmiller@energetics.com & Rapporteur \\
\hline
\end{tabular}

\section{Workshop \#6 - Bolster Basic Science Contributions to Technology Development}

\begin{tabular}{|c|c|c|c|c|}
\hline FirstName & LastName & Organization Name & e-mail & Role \\
\hline \multicolumn{5}{|c|}{ Workshop Leaders } \\
\hline Jerry W. & Elwood & |U.S. Department of Energy & |JERRY.ELWOOD@science.doe.gov & CCTP Chair \\
\hline \multicolumn{5}{|c|}{ Technical Experts } \\
\hline Ellyn (Lyn) S. & Beary & National Institute of Standards and Technology & ellyn.beary@nist.gov & Expert \\
\hline Lynn L. & Billman & National Renewable Energy Laboratory & lynn_billman@nrel.gov & Expert \\
\hline Linda G. & Blevins & The National Science Foundation & Iblevins@nsf.gov & Expert \\
\hline Craig & Blue & Oak Ridge National Laboratory & blueca@ornl.gov & Expert \\
\hline Marilyn & Brown & Oak Ridge National Laboratory & brownma@ornl.gov & Expert \\
\hline Michelle & Buchanan & Oak Ridge National Laboratory & buchananmv@ornl.gov & Expert \\
\hline Brian $\mathrm{H}$. & Davison & Oak Ridge National Laboratory & davisonbh@ornl.gov & Expert \\
\hline Richard & Eckman & NASA Langley Research Center & Richard.S.Eckman@nasa.gov & Expert \\
\hline Christopher F. & Edwards & Stanford University & cfe@stanford.edu & Expert \\
\hline William & Fulkerson & University of Tennessee, JIEE & wfulk@utk.edu & Expert \\
\hline Robin L. & Graham & Oak Ridge National Laboratory & grahamrl@ornl.gov & Expert \\
\hline Paul M. & Gunning & USEPA Headquarters & gunning.paul@epa.gov & Expert \\
\hline Kevin & Hurst & Office of Science and Technology Policy & KHURST@OSTP.EOP.GOV & Expert \\
\hline Gary & Jacobs & Oak Ridge National Laboratory & jacobsgk@ornl.gov & Expert \\
\hline Thomas W. & Jeffries & University of Wisconsin, Madison & twjeffri@facstaff.wisc.edu & Expert \\
\hline Thomas S. & Key & EPRI Solutions Corporation & tkey@epri.com & Expert \\
\hline Ehsan U. & Khan & U.S. Department of Energy & ehsan.khan@science.doe.gov & Expert \\
\hline Jeffrey & Logan & World Resources Institute & JLOGAN@wri.org & Expert \\
\hline Hylan & Lyon & Marlow Industries, Inc. & hlyon@marlow.com & Expert \\
\hline Gordon E. & Michaels & Oak Ridge National Laboratory & michaelsge@ornl.gov & Expert \\
\hline John C. & Miller & U.S. Department of Energy & john.miller@science.doe.gov & Expert \\
\hline John & Stamos & U.S. Department of Energy & john.stamos@nuclear.energy.gov & Expert \\
\hline \multicolumn{5}{|c|}{ CCTP and Support Staff } \\
\hline Bob & Marlay & US Department of Energy/CCTP & robert.marlay@hq.doe.gov & CCTP Dep. Dir. \\
\hline Mike & Curtis & US Department of Energy/CCTP & michael.curtis@hq.doe.gov & Project Manager \\
\hline Burt & Koske & Idaho National Laboratory & burton.koske@inl.gov & CCTP Support \\
\hline \multicolumn{5}{|c|}{ Facilitators and Rapporteurs } \\
\hline Melissa & Eichner & Energetics & meichner@energetics.com & Facilitator \\
\hline Matt & Antes & Energetics & mantes@energetics.com & Facilitator \\
\hline
\end{tabular}


A-4 
Appendix B

Sample Agenda and

\section{Homework Assignments}





\title{
AGENDA
}

\section{CCTP R\&D Portfolio Assessment Workshops}

\author{
Time \\ Session Topic Description of Activities \\ 8:30 am - \\ 9:00 am \\ Introductory Remarks Overview and workshop purpose \\ 9:00 am - \\ 9:15 am \\ Workshop Process Instructions for facilitated breakout sessions \\ 9:15 am - 9:30 am Coffee break
}

$9: 30 \mathrm{am}-$

Facilitated

Homework Assignment \#1 Brainstorm New Opportunities - entirely $12: 00 \mathrm{pm}$ Discussion new innovations and ideas as well as system approaches

Categorize, analyze, and rank ideas and opportunities

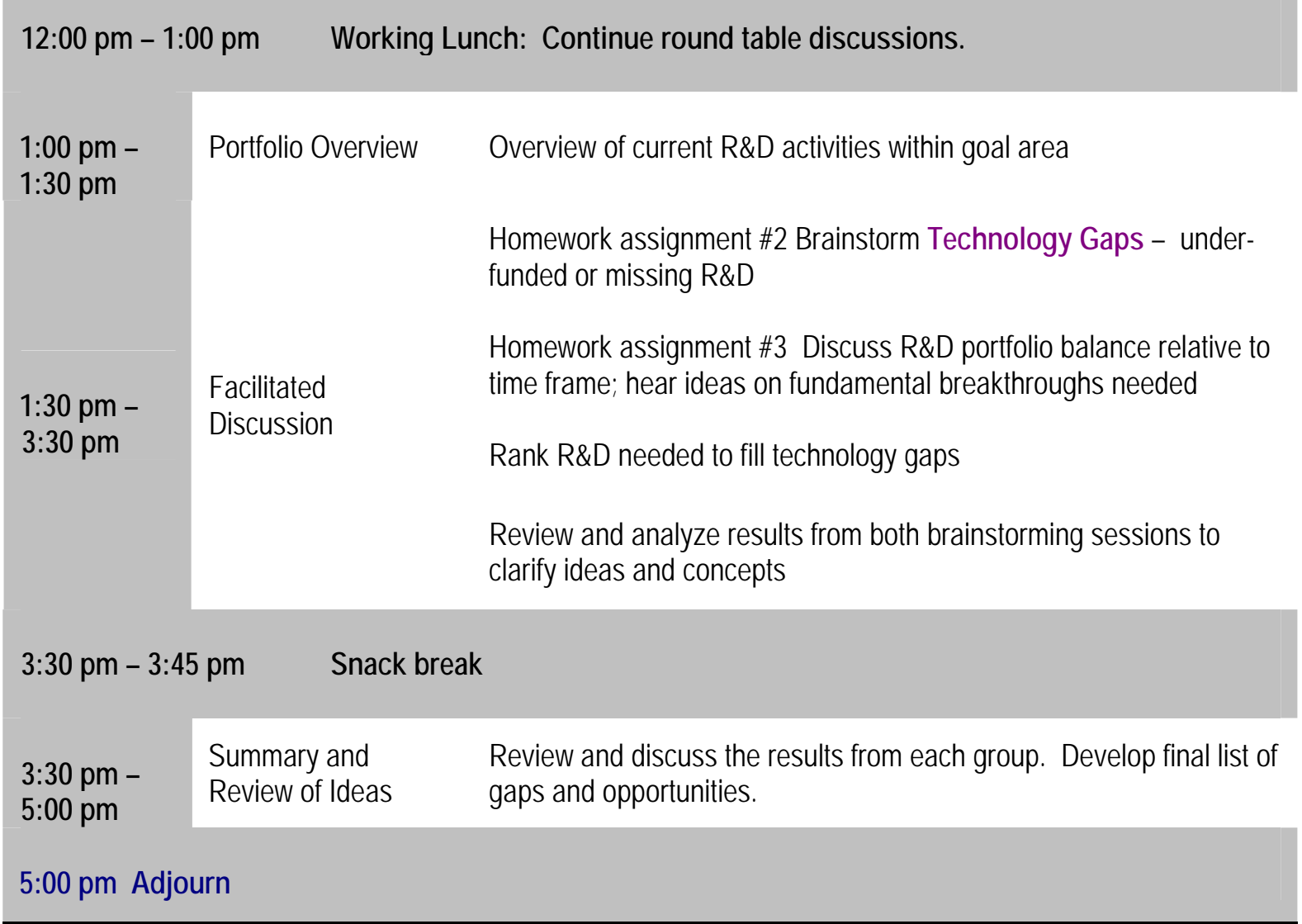




\section{Homework Assignments}

The workshops were organized around three homework assignments that were given to participants in advance of each workshop. The following details show how these homework topics were used in a combination of brainstorming and consensus-building activities.

Homework Assignment \#1: Brainstorm New Opportunities.

- In the goal area, what entirely new innovations could significantly contribute over a 100 year time horizon?

- Ask participants to consider the primary question, then take 5 minutes to jot down their ideas; emphasize gigaton impacts and the 100-year framework.

- Go around the room several times to generate ideas; facilitator records and clarifies ideas.

- Review any international work relevant to this goal area to stimulate thought.

- As ideas slow, use tickler questions to stimulate ideas.

- Categorize and analyze ideas: group ideas in logical areas (e.g., transportation, terrestrial sequestration, etc), group similar or related items, remove redundancies.

- Ask group to come up and look at the board, and clarify or rearrange ideas as needed.

- Rank opportunities: Move to a different board, and complete an X-Y plot based on potential impacts and probability of success. Solicit views on the timeframe of each innovation.

Homework Assignment \#2: Identify Technology Gaps.

- In the current portfolio, what R\&D activities are under-funded or missing (gaps) that could contribute significantly to the goal?

- Ask each participant to provide his/her top two ideas on what areas are under-funded or missing.

- Facilitator posts the ideas on a board, and categorizes ideas as they are presented.

Homework Assignment \#3: Balance and Breakthroughs.

- Ask the question about portfolio balance - is there an imbalance in near-, mid-, and long-term $\mathrm{R} \& \mathrm{D}$ in the current portfolio? If so, where is the imbalance?

- What are the most important fundamental breakthroughs needed? Allow one or two ideas only per person. Capture on cards.

- Rank R\&D needed to fill the technology gaps. Complete an X-Y plot based on potential impacts and probability of success. Reproduce ideas as needed on cards, indicate category with a symbol, and capture timeframe.

- Ask group to come up and look at the board, clarify ideas as needed, make comments. Review both gaps and opportunities from the day's sessions.

- Break into small groups to complete a one-page matrix of information for just the top tier new opportunities (those with high impacts and low risk).

- Review the results and asking for final comments on the ideas generated. 
Appendix C

\section{One-Page Summaries of Gaps and Opportunities}





\section{TABLE OF CONTENTS}

\section{One-Page Descriptions of Gaps and Opportunities Identified in the CCTP R\&D Portfolio Assessment Workshops}

Goal 1 - Reduce Emissions from Energy End-Use and Infrastructure

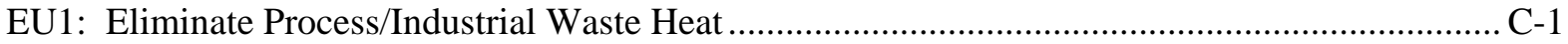

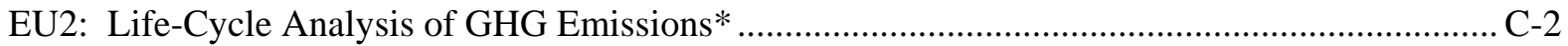

EU3: Advanced Aviation Technologies to Reduce GHG Emissions .................................................. C-3

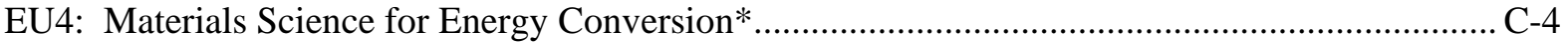

EU5: Engineered Urban Designs**.......................................................................................... C-5

EU6: Water and Energy System Optimization** ...............................................................................

EU7: Improved Control Systems for Distributed Energy …................................................................ C-7

EU9: Advanced Materials Development and Processing* ................................................................. C-8

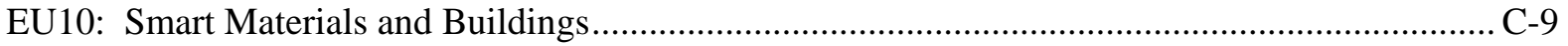

EU11: Integrated Transport/Electricity/Building/Industry/Communities** .................................. C-10

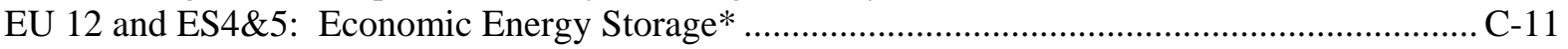

Other New Technologies for Energy End-Use ........................................................................... C-12

Goal 2 - Reduce Emissions from Energy Supply

ES1: Expanding the Fuel Resources for Long-term Use of Fission (and Fusion).......................... C-13

ES3\&7: Integration of Plug-in Hybrid Electric Vehicles with

Solar, Zero Energy Buildings and Utility Peak-Shaving** ...................................................... C-14

ES6: Solar Fuels (artificial photosynthesis) ….......................................................................... C-15

EU8 and Terr2: Optimized Biomass Production for Alternative Fuels,

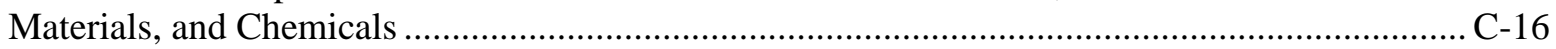

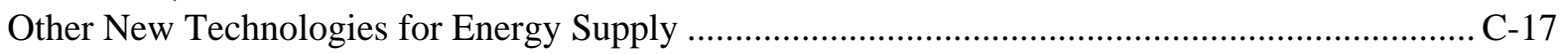

Goal 3 - Capture and Sequester Carbon Dioxide

CCS1: Quantify and Mitigate Effects of $\mathrm{CO}_{2}$ On Marine Ecosystems ............................................

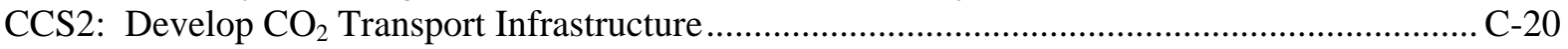

CCS3: Risk Management for Geologic Storage ................................................................................

CCS4: Underground In-Situ Processing of Hydrocarbons .............................................................. C-22

CCS6: Exploratory Research into New Approaches for $\mathrm{CO}_{2}$ Capture ..............................................23

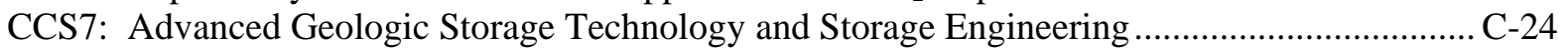

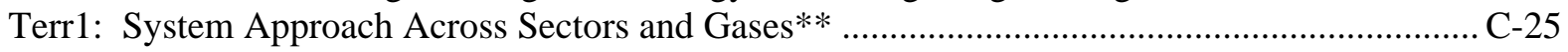

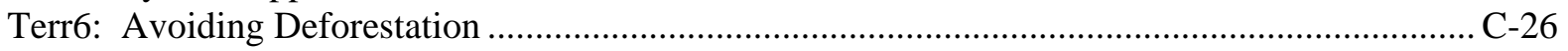

Other New Technologies for Carbon Capture and Sequestration ............................................... C-27

Goal 4 - Reduce Emissions of Non- $\mathrm{CO}_{2}$ Greenhouse Gases

OG1: Self-Repairing, Leak-free Gas Pipelines and LNG Conversion Systems............................. C-28

OG3: Integrated Systems Approach to Waste Management** .........................................................2-29

OG4: Eliminating HFCs in Refrigeration and Air Conditioning.....................................................30

OG5: Alternative Chemicals for Chemical Vapor Deposition and Plasma Etching ....................... C-31

OG6: Replace $\mathrm{SF}_{6}$ in High Voltage Switchgear and Airborne Radar ............................................. C-32

Other New Technologies for Other Gases.........................................................................................33

Goal 5 - Improve Capabilities to Measure and Monitor GHG Emissions

MM1: Design of Climate Change Technologies to Facilitate M\&M Processes* ........................... C-35 
MM2: Remote Sensing Capability of GHGs and Aerosols From Beyond

Low Earth Orbit, Located At Geostationary, L1 …........................................................................ C-36

MM3: Protocols and Concurrent Technologies for Multiple Assessments of

Energy End-Uses**.

MM4: Wide Area Networks to Enable Sensor-To-Sensor Communications.....

MM 5\&6: Integrated Management System Including Data Management and

Modeling**

MM 7: Rapid Prototyping and Benchmarking of Existing and Evolving R\&D

Components Configurations of Integrated System Solutions**

MM8: Multi-Agency Integrated Measurement and Monitoring

Field Experiment** .

Other New Technologies for Measuring and Monitoring

*Enabling Concept

**Integrative Concept 


\section{EU1: Eliminate Process/Industrial Waste Heat}

\section{Strategic Plan Section: 4.3.3: Energy Conversion and Utilization}

Description: Industrial processes that involve heating, drying, and cooling consume significant amounts of energy, leading to emissions of GHGs via combustion of fossil fuels. Alternative industrial approaches could either minimize the waste heat from these processes, or could put this waste heat to productive uses both within and between plants. Promising technologies include:

- Beneficial electrification such as infrared drying and induction heating to reduce waste heat

- Novel materials that do not require drying or curing and associated energy

- Micro-combined heat and power (CHP) systems to convert waste heat to drive other thermal processes

- Ways to boost low-grade temperatures to more useful high-grade heat

Barriers and Challenges: Technical barriers include the uniqueness and diversity of industrial facilities and processes (no universal solutions), and the lack of economical methods to upgrade low quality energy. Uncertain ROI, particularly when energy supply and prices are volatile, represents an economic barrier. Urban planning constraints and safety and health considerations in the location of businesses constitute societal barriers.

\section{R\&D Sequencing:}

- Near-Term: Systems analysis and modeling, heat transfer materials

- Mid-Term: Broader/scale-up deployment, explore methods for more rapid deployment, capture intra-plant benefits

- Long-Term: Deployment in multi-plant/energy parks, capture inter-plant benefits

Stakeholders: Manufacturers, zoning officials, system and control manufacturers, material manufacturers

Public/Private Sector Roles: Government: systems modeling (development of models); materials R\&D; state and local siting incentives. Industry: cost-sharing on materials research; systems implementation and materials development.

$\mathbf{R} \& \mathbf{D} /$ Implementation Strategies: Integrate community system and industry R\&D roadmaps and multiyear plans. Identify near-term critical path technologies and add technology elements to planning roadmaps. Facilitate test-case workshops with local planners and relevant manufacturing representatives. 


\section{EU2: Life-Cycle Analysis of GHG Emissions}

Description: Life-cycle analysis (LCA) of GHG mitigation opportunities are needed to identify those technologies that offer the greatest overall potential in all sectors of the economy, but especially in industry. In the absence of a comprehensive framework, investment decisions cannot be optimized. In addition, LCA tools are needed to direct the attention of end-use decision makers who may alter their consumption behavior if provided with credible information about the overall GHG impacts of their choices. This gap involves:

- Consensus-based protocols and methodologies for life-cycle assessment of energy use and attendant carbon emissions

- The development of a tool to measure impacts and inform decision making with respect to proposed implementation activities

Barriers and Challenges: There are many complex and often controversial assumptions that will need to be examined and evaluated. There are no major economic or environmental barriers to the successful development of these protocols and tools.

\section{R\&D Sequencing:}

- Near-Term: Extensive data gathering, model development, and sensitivity analysis. The short-term impact could be favorable in terms of enabling the accelerated use of low-GHG technologies.

- Mid-Term: Models need updating.

- Long-Term: Models need updating.

Stakeholders: Overseas economies; Federal, state and local governments; NGOs of all types; consumers; industry; environmental regulators; R\&D planners.

Public/Private Sector Roles: Government: data collection and model development. Industry: model and data review.

R\&D/Implementation Strategies: Identify the systems that will most benefit from better LC information for initial funding; use existing knowledge of carbon sinks and sources to set LC analysis priorities. 


\section{EU3: Advanced Aviation Technologies to Reduce GHG Emissions}

\section{Strategic Plan Section: 4.1.3: Aviation Fuel Economy}

Description: This gap focuses on the reduction of aviation emissions $\left(\mathrm{CO}_{2}, \mathrm{NO}_{\mathrm{x}}, \mathrm{HC}\right.$ and particles) from aviation sources, which have strong GHG effects because of their high altitude release. Technologies needing development include:

- Aircraft technologies (engine/combustor/air frame)

- Fuel chemistry (e.g., biobased jet fuels and jet fuel additives)

- Operational strategies (idling time on ground, air space management)

Barriers and Challenges: Understanding of atmospheric emission impacts at 40,000 ft. (i.e., air space elevations) is a technical barrier. The turnover period for aviation engines (lifetime is $>20$ years) will impede implementation of new technology. Achieving acceptable economics for low-GHG technologies in aviation systems will be a challenge.

\section{R\&D Sequencing:}

- Near-Term: Science program on aviation system emissions impacts; fuel chemistry/combustor/ control R\&D; operational strategies

- Mid-Term: Advanced combustor/airframes, alternative fuels (novel)

- Long-Term: Continual improvement

Stakeholders: FAA, EPA, NASA, DOD, DOE Aviation industry/airlines; fuel industry; airports; airport communities

Public/Private Sector Roles: NASA: fundamental research, combustion R\&D, testing and modeling, and integration. FAA: operational strategy coordination and implementation. Industry: engineering development, prototyping and commercialization.

R\&D/Implementation Strategies: Capitalizing on this opportunity would require the expansion and redirection of Federal aeronautics R\&D programs. The near-term focus would address whole-system emissions and atmospheric science of airspace emissions. A government/industry/university partnership approach would be required, and the product would be dual-use technology (civilian and military). 


\section{EU4: Materials Science for Energy Conversion}

\section{Strategic Plan Section: 4.3.3: Energy Conversion and Utilization}

Description: The digital economy is demanding more low-voltage DC power, which underscores the need for improved efficiency of AC/DC conversion. In addition, new markets are requiring long distance electricity transport which would benefit from the greater efficiencies of DC power transmission. On-site sources of PV and wind energy would be more efficiently utilized by supplying electricity to DC appliances (thus would eliminate the need for AC/DC converters). Research is needed to:

- Improve the efficiency of AC/DC energy conversion

- Decrease the cost of DC transmission

- Develop thermo-electrics devices that convert temperature differentials into electricity, made more affordable through nano-scale manufacturing

- Develop smart house and building designs that have smart wiring with a DC bus to allow both AC and DC power and end-uses

Barriers and Challenges: Advanced energy conversion devices need to move from the lab to manufacturability, including new materials that reach beyond silicon-carbide for AC/DC conversion. Thermo-electrics could be enhanced by the use of new nuclear materials (boron crystals). Industry is reluctant to retire current products before the end of their operating lives.

\section{R\&D Sequencing:}

- Near-Term: R\&D on materials moves from lab to manufacturability.

- Mid-Term: Commercial products could enter the market place within five years and achieve significant penetration by mid-century.

- Long-Term: Advanced energy conversion products would dominate the market.

Stakeholders: Electric utilities; electronics manufacturers; consumer product manufacturers; manufacturers of green power (wind, PV, fuel cells)

Public/Private Sector Roles: Government: materials science R\&D, thermo-electric conversion R\&D. Industry: Test, demonstrate, commercial applications, integration co-storage.

R\&D/Implementation Strategies: Develop a technology roadmap for electric (AC/DC), conversion (AC/DC) technologies. 


\section{EU5: Engineered Urban Designs}

Description: Land use designs are needed for urban areas that reduce vehicle miles of travel (VMT) requirements for people and goods, and co-locate activities with complementary needs for energy, water and other resources. Such designs could also create geometries that enable distributed energy, water, sewage, communications, and other infrastructures that are more secure and reliable while also reducing GHG emissions. The development of optimization algorithms to enable engineered urban designs would be enable evaluation of alternative configurations that could significantly reduce VMT and GHG emissions, such as:

- Higher density developments that can better deploy district energy systems

- Pedestrian and bicycle-friendly community design concepts

- Personal, modular vehicle systems

- Separation of truck and passenger traffic to enable safer small personal vehicles.

- Movement of freight traffic to barges and rails, with intermodal systems limited to the last leg in the transportation chain

- Performance management systems for transportation to enable more efficiency.

- Ultimate urban scale recycling - where products are all manufactured at their point-of-use

- Moving sidewalks and roads

Barriers and Challenges: Developing the modeling tools needed to produce an array of engineered urban designs would be technically challenging but doable. Policy initiatives to promote such designs would have to go beyond today's relatively weak land use planning and controls.

\section{R\&D Sequencing:}

- Near-Term: Optimization algorithms across multiples systems, considering energy, GHG emissions, economics, and equity

- Mid-Term: Sustainable community pilots based on engineered urban designs

Stakeholders: Low-mobility populations (elderly, low-income, and disabled) with needs for access to services and amenities; public health community concerned with air pollution and obesity; development/real estate stakeholders.

Public/Private Sector Roles: To be determined.

R\&D/Implementation Strategies: Policy assessment is needed at all levels of government to identify viable levers (planning, zoning, tax incentives, preferential permitting, public transit policies). Pilot communities (government facilities and surplus military bases) could be developed based on engineered urban designs. Tool development will be a key element. 


\section{EU6: Water and Energy System Optimization}

Description: Energy used by water infrastructure and water used in power plants and fuel supply systems are both emerging as important factors in public policy, planning and implementation. Numerous opportunities exist to optimize the nation's water and energy systems, including:

- Dehydration of end-use services, match the temperature and purity of the water to what is required

- Revolutionizing the design of buildings and municipal water systems to reduce use and the conveyance of water and to maximize reuse

- Energy-efficient water purification (e.g., natural systems, membranes, etc.)

- Grey-water system reuse in buildings and beyond

- Integration of clean water capture from the hydrogen fuel cells

- Integration of water storage and treatment with the intermittency of renewable power supplies

Barriers and Challenges: The social importance of water and the many stakeholders associated with water use will create a diverse set of challenges in optimization of water systems. Management of salt from desalination and the cost of water purification represent both technical and economic challenges.

\section{R\&D Sequencing:}

- Near-Term: Membrane technologies/grey water system re-use, improved distillation packing, waste heat/desalination integration

- Mid-Term: Advanced membranes, bio-X purification of water, municipal water system/building improvements

- Long-Term: Whole earth water management strategies, tidal powered - large scale desalination

Stakeholders: Bureau of Land and Mines; Southwestern and Western states; EPA; coastal communities

Public/Private Sector Roles: Government: advanced technology for purification, building design, regulation, R\&D. Industry: engineering development, prototype and commercialization; cost-shared R\&D.

R\&D/Implementation Strategies: In the near-term, an assessment should be undertaken to evaluate energy savings potential from water management (design, urban-scale distribution, and water pumping). Development of components and enabling technologies (e.g., membranes and bio-X purification) could occur during the mid-term. 


\section{EU7: Improved Control Systems for Distributed Energy}

\section{Strategic Plan Section: 4.4.3: Distributed Generation}

Description: The current electric power grid is a highly centralized system with operations, information systems and controls that have limited capability to accommodate new technologies. Improved controls and integrated systems would allow the greater dispatch of distributed energy (DE) from a broader array of sources including intermittent renewable resources. Necessary components of such a system include:

- Integrated "smart" systems to store/supply energy on demand to T\&D systems

- Learning or adaptive control systems to reduce energy demand from central systems

Barriers and Challenges: The distributed energy system is the primary technical barrier; electric control system development is a lesser technical barrier. Displacing large central power systems (if necessary) would be an economic challenge.

\section{R\&D Sequencing:}

- Near-Term: Needs significant R\&D investments

- Mid-Term: Begin technology development

Stakeholders: Public R\&D, household/commercial users, utilities

Public/Private Sector Roles: Government: public R\&D. Industry: collaborations.

R\&D/Implementation Strategies: Initial public investments will be needed in sensors, controls, and local technology development, i.e., storage systems. 


\section{EU9: Advanced Materials Development and Processing}

Strategic Plan Section: 4.1 (Transportation), 4.2 (Buildings), 4.3 (Industry), and 4.4 (Infrastructure)

Description: Advanced materials can reduce energy requirements and emissions in all sectors of the economy. Characterization of materials at the nanoscale can lead to engineered materials with improved functionality, including improved properties such as strength and corrosion resistance, and expanded functionality such as power conversion. This could lead to improved (e.g., room temperature) superconductors, low heat absorbing paints, moisture resistant materials, and thermoelectric materials for power conversion. The result could be:

- Reduction in building energy requirements

- Decreased processing loads and resource requirements (water, heat)

- Lower loss transmission and distribution grids

- High strength lightweight materials for vehicles

- Reducing the energy intensity of the economy by as much as 1 percent annually

Barriers and Challenges: Developing analytical techniques and scale-up of processes will be technical challenges. The cost of scale-up and system implementation are economic challenges. The potential environmental impacts (e.g., toxic waste streams) associated with some new materials is uncertain. Health and safety issues, e.g., understanding the long term impact of genetically modified organisms, could also be a factor. Societal acceptance of some materials (e.g., nanostructures, GMO engineered materials) could be a factor.

\section{R\&D Sequencing:}

- Near-Term: Better analytical and inspection techniques, cost-efficient high-throughput techniques for fabricating structured materials, R\&D on entirely new materials

- Mid-Term: Process design and scale-up reliability and long-term performance

- Long-Term: Large scale commercialization and continued improvements, replacement of most present-day technology

Stakeholders: Process industry, manufacturing industry, all end-users, academia, national laboratories, state and Federal commissions, local government for building codes, environmental groups, homeowners, business enterprises, industrial users.

Public/Private Sector Roles: Government: will require significant government support in early years $(<25)$ for basic R\&D, and early demonstration and scale-up. Industry: cost-shared testing and demonstration, pilot scale demonstration from R\&D to commercialization

R\&D/Implementation Strategies: An overall strategy is to develop a multi-path technology roadmap. National laboratories/academia teams could be formed for basic R\&D. National laboratories/industry teams could be formed to conduct testing, demonstration and pilot scale demonstration. A cross-energy steering committee could coordinate and expedite R\&D. 


\section{EU10: Smart Materials and Buildings}

Strategic Plan Section: 4.2.3: Intelligent Building Systems

Description: Smart buildings offer the potential to eliminate GHG emissions from the buildings sector. Components of a smart building include:

- Switchable solar reflective external opaque roof and wall surfaces

- Sheathings or membranes with dynamic moisture transport properties

- Time-of-day metering and IT tools/controls to allow consumers to make choices about how and when to best use energy in buildings

- Neural networks for predictive, anticipatory control of buildings based on wind, temperature, solar radiation and other inputs

- Harvesting fugitive energy in buildings to run low-power ubiquitous sensors with built-in communications

- Intelligent materials to inform occupants when performance is degrading (e.g., insulation is losing its R-value, furnace filter needs to be changed)

- Integration of ultra-efficient cooling, heating and power systems with lighter, smaller, cheaper heat exchangers capable of providing grid support

- Smart home designs - digital in-the-building technology - smart wiring for both AC and DC appliances

Barriers and Challenges: No major technical barriers currently exist. New materials may have environmental issues and challenges. Some technologies are more suitable for new construction than retrofit, which would constitute an economic barrier to replacement of existing building systems. Regulatory issues such as grid interconnection standards and standby and backup charges need resolution.

\section{R\&D Sequencing:}

- Near-term: Many sensors and controls exist, but some new ones are needed; systems integration is major focus; smart materials need focus, new construction could see benefits quickly

- Mid-Term: Ongoing smart material development

- Long-Term: Ongoing smart material development

Stakeholders: Homeowners, utilities, developers/builders/architects, code officials (state, local officials), building materials producers, environmental groups, sensors/controls manufacturers

Public/Private Sector Roles: Government: material development, systems simulation, regulatory/legislative incentives for $R \& D$ and implementation. Industry: cost-shared R\&D, especially for materials, integrated equipment and systems, control systems

R\&D/Implementation Strategies: Integrate R\&D with existing building technology roadmap and 5year plan. 


\section{EU11: Integrated Transport/Electricity/Building/Industry/Communities}

Description: An integrated system of transportation, power generation, residential and commercial buildings, industrial complexes, and entire communities could optimize the use of energy (and reduce GHGs) through co-location of energy sources and sinks, recovery and reuse of energy, and advanced energy monitoring and control. Elements of the integrated system could include:

- $\quad$ Plug-in hybrids (with conventional fuel, bio-fuel or $\mathrm{H}_{2}$ )

- Co-production of electricity and fuels (including hydrogen)

- Fully integrated buildings and communities using sophisticated controls to optimize resource use

Barriers and Challenges: Low-cost electricity storage will be a technical barrier, as will development of low cost sensors. Environmental challenges could arise, but will depend on the primary sources used for electricity or fuel production. Attaining urban planning consensus for integrated buildings/communities and winning consumer acceptance of efficiency technologies will be societal challenges.

\section{R\&D Sequencing:}

- Near-term: R\&D: storage, sensors, demo vehicles, market entry within 10-20 years

- Mid-Term: Commercial product, different paradigm for planning communities

- Long-Term: Fully developed commercial products

Stakeholders: Electric utilities, automakers, consumers, local governments (planning), Federal R\&D on storage and sensors

Public/Private Sector Roles: Government: storage, sensors, co-production concepts educate consumers and planners about possibilities to reduce GHG. Industry: commercial products for automobiles

R\&D/Implementation Strategies: DOE could support research to model the system and predict the potential energy savings and GHG reductions. DOE could also support material science research in energy storage.

\section{Impacts on Emissions:}

- Near-term: 2-3 yrs: takes long time for these technologies to penetrate the market

- Mid-Term: 7 years: if we do demonstrations and R\&D now, could be ready to make a significant contribution

- Long-Term: 9-10 years: could be tied into a proposed low cost electric/ $\mathrm{H}_{2}$ economy 


\section{EU 12 and ES4\&5: Economic Energy Storage}

\section{Strategic Plan Section: 4.4: Energy Storage}

Description: Large and small scale energy storage is needed to improve the efficiency, security, and reliability of the grid and to enable next-generation hybrid electric and hydrogen fuel cell vehicles. Economic, readily- reversible systems and technologies for storage of electricity or thermal energy are needed at multiple scales, including:

- Large scale for utility power systems

- Intermediate scale for distributed energy system

- Lightweight systems at vehicular scales

Potential storage methods include electrochemical systems (advanced batteries and ultracapacitors), kinetic systems (superconducting flywheels), thermal systems (phase change materials or high thermal inertia fluids) and electromagnetic systems. Electric grid and distributed energy support.

Barriers and Challenges: Technological breakthroughs will be needed for development of economic energy storage.

\section{R\&D Sequencing:}

- Near-term: Improvement on existing materials and processes, development of new materials and processes

- Mid-term: Reduction of system costs, improvement on existing materials and processes

- Long-term: Evolution to second and third generation systems

Stakeholders: Electric utilities, equipment vendors, end-users (home owners and car owners), Public Utility Commission (PUC), automotive industry, regulatory bodies.

Public/Private Sector Roles: Government: Basic and applied R\&D that leads to the definition of a credible technological pathway for low-cost, reversible energy storage. Industry: engineering development and applications.

R\&D/Implementation Strategies: Workshops should be conducted to assess the basic science needs for energy storage. An exploratory research program should be conducted on applied technology. Programs could leverage advances in ultracapacitor technology in DOD. Tax and price incentives (energy purchase) would encourage development and commercialization by the private sector. 


\section{Other New Technologies for Energy End-Use:}

Substitute technology and materials for cement, steel (coke making), limestone, and other highGHG products. This includes development of alternative materials (i.e., materials with comparable structural or other properties with manufacturing processes that do not produce GHG emissions). Alternative structural materials for steel in buildings reduce the use of concrete and could improve structural performance (resistance to seismic activity); ultra-light weight, strong materials could find application in vehicles. Technology developments could also be pursued to eliminate or reduce $\mathrm{CO}_{2}$ emissions from the processes currently used to produce steel, cement, limestone and other materials.

Computational modeling and process simulation for system optimization. Industrial process models are needed that enable system optimization through better understanding of energy use and GHG emissions from a life-cycle context. This could include the assessment of GHG reduction opportunities based on life cycle analysis.

Nanotechnology for efficient transmission of energy. The properties of nanomaterials could enable development of a more efficient energy transmission infrastructure (e.g., electricity grid). This could include, for example, low-temperature, low resistance carbon nanotubes to transmit electricity (alternatives to superconductors). Materials for transmitting heat could also be used in power plant systems to reduce waste heat and increase efficiency.

Magnetic fields for processing of industrial materials. The use of external magnetic fields can improve materials process performance and produce better quality products. Magnetic fields can provide efficient means to aid stirring, control turbulent flow and fluctuations, and eliminate solidification defects in industrial processes.

Development of catalytic and enzymatic processes in the industrial sector (including biotechnology). Enhanced fermentation or enzymatic processes can reduce energy intensity by creating more efficient processes for energy conversion. Enzyme technology for the production of antibiotics could have a large impact on the industrial sector. For example, industrial purification by monoclonal antibodies can dramatically reduce energy demand for industrial separations.

Virtual reality, holographic images to replace travel. In a substantial shift away from traditional travel, an advanced virtual reality society would dramatically reduce the need for travel. Instead of automobile, rail, or plane travel, realistic, 3-dimentional holographic images would be beamed anywhere in the world, allowing two-way interactions. That is, "real" people could interact with the beamed hologram imaged, and the hologram image could interact directly with the remote subjects.

Devise alternatives to current motors. Current mechanical motors have limited efficiency improvement potential, hampered by the laws of friction. Substitutes for mechanical motors, those that would replace the traditional spinning motor processes, could create new opportunities for substantial energy savings. Potential examples include expansion of fluids, photon power machines, crystals that produce a current with the application of an electric charge - solid state refrigeration.

Efficient self assembly with advanced robotics. Advances in robotics could bring down the costs of industrial production of numerous materials and assemblies. This could build on the auto industry's use of robotics to drive down costs and the military's effort to develop driverless transport vehicles to supply frontline troops without human risk. Robotics has the potential to produce extensive improvements energy efficiencies. 


\title{
ES1: Expanding Long-Term Fuel Resources for Nuclear Energy Through Fission Breeding and Fusion
}

\author{
Strategic Plan Section: 5.4: Nuclear Fission and 5.5: Fusion Energy
}

Description: Fission and fusion represent energy sources that could significantly reduce or eliminate the emission of greenhouse gases associated with combustion of fuels for power generation. To enhance the sustainability of nuclear fission, an effort should be undertaken to evaluate and develop unconventional sources of uranium supply and to develop better information on worldwide uranium resources and methods for their extraction (including lean ores, enrichment plant tails, and seawater uranium). Research is also needed to improve the efficiency of uranium fuel supply technologies (extraction, conversion, enrichment, fuel fabrication). Longer-term research objectives should include the development of economic plutonium and possibly thorium breeder reactors and spent fuel reprocessing. Eventually, the start-up of pioneer fusion energy plants would benefit from tritium supplies produced in fission reactors. Thus, fission/fusion crossbreeding of fuels (plutonium, tritium) should also be researched.

Barriers and Challenges: Waste disposition and proliferation sensitivities are technical and societal barriers. The need for large-scale demonstration facilities make fission and fusion development programs expensive. Public perception and acceptance of nuclear technologies represents a societal challenge. Development of high-temperature radiation-resistant materials with highly-assured mechanical properties is a significant technical challenge.

\section{R\&D Sequencing:}

- Near-term: Materials R\&D (fusion and fission), advanced gas centrifuges and stripping of enrichment plant tails (some at 0.35 and 0.4 percent U-235), breeding technology demonstration, fuel reprocessing demonstration

- Mid-term: Seawater extraction, advanced extraction methods from lean U ores, second generation breeder, Li test blankets

- Long-term: Continued evolutionary advances after commercialization

Stakeholders: Power companies, fuel vendors, enrichment services vendors, DOE/RW, electricity consumers, international consortia

Public/Private Sector Roles: DOE, National Laboratories: technology development; prototype demonstration. Industry: joint R\&D participation, acceptance for commercialization after demonstration.

$\mathbf{R} \& \mathbf{D} /$ Implementation Strategies: DOE/NE technology roadmaps are needed to guide RD\&D, a DOE/SC (fusion) technology roadmap is also needed, and International cooperation should be sought. 


\section{ES3\& 7: Integration of Plug-in Hybrid Electric Vehicles with Solar, Zero Energy Buildings and}

Utility Peak-Shaving

Strategic Plan Section: 4.1: Transportation, 4.2: Buildings, and 4.4: Infrastructure

Description: Wide-scale adoption of plug-in hybrid electric vehicles would dramatically reduce $\mathrm{CO}_{2}$ emissions (up to four times) from automotive vehicles and is assumed to involve the night-time charging of vehicular batteries. Solar and wind power systems are intermittent and inconstant energy sources and as such are ideally suited for charging batteries for plug-in electric hybrids. The approach is to integrate solar and /or wind electricity production (and consider thermoelectric-based electricity production from waste heat) in a near-zero energy building (ZEB) with battery charging capability for plug-in hybrid electric vehicles. The distributed system of plug-in hybrid electric batteries could provide electric power reserve for the grid - regulation reserve, operating reserve and planning reserve.

Barriers and Challenges: The high cost of photovoltaics (PV) and other renewable energy technology is a barrier to deployment. There is also industrial stakeholder resistance to shifting transportation fuel revenues from the oil/gas industry to the electric power industry. Implementation of this technology concept will require integrated planning and product integration across multiple sectors (buildings, electric power distribution, automotive). A societal and economic challenge is charge-back and value distribution of the energy resource to end-users.

\section{R\&D Sequencing:}

- Near-term: PV cost reduction, Zero Energy Building redesign to reflect range of battery charging requirements, R\&D on high discharge, low cost battery systems, monitoring and control technology for electric power T\&D grid system, prototype demonstrations and commercialization

Stakeholders: Automotive industry; building industry; utilities (state, local government and regulators); oil/gas industry

Public/Private Sector Roles: Government: R\&D and prototyping that is cost shared with industry; development of cross-industry, cross-disciplinary teams; development of standards and codes; information development for regulators; overall advocacy of concept as meeting Federal objectives for climate change and incentives for change-overs. Industry: cost-shared R\&D. 
ES6: Solar Fuels (artificial photosynthesis)

Strategic Plan Section: 5.4: Renewable Energy and Fuels

Description: The objective is development of artificial photosynthetic systems that operate at higher rates and efficiencies than natural photosynthetic processes in plants. Such systems might either be photo-biologically-based or electro-photo chemistry-based and would consume $\mathrm{CO}_{2}$ and water from the atmosphere and produce $\mathrm{H}_{2}, \mathrm{O}_{2}$, and (very) small photosynthetic electric currents.

An alternative or supplementary technology might involve the solar-powered photo-catalyzed production of liquid transportation fuels from $\mathrm{H}_{2}$ and $\mathrm{CO}_{2}$ Notionally, the $\mathrm{CO}_{2}$ might be present in the atmosphere or introduced as a pure gas stream from carbon capture steps at other power plants, and the $\mathrm{H}_{2}$ would be biologically produced or produced from another carbon-free source.

Barriers and Challenges: Solar fuels will require several breakthroughs in fundamental and engineering science and an overall cost reduction in the technology. This is a high-risk R\&D objective.

\section{R\&D Sequencing:}

- Near-term: Searching for major breakthroughs

- Mid-term: Systems testing, prototype, scale-up

- Long-term: Large scale, penetration

Public/Private Sector Roles: Government: R\&D funding for basic biological and chemical sciences, and for lab-scale technology development. Industry: public/private partnership for larger scale development; eventual commercialization.

R\&D/Implementation Strategies: Federal government could provide support for ideas and evaluation (seed money) and exploratory research. 


\section{EU8 and Terr2: Optimized Biomass Production for Alternative Fuels, Materials, and Chemicals}

Strategic Plan Section: 5.3.3: Energy Crops and 7.2.1: Advanced Agricultural Systems for Nitrous Oxide Emissions Reductions

Description: Biomass could be used as an alternative to petroleum and natural gas for the production of fuels, materials and chemicals. Biomass is a carbon sink, and thus theoretically could provide a net-zero GHG energy resource. Optimization technologies could raise estimates of a 10 percent displacement of fossil fuels (based on current assessment of feedstock availability) to a 25 percent displacement of fossil fuels. Technology elements for biomass utilization include:

- Biotechnology/nanotechnology applications to ligno-cellulose feedstocks to enable large scale production of bio-fuels, bio-energy and bio-products

- Bio-engineering to increase yield and productivity, sustainable high yield land use

- Plantations optimized for production of co-products (e.g., fuels, fiber, chemicals) from a single feedstock

- Land management for efficient harvest and minimal transport, fast growth feedstocks

- On farm production improvement, crop breeding processing technology improvement, hauling and handling systems design

- Advances in conversion of biofeedstocks and liquid conversion of bio-fuels

Barriers and Challenges: Technical challenges are genetic mapping/sequencing of current species; nano-scale cell wall analysis; liquid fuel conversion efficiency, year-round supply dependability; synthesis gas clean up; soil sustainability; and ethanol transport. The long term impact of genetically modified organisms is unknown. The cost of large-scale demonstrations across multiple plant species is an economic barrier. Credits for GHG savings could be an incentive. Public acceptance of genetically engineered organisms is a societal issue.

\section{R\&D Sequencing:}

- Near-term: Cost-effective facilities, ethanol production efficiency gains, yield enhancement and quality, plant construction, sustainable production and storage methods

- Mid-term: Yield and quality, possible hydrogen source, combine with CCS

- Long-term: Should approach maturity

Stakeholders: Owners of forests and agricultural lands; forest products, industry and agriculture; small/large energy producers; U.S. Departments of Energy and Agriculture; EPA; Department of Transportation; DoD and NASA; State energy and agricultural organizations; state/regional economic development; environmental groups; automotive manufacturers.

Public/Private Sector Roles: Government: fund R\&D, cost-share demonstrations; regulatory and fiscal incentives for R\&D and bio-fuel use; investigate sustainability (soil, water, etc) and siting for rural development. Industry: cost-shared research, demonstration and pilots.

R\&D/Implementation Strategies: Formation of electricity and ethanol consortia, develop technology roadmap. 


\section{Other New Technologies for Energy Supply:}

Advanced solid state thermoelectrics. This technology could convert mid-grade and low-grade heat to electricity at economically attractive efficiencies. It could be applied to multiple applications for improving the overall efficiency of any process involving significant amounts of heat, including combustion and fission-based power generation, transportation vehicles, industrial processes, and conversion of solar heat.

Low-loss heat transmission. Advanced low-loss heat transmission over 10-meter length scales via directionally conductive or convective media could dramatically reduce energy losses. An example technology might involve thermal wires that move heat in one direction without dispersing heat in the other directions. The low-loss heat transmission technology would capture and move heat to improve efficiencies over longer length scales that would enable efficient district power and heating concepts.

Wave energy and tidal dams. Tidal dams based on using a barrage at a bay or estuary with a large tidal range could be used to generate power. Power is generated primarily at ebb tides as the barrage creates a significant head of water, much like a hydroelectric dam. Wave energy can be used for slow motion turbine generation of electricity. The changing elevations of man-made floating islands bobbing up and down from wave energy can also generate power.

Next-generation nuclear reactors. Next generation nuclear plants are needed for high-temperature heat for hydrogen and chemical production. Development of advanced fusion and fission reactors include: breeding concepts (fast breeders); thorium nuclear fuel cycles such as those pursued in India; dry cycle nuclear plants; converting heat of nuclear reaction (fission/fusion) directly to electricity (instead of heat); bubble fusion for power generation (alternative approaches to fusion); and small-scale plug and play nuclear reactors.

Link nuclear and fossil energy. Integrate nuclear technology with fossil energy to create new systems (nuclear - coal hybrid, liquefaction plus nuclear heat). Marrying the most efficient systems in nuclear power facilities with fossil energy may create a safe hybrid system that generates far fewer emissions and much less radioactive waste.

Long-term nuclear computations. Advances in computational science could be used to simulate and predict performance and behavior of nuclear fission and fusion systems and enable improved designs (chemistry, materials, thermal behavior). An example would be creating integrated models of reactor and fuel performance with coupled physics and high-fidelity computations.

Nano-engineered materials for fission and fusion. Develop nano-engineered materials suitable for application in fission and fusion systems. Radiation-resistant materials are needed for both fission and fusion, and nano-engineered materials appear to be a promising direction for research. Nanoscience by definition involves the study of particles approaching atomic-order dimensions, which, when applied to quantum-based fission and fusion systems, may produce breakthrough improvements.

Inertial fusion energy. This technology involves an advanced fusion concept during which the fusion fuel - deuterium and tritium - are compressed spherically to very high density and driven with sufficient energy to ignite and burn the fuel. The major challenge is to ignite a small mass of fusion fuel with a minimal amount of energy from a laser or accelerator, while maximizing the ratio of driver energy input to fusion energy output. 
Superconducting magnets for magnetic fusion. Nanotechnology could be applied to the development of highly conducting superconductors that maintain their functionality in the presence of high-magnetic fields. This would have the benefit of decreasing power consumption in magnetic fusion system designs.

High altitude wind power. Wind power scales linearly with the air density but as the cube of the wind velocity; thus, the jet stream represents a continuous source of very high energy density wind.

Notionally, this concept involves a tethered power turbine system emplaced in the jet stream like a high altitude wind kite. The tether also serves as a transmission line for the generated electricity. Location of tethered high altitude wind power systems around Antarctica would allow use of the steady, high winds at the pole and might pose minimal disruptions to air traffic patterns.

Liquid photovoltaics. This technology involves nanostructured liquid gel and highly homogeneous, solid PV substrates that directly convert sunlight into usable energy. Liquid crystalline materials can be formed into thin films with structures optimized for use in photodiodes through simple solution-processing steps and may enable inexpensive, high-performance, thin-film photovoltaic technology.

Small-scale waste digesters. This technology involves anaerobic digestion, typically of agricultural, food residues, or animal waste, for direct combustion in cooking applications or for electricity generation. If digesters are located close to the point of use, it eliminates methane and offsets energy production by the grid. Waste digesters can be especially valuable when integrated with large farming operations where there is excess animal manure or farm waste, while advancements in smaller scale waste digesters could enable use at typical non-farm households.

Power beaming. Wireless transmission of power could enable novel terrestrial systems as well as geosynchronous orbital satellites with solar reflectors for collecting and concentrating power. The concept of wireless transmission of electrical energy - or power beaming - has been discussed for decades, proposed primarily for space-based solar farms to supply energy to Earth or the surface of another world, or for wireless power on Earth. The two technologies that appeared suitable for power beaming involved microwave or laser energy. The nature of the microwave beam causes it to spread out with distance, with a commensurate decrease in the power delivered to the target. Until recently, laser technology had not advanced to the state where such applications could be possible. A key breakthrough to the potential success of power beaming is use of a new system of clustered tunable lasers.

Microbial carbon dioxide sequestration. Sequestered $\mathrm{CO}_{2}$ by microbial processes could produce high value carbon-based products underground, using pressure and temperature differentials, which could be reused as fuel in the future. Essentially, the cycle of plants to fossils to fuels to $\mathrm{CO}_{2}$ would be a closed loop, using microbial processes to convert the $\mathrm{CO}_{2}$ back to fossil fuel-like materials for re-combustion.

Personal power. This technology involves miniaturized space comfort systems that keep the space around us comfortable. These systems could be wearable and applied in particular to office buildings. Such a technology avoids heating of lightly-occupied high volume buildings for the purpose of providing comfort to individuals.

Methane hydrates. Natural gas as a transition fuel from coal to zero-emission electricity and transportation fuels could be greatly facilitated by the mining of methane hydrates. Gas hydrate is a crystalline solid consisting of gas molecules, usually methane, each surrounded by a cage of water molecules. They occur abundantly in nature, both in Arctic regions and in marine sediments. Extraction of methane from hydrates could provide an enormous low-carbon energy and petroleum feedstock resource. However, the natural controls on hydrates require further research, and environmentally safe methods for extracting the methane need to be developed and demonstrated. 


\section{CCS1: Quantify and Mitigate Effects of $\mathrm{CO}_{2}$ On Marine Ecosystems:}

\section{Strategic Plan Section: 6.4: Ocean Sequestration}

Description: Research is needed to quantify and understand the effects of $\mathrm{CO}_{2}$ on individual marine ecosystems as functions of concentration and duration of $\mathrm{CO}_{2}$ in different oceanic environments (shallow, deep). Need to develop an ocean acidification metric, an understanding of kinetics in sea water, and clever ways to predict ocean residence time for $\mathrm{CO}_{2}$. Technical elements include:

- Mitigation

- Dilution

- Isolation

- Buffering (alkalinity addition)

Barriers and Challenges: It is difficult to perform long-term ecosystem effects and to assess these effects. For example, how important is the loss of a few million bacteria? Public acceptance in view of uncertainty of environmental impacts to marine systems (detected and isolated) is questionable. The high cost and material handling issues of alkalinity addition are a challenge.

\section{R\&D Sequencing:}

- Near-term: Observation of ongoing ocean changes (BAU), evaluate Mesocosym and larger scale ocean $\mathrm{CO}_{2}$ exposure environments

- Mid-term: Continue evaluation of Mesocosym and larger scale ocean $\mathrm{CO}_{2}$ exposure environments

- Long-term: New isolation techniques (e.g., plastic bags), under location transport processor at $1000 \mathrm{~m}$ to $100 \mathrm{kM}$ space scale, modest scale alkalinity demonstrations

Stakeholders: All inhabitants of the earth

Public/Private Sector Roles: Must be undertaken by the government, risk is too high for the private sector.

R\&D/Implementation Strategies: To be determined. 


\section{CCS2: Develop $\mathrm{CO}_{2}$ Transport Infrastructure}

Strategic Plan Section: 6.1: Carbon Capture

Description: The objective is to develop a $\mathrm{CO}_{2}$ transport infrastructure (pipelines, ships, etc.) with low losses and low probability of accidents that could potentially affect public safety.

Barriers and Challenges: Experience with existing $\mathrm{CO}_{2}$ pipelines indicates a low technical challenge, low economic costs for pipeline installation, and low environmental impact. The societal challenge is "the" issue. Permitting for $\mathrm{CO}_{2}$ pipeline installation will be a long-term challenge. There are parallels to natural gas siting approval. Transport systems must pass DOT regulations for safety. Education of the public may be an issue. Policy requirements could include carbon pricing and regulatory changes.

\section{R\&D Sequencing:}

- Near-term: R\&D on leak detection and warning, early warning of digging near pipeline

- Mid-term: R\&D on preventing major pipeline failure

- Long-term: Linkages to a national $\mathrm{CO}_{2}$ pipeline infrastructure, improved ways to control pipeline failures

Stakeholders: Utilities, pipeline operators, regulators, community groups

Public/Private Sector Roles: Government: DOE, DOT. Industry: pipeline operators

R\&D/Implementation Strategies: Activities could be coordinated with regional carbon sequestration partnerships. 


\section{CCS3: Risk Management for Geologic Storage}

Strategic Plan Section: 6.2: Geologic Storage

Description: The goal is understand the key elements for effective risk management of geologic storage. Technical objectives would be to characterize all available storage formations in terms of size and location; characterize leakage rates from available storage as a bases for risk management/regulation; and conduct large scale, near-term testing of representative formations $\left(>10^{6} \mathrm{MT}\right)$.

Barriers and Challenges: A key challenge is managing sequestration/transport risk over a long time period during which substantial learning occurs. The risk associated with the activities above is relatively low. The negative impact of not conducting these activities is very high from a policy perspective, although the near-term value of information as a technical matter is not necessarily large.

\section{R\&D Sequencing:}

- Near-term: Not available

- Mid-term: Not available

- Long-term: Not available

Stakeholders: Regulators (both EPA and PACs), industry, general public

Public/Private Sector Roles: Government: not available. Industry: not available.

R\&D/Implementation Strategies: Engage regulators (both EPA and PACs), industry, and public in evolution of the above process. Regional partnerships could also be a vehicle. 


\section{CCS4: Underground In-Situ Processing of Hydrocarbons}

\section{Strategic Plan Section: 6.2: Geologic Storage}

Description: Underground in-situ liquefaction and gasification of solid hydrocarbon deposits such as oil shale and coal would greatly reduce the GHG emissions from refining operations that are currently released to the atmosphere. This technology introduces in-situ heat, either from combustion or noncombustion sources, to liquefy, gasify and/or partially reform the deposits and recover fluids and gases via extraction wells.

About 60 percent of refining (liquefaction and gasification of hydrocarbon deposits, and reformation/refining) occurs in-situ. Natural gas and partially reformed liquid fuel products are transported to the surface via injected gases/fluids. Industry is planning an in-situ refining project to mine oil shale in which the deep geologic formations will be brought to elevated temperatures for multiple years using electrical heating systems.

Barriers and Challenges: Commercial development will have some technical risk. Other technical challenges are associated with heater technology (lifetimes) and sealing off aquifers from the affected site. Environmental effects have not yet been completely analyzed and this will be a challenge. Need to better understand $\mathrm{CO}_{2}$ movement in hydrocarbon-bearing formations. Societal challenges will be public acceptability of heating underground formations. High power requirements could represent a resource challenge.

\section{R\&D Sequencing:}

- Near-term: Development of heater and immobilizations, demonstration/Production by 2015

- Mid-term: Large scale deployment, R\&D to improve energy efficiency, mitigate environmental

- Long-term: Uncertain

Stakeholders: Oil and gas companies, coal companies, transmission grid, utilities (new power plants), environmental NGOs

Public/Private Sector Roles: Government: enabling technologies and environmental research by public sector. Industry: provides large majority of funding.

$\mathbf{R} \& \mathbf{D} /$ Implementation Strategies: There is a need to prepare environmental assessments with GHG mission impacts. Also, an assessment of the application of the technology to non-oil shale deposits such as deep coal deposits is needed. 


\section{CCS6: Exploratory Research into New Approaches for $\mathrm{CO}_{2}$ Capture}

\section{Strategic Plan Section: 6.1: Carbon Capture}

Description: Innovative technologies could employ new techniques for separation of $\mathrm{CO}_{2}$ at point sources or within the atmosphere. Examples include ionizing $\mathrm{CO}_{2}$ to enable separation via electric fields, utilizing new technology to facilitate separation, new materials that respond to small stimuli, and direct $\mathrm{CO}_{2}$ capture from the atmosphere. These technologies could replace existing approaches that rely on chemical absorbents, which are very energy intensive. The desired performance capabilities include high $\mathrm{CO}_{2}$ selectivity, high recovery rates, and low energy consumption. Materials for $\mathrm{CO}_{2}$ storage now require lots of stimuli; new materials are needed that require less stimuli. Nanotechnology to recognize the $\mathrm{CO}_{2}$ molecule will facilitate separation and capture of $\mathrm{CO}_{2}$.

Barriers and Challenges: Identifying (and/or developing) the right materials will be a technical challenge. Cost-effectively scaling-up from lab to field could be a challenge.

\section{R\&D Sequencing:}

- Near-term: Currently immature technologies, feasibility assessment to identify best candidates, and development of basic materials and their adaptation to the problem

- Mid-term: Can retrofit existing infrastructure, scale-up to commercial size, and wide-scale implementation

- Long-term: Could be industry standard

Stakeholders: Electric utilities: primary market is electric power plants and other energy intensive industries, also all electricity users.

Public/Private Sector Roles: Government: set-up program to identify best approaches and materials -fund academic/basic research. Industry: take ideas from laboratory to the field, fund pilots and scale-up.

R\&D/Implementation Strategies: A first step is to set performance goals and milestones (see capabilities, e.g., energy consumption targets). One approach is to develop roadmaps for different technology areas, e.g., nano-technology. 


\section{CCS7: Advanced Geologic Storage Technology and Storage Engineering}

\section{Strategic Plan Section: 6.2: Geologic Storage}

Description: Innovations in storage engineering, monitoring technology and materials will significantly improve the reliability and acceptance of geological storage of carbon dioxide. Storage engineering could maximize poor volume utilizations and accelerate capillary, solubility and mineral trapping from thousands of years to timescales of hundreds of years. Permanent geophysical arrays could provide realtime, low-cost and high resolution data to continuously track the movement of $\mathrm{CO}_{2}$ in the subsurface, thus providing early warning of problems and the ability to optimize storage operations. New materials and approaches to sealing wells after they are not needed would ensure that the wells do not leak, thus eliminating the largest source of risk and increasing public confidence.

Barriers and Challenges: The large scale of at which this technology is deployed will challenge our ability to characterize and monitor storage sites. The costs of capture may limit economical deployment of $\mathrm{CO}_{2}$ storage. Societal challenges include public concerns for local health and safety, which may make the siting of storage projects difficult. Advanced sequestration technologies could help to allay these concerns.

\section{R\&D Sequencing:}

- Near-term: Build confidence in prospects for storage reliability including: development of storage engineering strategies, development and deployment of monitoring array, and development of new well construction/closure methods.

- Mid-term: Geologic storage becomes a real option for storing power plant emissions with testing and enhancement of storage engineering strategies, enhancement of monitoring performance and degree of quantification, and building performance track record for wells.

- Long-term: Method of choice for fossil fuel point sources emission options for $\mathrm{H}_{2}$ transportation; full-scale and routine deployment for coal-fired systems being explored (power plants); expansion to $\mathrm{H}_{2}$-based transportation systems under consideration, or underway.

Stakeholders: Utility companies: generation, transmission. Regulatory agencies: EPA, state groundwater quality overseers, oil and gas regulators. Public utility commissions, public near storage facilities. Public: rate payers.

Public/Private Sector Roles: Government: capability building, new concepts, tools, pilot tests. Industry: deployment, demonstration projects, commercialization of new technology, and cost-shared pilot tests.

R\&D/Implementation Strategies: $R \& D$ should build on the NETL carbon sequestration roadmap, and bridge to the Office of Science for fundamental geosciences research. One approach is to combine singleinvestigator and directed team-based research programs. International cooperation should be obtained for pilot and demonstration tests. 


\section{Terr1: Systems Approach across Sectors and Gases}

Strategic Plan Section: $7.0,6.0$

Description: Apply a systems approach across sectors and gases to synergize technologies (e.g., biofuels or other synergistic GHG efficiencies, general agriculture, bio-fuels carbon sequestration and nitrogen reduction). The goal is to optimize what knowledge and technology we have, and determine via a systems approach how technologies can be configured to work together.

Barriers and Challenges: The development (technical) risk is low, with a high potential for success. The deployment (market) risk is high. Resource requirements are low; this is not a high cost activity. Technical challenges will be developing a cost-effective balance sheet (accounting) and an integrated systems economic model. Integration will actually reduce economic and societal barriers to terrestrial sequestration.

\section{R\&D Sequencing:}

- Near-term: Not enough is known with existing technology. Development/Demonstration of Accounting practices

- Mid-term: Increases in value as options increase, continued testing, implementation, and continued refinement

- Long-term: Greatest benefit occurs in long-term; implementation and continued refinement

Stakeholders: Agricultural industries, rural electrical cooperatives, USDA, DOE, PA, rural communities/economy, business and home owners

Public/Private Sector Roles: Government: near term subsidies; near term protocol for standardization; mid subsidies - declining and eventually not needed. Industry: cost share research/pilot projects.

R\&D/Implementation Strategies: Universities/Government agencies should develop standards for measurement and monitoring protocols. 


\section{Terr6: Avoiding Deforestation}

\section{Strategic Plan Section: 7.2}

Description: Avoiding deforestation (maintaining stocks) could have a significant impact on GHG emissions. Elements include:

- Creating sustainable agricultural, forest, and infrastructure systems in developing countries

- Creating mechanisms to internationalize environmental goods and services

- Increasing productivity from existing systems and developing alternatives to existing land management practices

Barriers and Challenges: National development policies and sovereignty issues could be a barrier, along with the underlying economic drivers for deforestation. Education, outreach, and extension services could be key to reducing societal and economic barriers.

\section{R\&D Sequencing:}

- Near-term: Geographically complex observation; education/outreach, internationalizing

- Mid-term: Becomes easier with economic development and raised expectations from developing countries

- Long-term: Transition from unsustainable practices to practices to rebuild and stock

Stakeholders: Other governments, local people, NGOs, industry, market sectors, development bankers

Public/Private Sector Roles: Government: engage other governments, certification of good practices. Industry: provide incentives, maintain good practices/standards.

R\&D/Implementation Strategies: Strategies are to improve quantification of current losses, improve observations systems, and conduct C/B analysis of options. Creating regional/bilateral mechanisms for cooperation could facilitate progress. 


\section{Other New Technologies for Carbon Capture and Sequestration (CCS):}

Distributed hydrogen production integrated with $\mathrm{CO}_{2}$ capture. This technology focuses on utilizing a distributed infrastructure to produce hydrogen in a hydrogen economy. Cost-effective materials and ways to capture $\mathrm{CO}_{2}$ from small-scale systems, including mobile sources, are essential for this system.

Integrated modeling framework to evaluate CCS technology. An integrated modeling framework would enable comparison of the benefits and disadvantages and viability of various carbon capture strategies. In the long term, this could help to reduce the cost of carbon capture by identifying the best approaches.

Oxyfuel power plant with $\mathrm{CO}_{2}$ capture. An oxyfuel plant is a fossil-fuel based power plant configured such that the oxygen is separated from the ambient air prior to combustion. This results in an exit stream of $\mathrm{CO}_{2}$-rich flue gas, some of which is recycled back to the boiler to control combustion temperatures, and the remaining sent to $\mathrm{CO}_{2}$ capture systems. Oxyfuel plants enable more efficient $\mathrm{CO}_{2}$ separation than conventional power plants since the flue gas concentration of $\mathrm{CO}_{2}$ is much higher. Eventually, it is envisioned that $\mathrm{CO}_{2}$ separation would be unnecessary with oxyfuel plants, simply transport the $\mathrm{CO}_{2}$-rich stream along with small amounts of other pollutants directly to underground storage. Challenges include transport pipelines, sulfur management, high-temperature materials, and low-cost air separation units.

Large scale demonstration of $\mathbf{C O}_{2}$ storage. Verifiable proof may be needed to establish the viability of large scale geologic storage over a long-term time horizon. Long-term stabilization studies should be conducted in parallel to expedite the verification process.

Vegetation in urban settings. This encompasses the use of uniquely-designed landscaping to aid in the sequestration of carbon, effectively utilizing plants as carbon sinks. Vegetation can also mitigate heat island effects in dense urban areas.

Ocean injection. Injection of $\mathrm{CO}_{2}$ into the ocean could be very important as a complement to geological sequestration. One approach is to react flue gas with a $\mathrm{CaCO}_{3}$ solution to enable direct ocean injection. Another approach is shallow-water injection of $\mathrm{CO}_{2}$ in areas to combat land subsidence, and space, land management of $\mathrm{CO}_{2}$ sequestration (controlled sea-level rise).

Calcium forests. Calcium plays an essential role in regulating processes that influence both forest growth and responses to environmental stresses. Calcium forests would increase release to the ocean (analogous to the earth's natural response to carbon, which is formation of carbonates in the ocean).

Hydrocarbon reservoirs. Combining $\mathrm{CO}_{2}$ storage with hydrocarbon reservoirs could create fuel/energy layers over time. Hydorcarbon reservoirs may enable geologic CO2 storage to truly be temporary, allowing extraction of $\mathrm{CO}_{2}$ in the future once converted to fuels. One possible method of achieving this could be by integrating with Bio-x. 


\section{OG1: Self-Repairing, Leak-free Gas Pipelines and LNG Conversion Systems}

\section{Strategic Plan Section: 7.1.3: Natural Gas and Petroleum Systems}

Description: Pipelines carrying natural gas as well as facilities where natural gas is liquefied are a source of fugitive emissions of methane, a gas with high global warming potential. Advances in materials, seals and valve technology could eliminate or reduce these emissions at the source. Technology components include:

- Smart materials that detect and seal leaks thereby eliminating fugitive gases. Leak activated, self-sealing systems might use a marker gas that is blended with the methane to detect a leak and activate a sealing process.

- Perfect seals and leak-less valves throughout gas compression systems and especially for liquefied natural gas (LNG) facilities that are anticipated to grow in number as the demand for imported gas rises.

Barriers and Challenges: Technical challenges could be significant, especially to produce a low-cost system that provides a reasonable payback in terms of recovered or saved methane. Financial incentives are needed, especially to capture large opportunities worldwide (e.g., Russia).

\section{R\&D Sequencing:}

- Near-Term: Incremental improvements in seals and valves

- Mid-Term: Self-sensing and healing features should be proven and cost-effective; deployment of new products in developed world

- Long-Term: Widespread deployment worldwide as new pipelines and LNG systems are built

Stakeholders: Gas distribution companies; foreign exporters of LNG (Algeria, Azerbaijan).

Public/Private Sector Roles: Legitimate role for government for public funded R\&D since the technical risks are significant; close collaboration with industry is needed.

R\&D/Implementation Strategies: Potential approaches include evaluation of alternative marker gases and self-healing approaches, and systems analysis of leakage in LNG facilities. 


\section{OG3: Integrated Systems Approach to Waste Management}

\section{Strategic Plan Section: 7.1.1: Landfills}

Description: Landfills are a source of methane emissions and also represent a significant land use issue for state and local governments as land availability grows increasingly scarce. An integrated systems approach for waste management could reduce the magnitude of landfill waste and ultimately eliminate new landfill waste by:

- Designing products to tag and identify them for recycling

- Distributed waste processing: on-site conversion (e.g., home, industrial) of waste to hydrogen, other fuels, or electricity

- Sorting the entire waste stream into processing categories (recyclables, organics, inerts/toxics, etc.) for more complete recycling

- Using engineered bacteria that breakdown and process waste without producing methane. One approach would be to reduce $\mathrm{CH}_{4}$ into hydrogen and carbon that is sequestered in the soil.

Potential technology options include sort weight recognition technology; tagging and tracking technology; small-scale waste conversion to fuels, power, and products; and genetically engineered bacteria.

Shifting the manufacture of products closer to the point of use would also assist in closing the loop between waste and input streams.

Barriers and Challenges: Development of effective sort weight recognition technology will be a technical challenge. Pre-treatment techniques are needed to effectively convert landfill gas of varying composition, since fuel properties such as ignitability, combustion phasing, and stability effect the combustion process. Energy platforms operating on opportunity fuels are potentially at-risk for heightened deposition, erosion, and corrosion caused by fuel contaminants, combustion byproducts, and significant changes in heat flux. Mitigation of these effects can involve materials substitution, protection schemes, or changes in component or system design - all options that require an understanding of materials degradation mechanisms. Sizing and siting of the facility could create societal challenges.

\section{R\&D Sequencing:}

- Near-term: Develop separation and sorting technology, develop bio-engineering organisms to break down materials

- Mid-Term: Demonstration

Stakeholders: Waste management industries; state, local, city governments; the general public.

Public/Private Sector Roles: Federal government/National Laboratories: conduct basic research and design. Industry role: cost-shared research and demonstration.

R\&D/Implementation Strategies: Develop Technology Roadmap to guide research, development and demonstration. 


\section{OG4: Eliminating HFCs in Refrigeration and Air Conditioning}

Strategic Plan Section: 7.3.1: Substitutes for Ozone Depleting Substances

Description: Hydrofluorocarbons (HFCs) are compounds containing carbon, hydrogen, and fluorine. Although they do not destroy stratospheric ozone, they are powerful greenhouse gases. HFCs are used in many applications, such as solvents, domestic and commercial refrigerants, firefighting agents, propellants for pharmaceutical and industrial aerosols, foam-blowing agents, and in blends for air conditioning refrigerants. Emissions of HFCs are steadily rising as they are being phased in to replace chlorofluorocarbons (CFCs), halons and other ozone-depleting chemicals under the Montreal Protocol. While HFCs are emitted in small quantities, they have a disproportionately high global warming potential (GWP). Approaches to reducing emissions of HFCs include:

- Replacement of current HFCs with alternate non-GWP gases

- Solid state refrigeration and air conditioning

Solid state refrigeration could reduce refrigerator size by 25 percent by eliminating the compressor and pipes. It uses electricity to create a small temperature differential that moves heat out of the cabinet.

Barriers and Challenges: Challenges include the cost of new infrastructure and the reliability and performance of new materials. There are few societal issues other than cost inflation, since alternative refrigeration technologies should be largely transparent to consumers.

\section{R\&D Sequencing:}

- $\quad$ Near-, mid-, and long-term: Materials testing, demonstration, and deployment based on retirement of the current infrastructure

Stakeholders: Industry (manufacturers); commercial and residential users.

Public/Private Sector Roles: Federal government: screening alternative lower-GWP chemicals and fundamental materials research to evaluate compatibility issues (corrosion, degradation of components). Industry: cost-shared R\&D.

R\&D/Implementation Strategies: Policy drivers will need to be in place to move this forward. 


\section{OG5: Alternative Chemicals for Chemical Vapor Deposition and Plasma Etching}

\section{Strategic Plan Section: 7.3.2: Industrial Use of High GWP Gases}

Description: Sulfur hexafluoride $\left(\mathrm{SF}_{6}\right)$ and perfluorocarbons (PFCs) such as perfluoroethane and perfluoropropane (C2F6, C3F8) are high global warming potential (GWP) gases used in chemical vapor deposition (CVD), cleaning and plasma etching processes for numerous electronics applications (e.g., semiconductors, photovoltaics, LCDs). PFCs and $\mathrm{SF}_{6}$ have particularly high GWPs because of their stability, strong infrared absorption in the atmosphere, and long atmospheric lifetimes. $\mathrm{SF}_{6}$ is the most potent of these greenhouse gases.

The use of pure fluorine (direct $\mathrm{F}_{2}$ generation) could displace the use of $\mathrm{SF}_{6}$ and PFCs in many applications. An alternative process would involve the use of a new on-site chemical generation system for $\mathrm{F}_{2}$ in conjunction with a hydrocarbon (HC) for etching. Plasma etching could use direct fluorine compounds that also provide the $\mathrm{HC}$, instead of $\mathrm{PFC}$ and $\mathrm{SF}_{6}$.

Photovoltaics use a CVD process for etching that currently consumes PFC gases to clean the CVD chamber. One option is to bring fluorine on site for cleaning electronics (applicable to PVs, semiconductors, and LCDs).

Barriers and Challenges: Safety Challenge: Fluorine is the most reactive of all chemical elements and fluorine gas is known to react with nearly all organic and inorganic materials. Fluorine gas will react with water vapor in the air to form gaseous hydrofluoric acid, a highly toxic and corrosive compound. Thus, designing highly reliable systems to contain fluorine will be a challenge. Economic Challenge: The substitution of fluorine for PFCs and SF6 will be limited by the fact that there is no engineering performance nor cost issue with the current process/materials, and that there are currently no regulatory drivers to reduce use of $\mathrm{SF}_{6}$ or PFCs (no incentive to change).

\section{R\&D Sequencing:}

- Near-term: Development and demonstration of materials and safety technologies, demonstration projects to accelerate understanding and adoption of F2.

Stakeholders: Electronics manufacturers, material and equipment suppliers, local communities and employees (exposure risk).

Public/Private Sector Roles: Government: subsidize/sponsor demonstration projects Industry: International Sematech, WXLO Semiconductor Council (WSC), cost sharing/hosting demonstrations.

R\&D/Implementation Strategy: Government could serve as coordinator of R\&D, with agreement to share results publicly. 


\section{OG6: Replace SF6 in High Voltage Switchgear and Airborne Radar}

\section{Strategic Plan Section: 7.3.2: Industrial Use of High GWP Gases}

Description: SF6, a GHG with high GWP is currently used in dielectric materials in high voltage electrical transformers, switchgear and circuit breakers, and in present airborne military radar systems. Airborne warning and control systems (AWACS), for example, use SF6 for military radar applications. SF6 can escape through seals, especially in older equipment, and is vented in airborne radar systems where it then becomes a source of GHG emissions.

In the midterm, radar systems could be redesigned to eliminate venting to the atmosphere. Designs could incorporate non-corrosive equipment and fewer parts to minimize leakage of SF6 in utility systems. In the long-run, use of SF6 as a dielectric gas could be eliminated entirely by:

- $\quad$ substituting lower-GWP replacement gases

- developing vacuum or solid state technologies that do not require working fluids with high GWPs

- developing equipment designs that do not require $\mathrm{SF}_{6}$ or other greenhouse gases

Substitute gases, new materials, alternative technologies, and new engineering designs are needed.

Barriers and Challenges: There are no problems with the current technology and thus little motivation for change without regulatory or other drivers. In addition, replacing current systems and infrastructure would be costly.

\section{R\&D Sequencing:}

- Near-term: Basic research, material science issues, new engineering design

- Mid-term: Continued testing and development, new materials/designs

- Long-term: Implementation/deployment, equipment turnover - same equipment has 40-year lifetime

Stakeholders: Utilities/switchgear manufacturers; chemical manufacturers; DOE, DOD, defense contractors; EPA, NFPA, UL.

Public/Private Sector Roles: Government: basic research. Industry: development, validations, commercialization.

R\&D/Implementation Strategies: A technology roadmap should be developed in collaboration with affected industries and stakeholders. 


\section{Other New Technologies for Other Gases:}

Catalytic reduction of $\mathbf{N}_{2} \mathrm{O}$ from combustion. This process includes new catalytic materials, especially nano-materials to reduce $\mathrm{N}_{2} \mathrm{O}$ from combustion; and combining advanced combustion simulation with well known combustion chemistry to devise $\mathrm{N}_{2} \mathrm{O}$ reduction strategies from the combustor.

Understanding formation and life of nitrous oxide from combustion. Fundamental scientific understanding of the production and characteristics of $\mathrm{N}_{2} \mathrm{O}$ from combustion, and understanding heterogeneous chemical mechanisms for $\mathrm{N}_{2} \mathrm{O}$ formation in catalytic converters could help uncover methods for controlling emissions. .

Mining systems. Mining systems could be automated to better control and/or eliminate emissions of methane. Bio-engineered organisms (e.g., copper/gold mining of tailing) that break down waste into recoverable liquid or gas streams are another approach to reducing methane emissions from mining operations.

Precision agriculture. This idea encompasses techniques, technologies, and management strategies to address within-field variability of parameters that affect crop growth, such as soil type, soil organic matter, plant nutrient levels, topography, water availability, weed pressure, and insect throats. Precision agriculture could be used to monitor/control soil carbon via biosensors.

Rumen microbial processes. Understanding rumen microbial processes can uncover methods that could be used to inhibit the formation of methane in the digestive track of livestock. A better understanding of these processes and their impacts on nutrient uptake would enable new techniques to utilize rumen bacteria specifically for the purpose of reducing methane emissions from farm animals.

Soil microbial processes. A better understanding of soil microbial processes, soil carbon and the relationship of soil agricultural practices on GHG emissions would enable the analysis and development of strategies and policy options for soil carbon management that optimize natural resource utilization and mitigate adverse effects of global climate change.

Reduction and control strategies for diesel engine emissions (particulates and $\mathrm{NO}_{\mathbf{x}}$ ). Strategies might include retrofit designs for existing engines; characterizing $\mathrm{N}_{2} \mathrm{O}$ from diesel and heavy duty-diesel engines; advanced technology engines; and advanced combustion systems for diesel engines.

Computational models of soot formation. These models could enable scientists to predict soot and particulate emissions from various fuel types in combustion engines. This will lead to a better understanding and control of carbon emissions from these sources.

Advanced semi-conductors. Current semi-conductor manufacturing requires the use of some high-GWP gases. Advanced semi-conductors should use alternative materials that do not require toxic processing (e.g., DNA - memory chips, quantum or photon-based processing).

Alternative cover gases. In the production of magnesium alternative cover gases are needed to replace $\mathrm{SF}_{6}$. Demonstrations of alternative magnesium melt "cover gas" are needed to answer questions about cost and performance of substitutes (e.g., HFC134a).

New aluminum production technologies. The aluminum smelting process is a significant source of perofluorocarbon (PFC) emissions, a high GWP greenhouse gas. The Hall-Héroult process is the only method of aluminum smelting currently used in the industry. Alternative technologies as well as advanced controls should be pursued, or investigate eliminating use of aluminum as a material altogether. 
The role of black and organic carbon and tropospheric ozone precursors. Basic scientific

understanding into the role of black and organic carbon and tropospheric ozone precurors must be better understood to form climate change mitigation strategies. Areas of interest include fundamental research, understanding health effects, lifetimes, sources and sinks, concentrations, and emission factors. 


\section{MM1: Design of Climate Change Technologies to Facilitate Measurement \& Monitoring Processes}

Strategic Plan Section: 8.5: Integrated Measurement and Monitoring System Architecture

Description: Measurement and monitoring (M\&M) systems will be needed to complement GHG emission reducing technologies in order to assess their efficacy. M\&M technologies can function to provide accurate characterizations of advanced technologies, enable increased understanding of performance, guide further research, reduce costs, and improve effectiveness. It is necessary that climate change mitigation technologies be designed to facilitate M\&M technologies, and to be compatible with an integrated management system. To facilitate M\&M processes, performance standards for climate change mitigation technologies will be necessary.

Barriers and Challenges: Performance standards for climate change mitigation technologies are needed. These performance standards will vary with the type of mitigation technology (energy supply, efficiency, etc.). In addition, there will be resistance to mandating performance designs and potential conflicts regarding intellectual property protection. The need to include technology performance standards for M\&M systems adds another layer of difficulty to the management task.

\section{R\&D Sequencing:}

- All phases: Performance standards need to be incorporated with the development of climate change mitigation technologies.

Stakeholders: Regulators, technology developers, standards setting organizations

Public/Private Sector Roles:

- Federal agencies (DOE, EPA, NASA, USDA, DOT, others) charged with developing mitigation technologies need to incorporate M\&M performance standards into $R \& D$ projects

- Private sector technology developers must have information about the performance standard requirements

- Owners and users of the mitigation technologies must have information on the M\&M data requirements

R\&D Planning and Implementation: M\&M data needs and performance standards need to be established to incorporate these into technology R\&D programs. Once the data needs and performance standards are established, technology developers and users need to incorporate the standards in their designs. 
MM2: Remote Sensing Capability of GHGs and Aerosols From Beyond Low Earth Orbit, Located At Geostationary, L1.

Strategic Plan Section: 8.5: Integrated Measurement and Monitoring System Architecture

Description: This measurement and monitoring (M\&M) technology would provide the capability to remotely sense GHG emissions and aerosols from beyond the low earth orbit. Features of this technology would include:

- Multi-spectral spectrometers, ranging from ultraviolet to near infrared to thermal infrared wavelengths

- "Stare" capability that yields high temporal resolution (near continuous) monitoring of GHGs and aerosols

- Spatial resolution on the order of a few kilometers with surface coverage ranging from geostationary, $60^{\circ} \mathrm{n}$ to $60^{\circ} \mathrm{s}$ covering $1 / 5$ of the earth for each satellite to L1 position covering the sunlit portion of the earth.

- Ability to measure $\mathrm{CO}_{2}, \mathrm{CH}_{4}, \mathrm{~N}_{2} \mathrm{O}, \mathrm{O}_{3}, \mathrm{H}_{2} \mathrm{O}$ vapor, aerosols, and $\mathrm{NO}_{2}$

- High fidelity measurements can contribute to high quality results and support further management of emissions

Barriers and Challenges: There are major technological challenges in locating telescopes, light capable spectrometers, and high data rate communication at L1.

\section{R\&D Sequencing:}

- $\quad$ Near-term: Deploy current systems in low earth orbit by 2008. R\&D investments for high Earth orbit are now being made.

- Mid-term: Not available

- Long-term: Not available

Stakeholders: Federal, state, and local governments and policymakers; industry sectors, including energy, transportation, healthcare, agriculture, homeland security, weather and climate prediction, and air quality.

Public/Private Sector Roles: NASA is coordinating and funding some R\&D now. Technology developers will implement and further develop the technology, however there are no current market incentives that serve to "pull" the technology development.

R\&D/Implementation Strategies: Current vision has been developed by NASA and needs to be revisited. 


\section{MM3: Protocols and Concurrent Technologies for Multiple Assessments of Energy End-Uses}

\section{Strategic Plan Section: 8.2: Energy Production and Efficiency Technologies}

Description: There is a need to establish protocols as well as concurrent technologies to be able to conduct multiple assessments of the performance of end-uses of energy, including transportation, buildings, and industry. Protocols and technologies would enable the assessment to be conducted in time series, and ultimately in real time. There are current protocols and technologies to measure energy efficiency (e.g., automobile emissions testing), and these diagnostics could be extended to GHG emissions. Another feature of this concept is to have real time feedback to the user of the end-use technology, such as the vehicle owner that attention is needed. There would be a complementary public outreach effort along the lines of "Energy Star" to raise awareness of this technology.

Barriers and Challenges: Education challenges: It will be necessary for the metrics to be defined and understood by the public. Technical challenges: There is a need to develop sensors and monitors that function at the technology/human interface. Economic: Securing public funding to assist/validate/develop common protocols will be a challenge.

\section{R\&D Sequencing:}

- Near-term: Begin development of sensor technologies; begin introduction of technologies in consumer products

- Mid-term: Begin commercial application of protocols and technologies

- Long-term: Not available

Stakeholders: Environmental NGOs, green consumers and green product industries, standard setting Federal agencies and other standards institutions.

Public/Private Sector Roles: Government agencies and Federal research labs: develop protocols and systems requirements; R\&D on sensor development/microprocessors/wireless communications/lowenergy equipment to detect migration, uptake, and distribution of GHGs. Industry: cost-shared R\&D and performance testing to beta test, new product development and marketing

$\mathbf{R} \& \mathbf{D} /$ Implementation Strategies: One approach is a consortia established by DOE, NIST, and industry trade organizations to develop technology roadmap, program plan, and implementation. 


\section{MM4: Wide Area Networks The Enable Sensor-To-Sensor Communications}

Strategic Plan Section: 8.5: Integrated Measurement and Monitoring System Architecture

Description: These networks use wireless mesh-communications (no towers or satellites connecting the sensors) that provide robust communications. Mesh communications are envisioned to have some similarities to the world wide web, in that each sensor pushes information to a neighboring sensor until the information arrives at its point of use. These networks would employ point GHG sensors that collect data at a frequency and spatial resolution appropriate for the needs. Point sensors must be low cost and low-power to enable the use of a large number of sensors, each having very long intervals between battery replacements.

There is a high probability of success in developing and deploying this technology on a large scale. It is viewed as being beneficial to reducing GHG emissions for the investment required.

Barriers and Challenges: Technical challenges include miniaturizing multi-purpose sensors, and communicators' networks. Developing low cost sensors will be an economic challenge.

Societal challenges include public acceptance of the proliferation of sensors, i.e., the "big brother" concerns, and the fact that permissions will be needed to install platforms on private property.

\section{R\&D Sequencing:}

- Near-term: Technology development of the sensors, small scale prototype and demos. Also some initial deployment

- Mid-term: technology development leading to reduction in costs, widespread US deployment

- Long-term: international deployment and in developing countries

Stakeholders: Federal agencies including EPA and DOE. The US platforms might be shared with other government sensor missions. Other non-Federal interests: scientists from academia and NGOs. Telecommunication industry: technology developers.

Public/Private Sector Roles: Government agencies and Federal labs: miniaturizing multi-spectrum sensors for GHG. Industry: development of communication network technologies.

R\&D/Implementation Strategies: Multi-GHG emission sensors need to have a topic for a separate roadmap. Communications network R\&D plan is similar to other applications. 


\section{5\&6: Integrated Management System Including Data Management and Modeling}

Strategic Plan Section: 8.5: Integrated Measurement and Monitoring System Architecture

Description: An overarching architecture that integrates a diverse set of models and data, from local point sources. This integrated system architecture would provide a framework for assessing M\&M technology developments in the context of their contributions to observation systems that support integrated system solutions for GHG reduction. The integrated management system functions at a multiscale (local-regional-global), and has the ability to integrate across spatial and temporal scales and at many levels, ranging from carbon measurements in soils to emissions from vehicles, from large point sources to diffused area sources, from landfills to geographic regions. [See Figure 8-2 and 8-3 of the CCTP Strategic Plan.] Features of the system would include: remote sensing, satellite, UAVs, in-situ, ocean based, distributed, from/to space.

Barriers and Challenges: International relations will be a challenge. This is an international issue, and we would need to establish some level of understanding and trust. A technical barrier is that calibration standards will need to be established. In addition, technical capability varies across countries. Common standards and calibration would be need to be addressed. Societal issues include public acceptance of the proliferation of sensors, i.e., the "big brother" concerns, and that permissions will be needed to install platforms on private property.

\section{R\&D Sequencing:}

- Near-term: Continued development of observation platforms at varying scales, i.e., local, regional, global; develop data protocols, data security requirements

- Mid-term: Begin integration of all systems; build capability for large data storage system, data visualization capabilities

- $\quad$ Long-term: Extend the integrated system to the developing world

Stakeholders: Federal agencies including NASA, NOAA, DOE, EPA; Policy makers; Public advocacy groups; Country governments; UNFCCC; Industry technology users and developers

Public/Private Sector Roles: Government and Federal laboratories: need a coordinated plan; Academia: conduct research on network design; Industry: technology developers of sensors and mitigation technologies; technology developers of software, hardware, and networks.

R\&D/Implementation Strategies: The US Integrated Earth Observation System (IEOS) that is a contribution to the Global Earth Observation System of Systems (GEOSS) provides some concepts useful in implementation strategies. 
MM 7: Rapid Prototyping and Benchmarking of Existing and Evolving R\&D Components Configurations of Integrated System Solutions

Strategic Plan Section: 8.5: Integrated Measurement and Monitoring System Architecture

Description: The goal is to develop the laboratory capability to test and evaluate the efficacy of solutions to systems integration. This would include the capability to calibrate, verify, validate, and benchmark existing and evolving R\&D components (sensors, data handling, models, algorithms, decision support).

Barriers and Challenges: The technical challenge will be to bring together and characterize calibration and validation equipment and capabilities. Benchmarks lead to confiding in government and industry investments. Metrics to predict viability and benefits will be needed to justify government investment. Probability of success: development and deployment is a high probability; there is a large scale potential for deployment; and large benefits could be realized.

\section{R\&D Sequencing:}

- $\quad$ Near-term: All R\&D to be performed in the near term ( $<25$ years)

- Mid-term:

- Long-term:

Stakeholders: Supply: science agencies, technology developers, for observing systems, modeling systems, data handling systems, decision support systems.

Public/Private Sector Roles: Government and Federal labs: defining tools and protocols for rapid prototyping (architectures); developing configurations/expectation. Industry: conduct rapid prototyping; deliver benchmark reports; transition research configurations to operations.

R\&D/Implementation Strategies: Steps for a strategy going forward might include the following:

1. Define architecture, tools, contributing agencies and programs

2. Prioritize configurations for tests/experiments

3. Define expectations for deliverables

4. Conduct (oversee) experiments and resulting demonstrations/reports 


\section{MM8: Multi-Agency Integrated Measurement and Monitoring Field Experiment}

Strategic Plan Section: 8.5: Integrated Measurement and Monitoring System Architecture

Description: The overall concept is to locate a small region that includes municipal activities, fossilbased power plant with carbon capture that is coupled with geologic storage and/or terrestrial sequestration. The approach is to define a multi-agency experiment that would be carried out for one year. Federal agencies would include DOE (lead), USDA, NASA, EPA, NOAA and appropriate state and local agencies. Activities would include developing test objectives, defining roles/responsibilities, data collection, data analysis, modeling and feedback. Research would examine the interface between emissions, data reporting and collection, analysis, etc. The outcomes would be a report on costs, complexity, and other issues.

Barriers and Challenges: A challenge will be to examine the various requirements, measuring and monitoring performance, communications, data collection and analysis. The various models used will need to be examined and differences identified.

\section{R\&D sequencing:}

- $\quad$ Near-term: Get a baseline across spatial and temporal scales. Look at gaps in data.

- Mid-term: Collect and analyze data from field experiment

- Long-term: Develop a global network to monitor and measure geologic and terrestrial sequestration

Stakeholders: Industry: emitters, technology developers, utilities, agricultural industry. Government: $\mathrm{R} \& \mathrm{D}$ agencies, state and local regulators.

Public/Private Sector Roles: Government: funding for transport and storage; Industry: technology developer.

R\&D/Implementation Strategies: Not available 


\section{Other New Technologies for Measuring and Monitoring:}

Measurement and tracking of $\mathrm{CO}_{2}$ injected into oceans. New measurement and monitoring technologies will be required for carbon sequestration in deep ocean environments. Very high pressure, low temperature, unique characteristics of $\mathrm{CO}_{2}$ under these conditions, chemical interactions, and the remote nature of deep ocean present significant challenges.

$\mathbf{N}_{2} \mathrm{O}$ measurement techniques. Nitrous oxide presents a specific measurement need for emissions from advanced gasoline and diesel engines. These measurement techniques should be on-line measurement devices that provide real-time data.

Advanced, real-time measurement for fine particulate matter and soot. This capability would enable better monitoring of these carbon sources, particularly in transportation. Current emissions from these sources may be significantly under-estimated.

Location of non-point sources and sinks. High resolution activity data from satellites could enable remote sensing of GHG sources and sinks. For example, this technology could communicate where fertilizer is used, where cows are located, etc.

Nano-sensors for monitoring methane and $\mathrm{CO}_{2}$ leaks in pipelines. Nanosciences could enable sensors that detect methane and $\mathrm{CO}_{2}$ emissions from stack gases and fugitive leaks in pipelines. These sensors could be positioned in the pipe or outside the pipe, and help detect corrosion, stress cracking, structural issues, and other hazards in addition to monitoring GHG emissions..

Low-orbit monitoring. Low-orbit satellites could monitor GHG sources from space using advanced radar or other remote sensing technology. This technology could have the ability to accurately and reliably monitor any point source in the world (e.g., industrial plants) in real-time.

Unmanned aerial vehicle (UAV) systems. UAVs are remotely piloted or self-piloted aircraft that can carry cameras, sensors, and communications equipment. Research is needed to enable medium and high altitude endurance and near-real-time imagery intelligence. UAVs could be equipped with measuring and monitoring equipment to detect concentrations of airborne GHGs.

Low-cost airborne detection sensor systems. These systems would be able to detect $\mathrm{CO}_{2}$, methane and other gases using low-cost materials released in the atmosphere that automatically transmit data to central collection stations, which process and report the collected information.

Emissions tracers. Tracers involve an identification process that enable attribution of GHG sources by country, by company, and at other levels. Tracers would enable scientists to determine the source of GHGs by collecting samples.

Atmospheric spectroscopy. This technology could be used to monitor the atmosphere in many locations (cities, country, industrial districts, ocean) looking for greenhouse gases. It would provide a check that we are not missing some significant infrared absorber locally, regionally, or globally. 
